العوامل المؤترة في قَرار المراجع الخارجي المتعقى بتعطيل تقرير

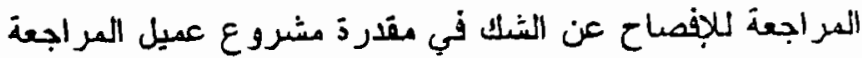

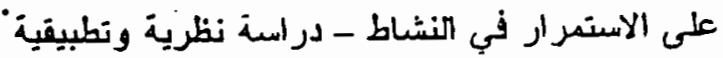

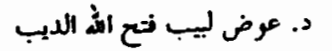

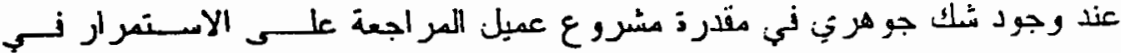

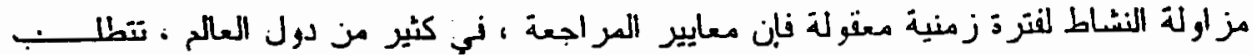

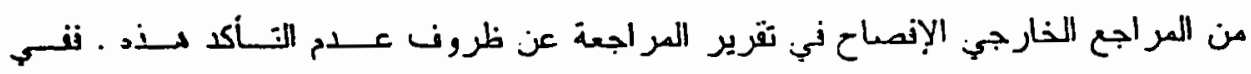

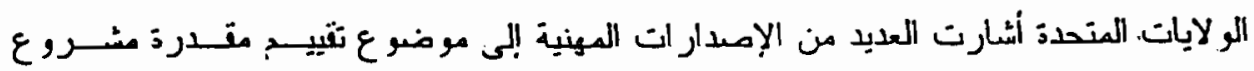

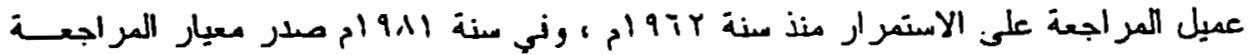

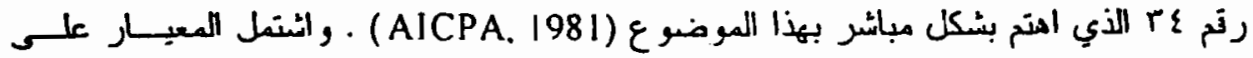

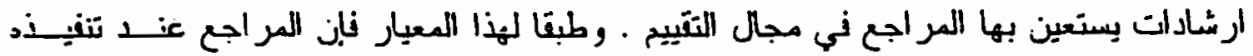

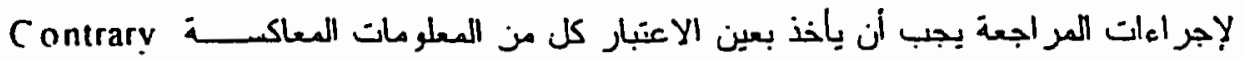

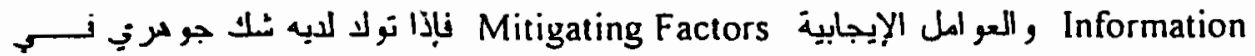

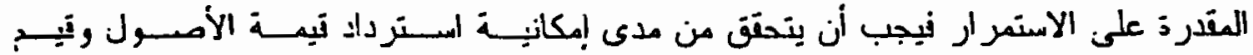

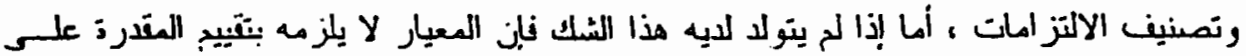

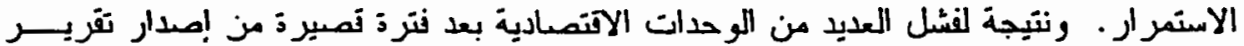

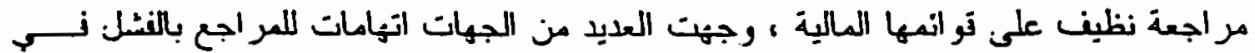

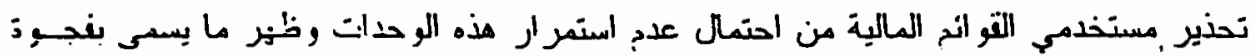

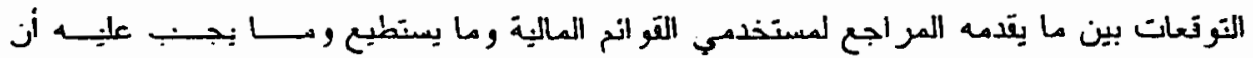

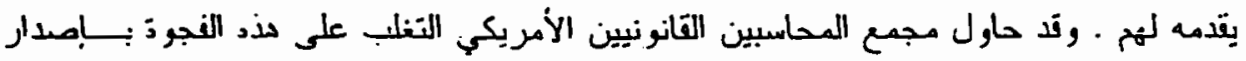

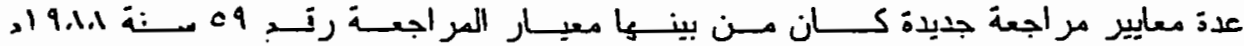

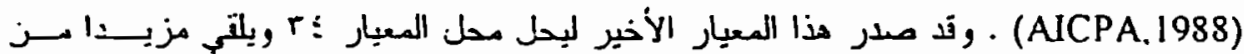

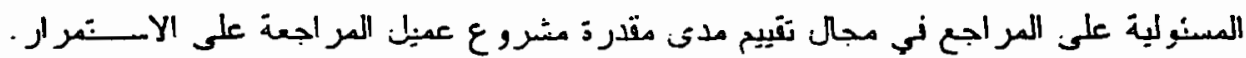

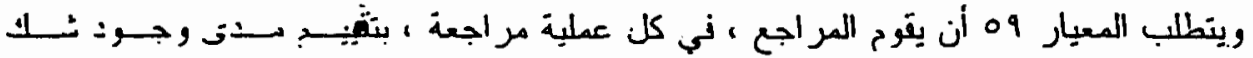

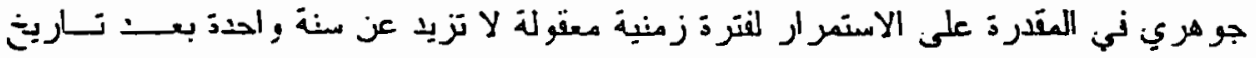


القوائم المالية موضع المراجعة ، وان يقوم بتعديل تقرير المر اجعة إذا كان لديه شاك جوهـري

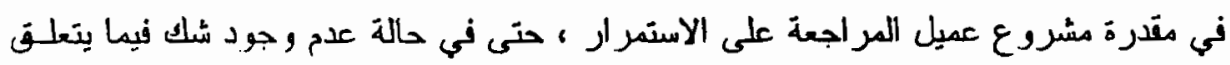

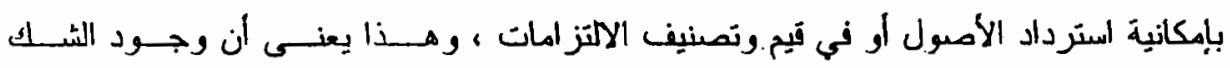

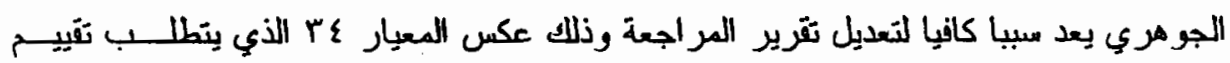

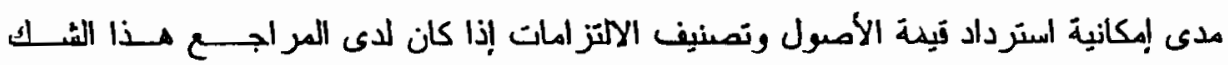

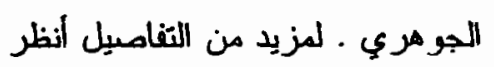

(Ellingson, et al., $1989 \&$ Koh and Killough, 1990)

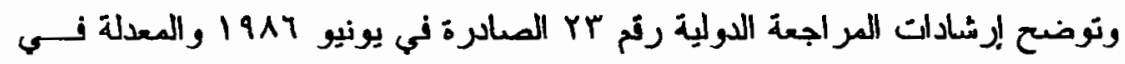

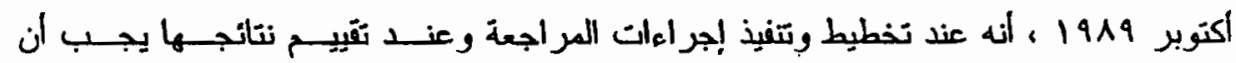

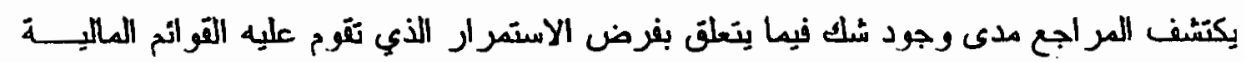

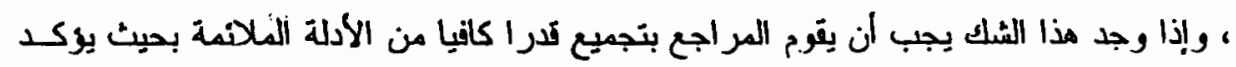

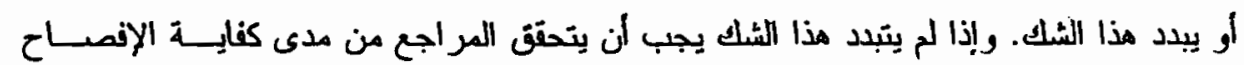

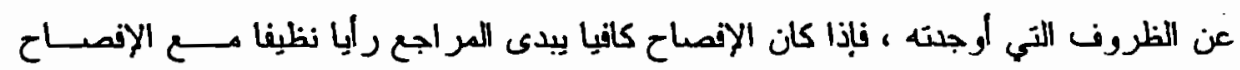

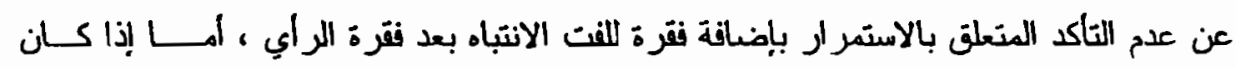
الإنماح غير كاف فيجب أن يبدى المراجع رايا منحفظا أو سلبيا حسبما ير اه ملانما.

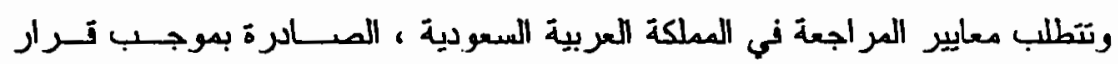

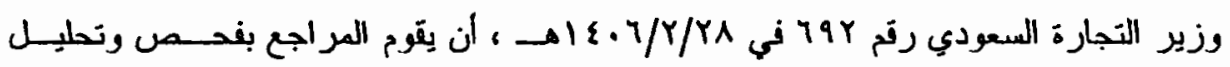

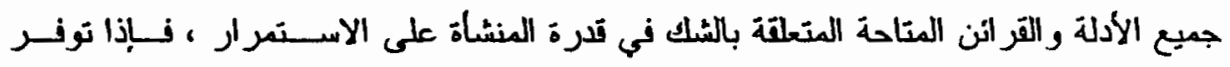

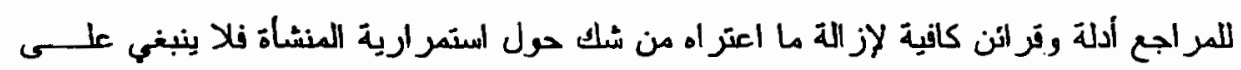

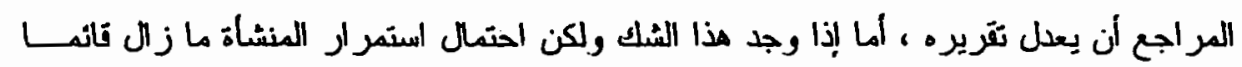

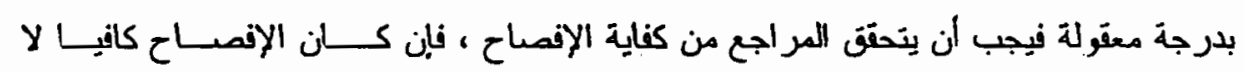

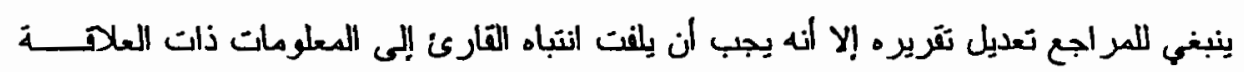

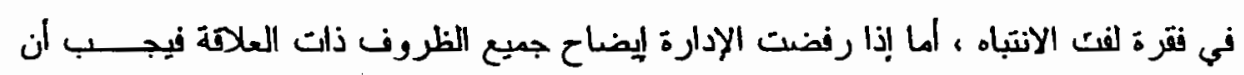

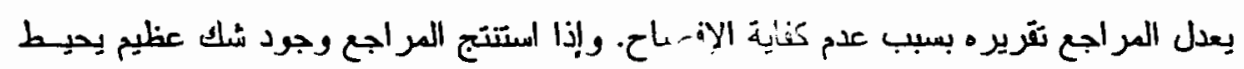

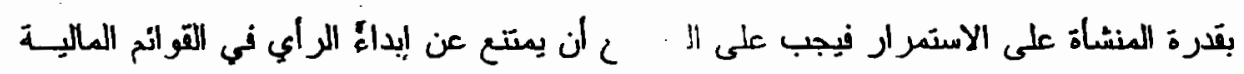

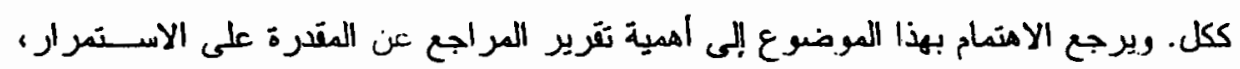

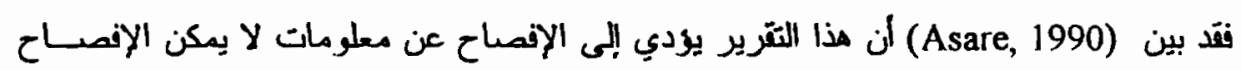


عنها بطريق أخر ، وهذه المعلومات ذات أئر كبير على السعار السهم القُركات وعلى ذهـرارات المستثرين الحاليين و.المرتقبين.

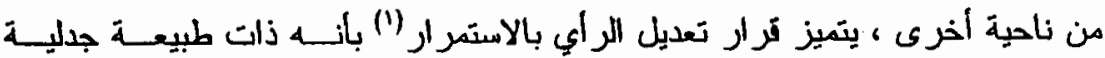

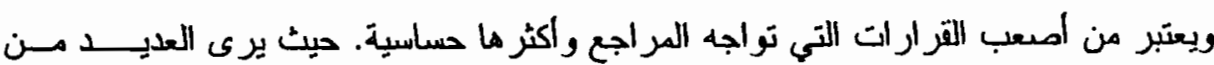

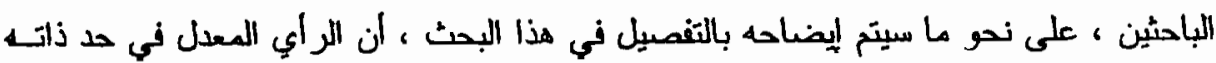

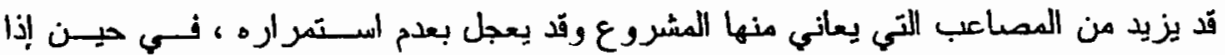

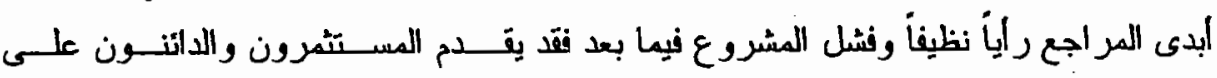

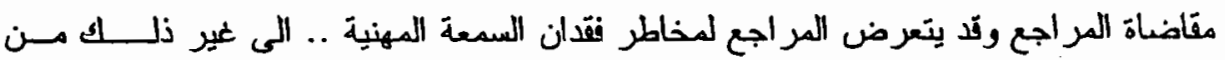

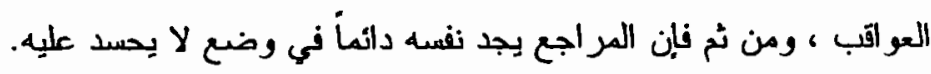

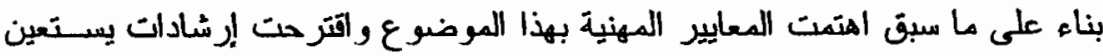

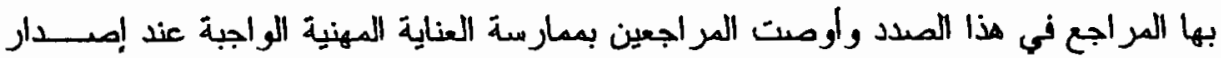

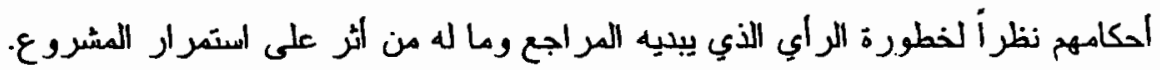

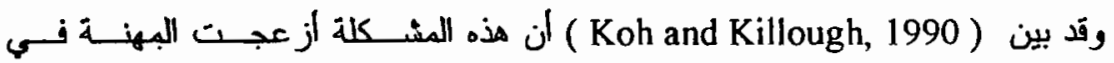

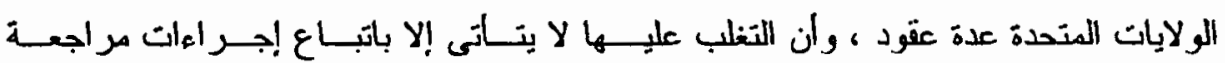

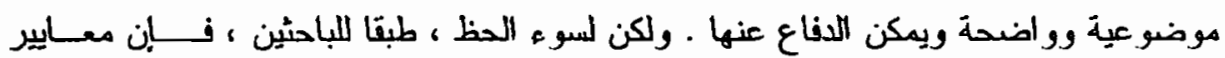

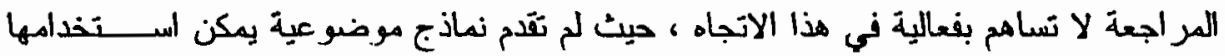

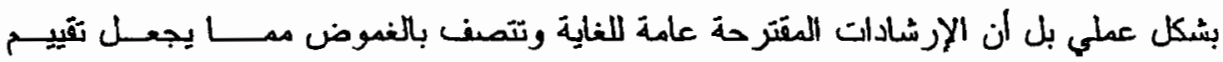

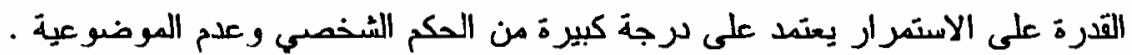

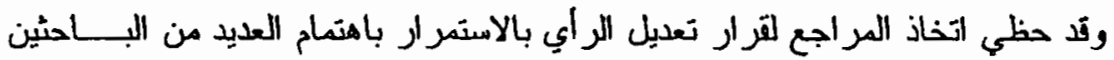

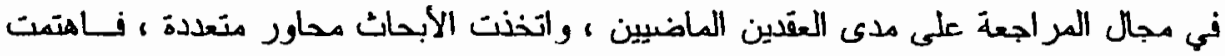

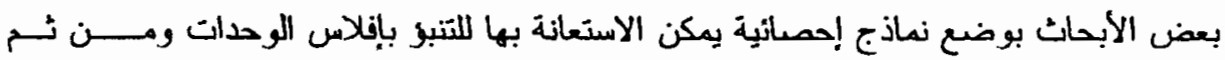

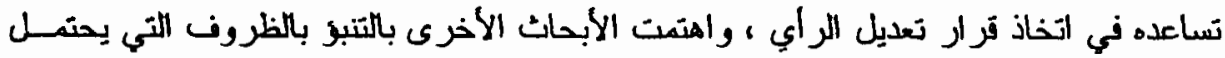

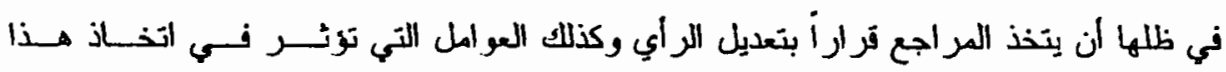
القرار .

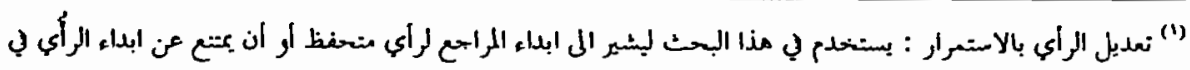

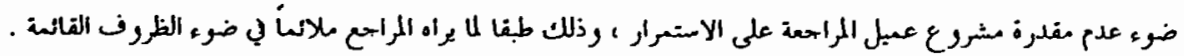




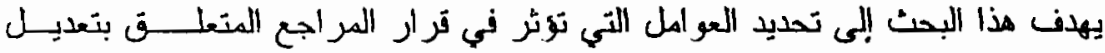

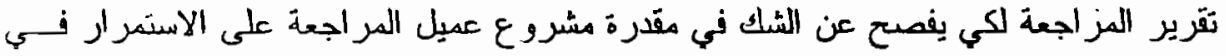
هز اولة النشاط من وجهة نظر الباحتين في الدول المتقدمة وبخاصة الولايات المتحدة و المملكـئن

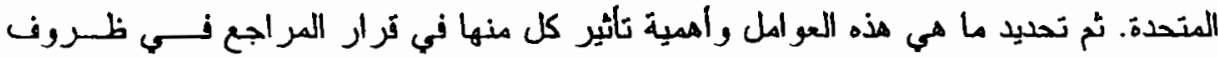
بينية مختلفة بالتطبيق على ممارسي مهنة المراجعة في المملكة العربية العبعودية.

خطة البحث تحقيقا لأهداف البحث تم تقسيمه إلمى قسمين :

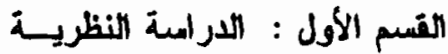

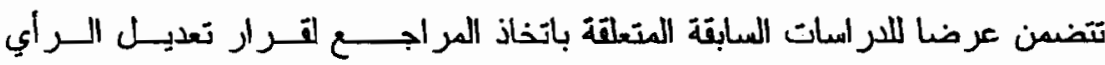

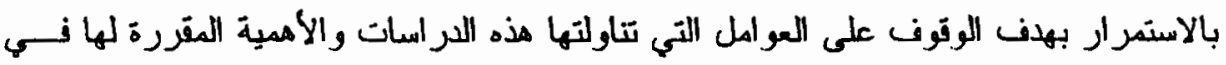
اتخاذ قرار تعديل الرائي بالاستمرار .

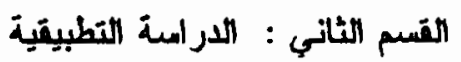
تهدن إلى تحديد مدى أهمية كل عامل من العوامل التي تم التوصل إليها في الارباسية النظرية من وجهة نظر ممارسي مهنة المراجعة في المملكة العربية السعودية. القسم الأول : الار امنة التنظرية

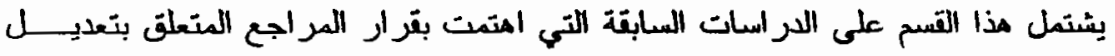

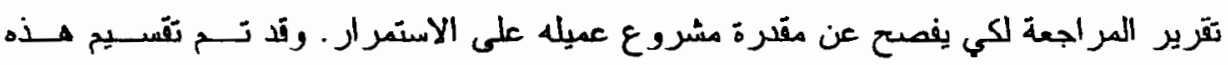
الدراسات إلى مجمو عتين : المعرهير

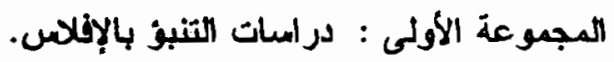

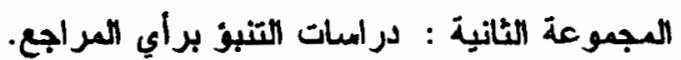

المجبوعة الأولى: دراسات التنبؤ بالإفلاس

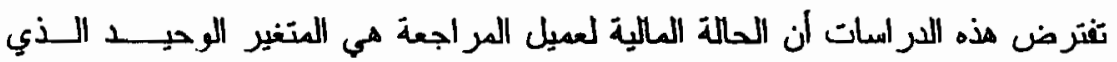

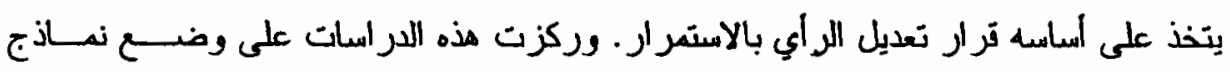




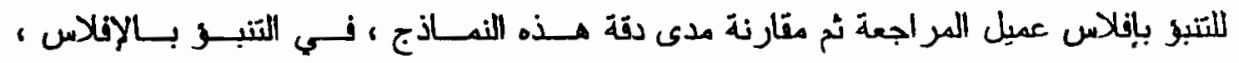

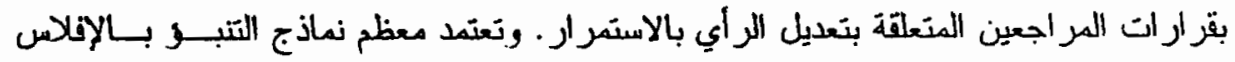

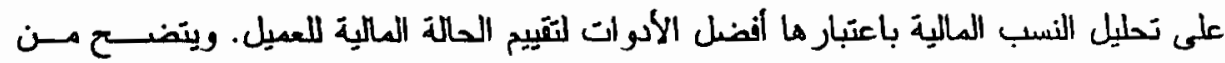

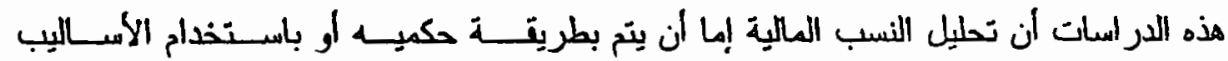
الإحصائية. ونعرض فيها يلي لكل منهما.

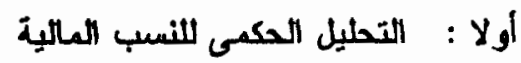

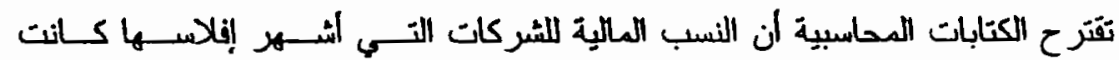

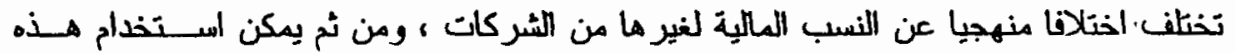

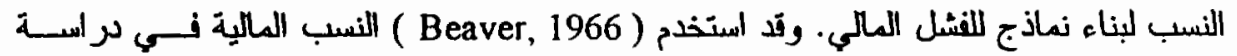

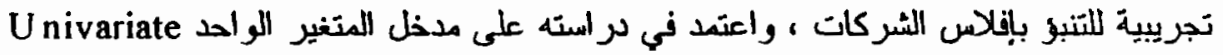
Approach أكثر من Chen and Shimerda, 1981) سبعة استخدامات للنسب المالية في مجال التخليل المالي ، والنسب الأساســية.

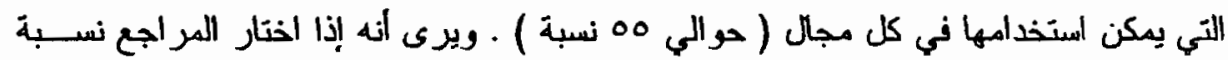

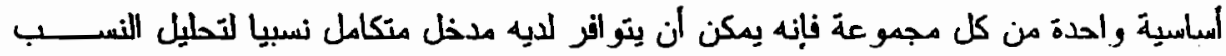

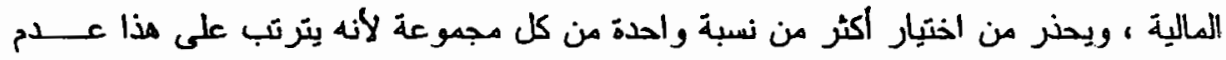

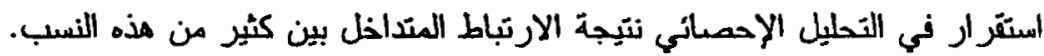

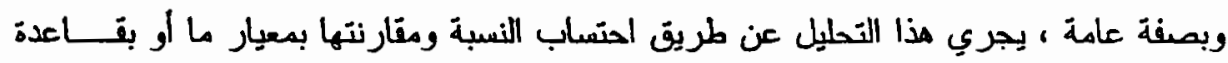

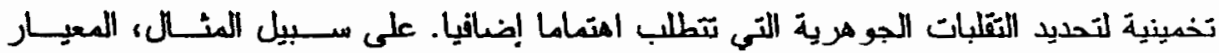

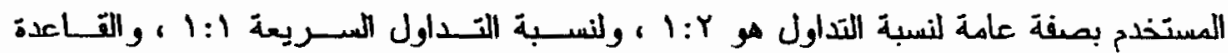

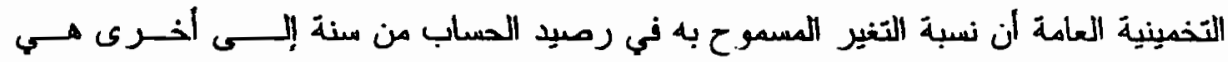

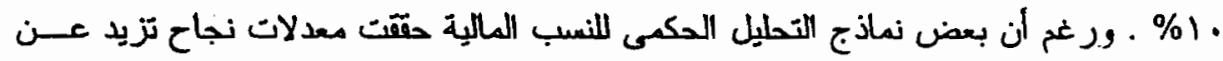

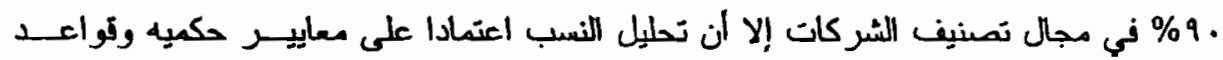

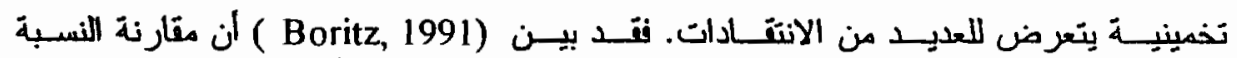

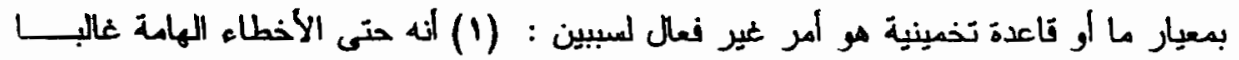

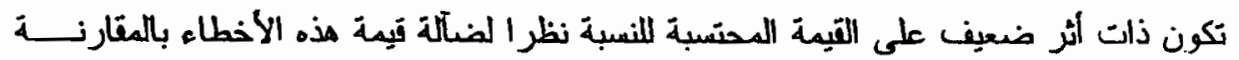

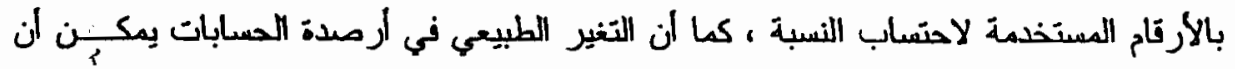

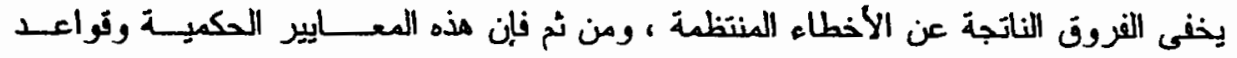




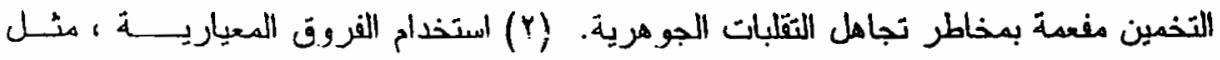

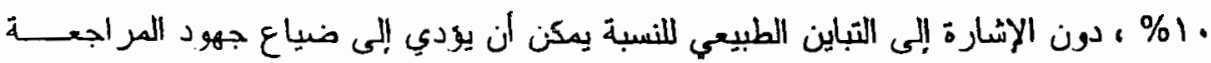

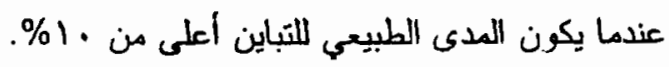

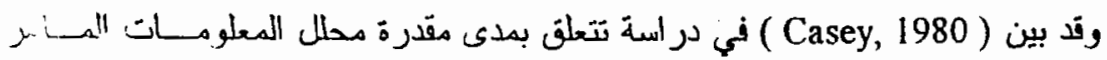

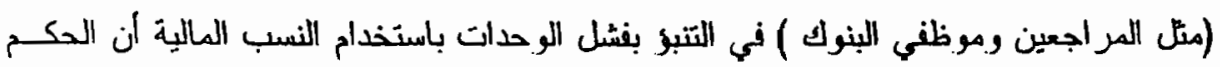

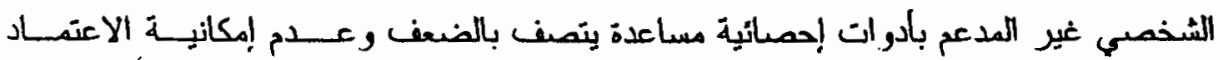

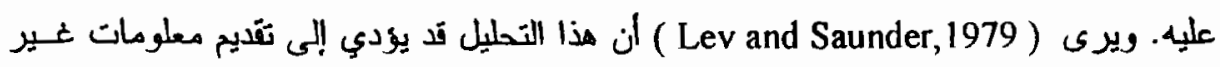

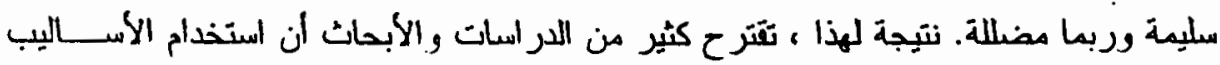

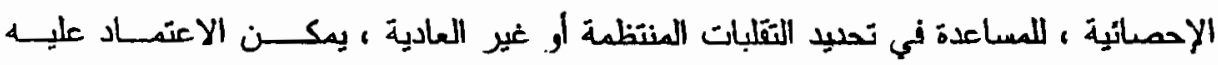
بدرجة أكبر هن استخدام المعايير الحكمية أو تواعد التخمين بمفردها. ثانيا : الأساليب الإحصائية نعرض فيما يلي باختصار لبعض الأساليب الإحمائية واسعة الانتشــار المســتخدمة اتحسين فعالية تَييم الحالة المالية للعميل. بعلئ. أ- التحليل الإحصائي للنسب المالبية

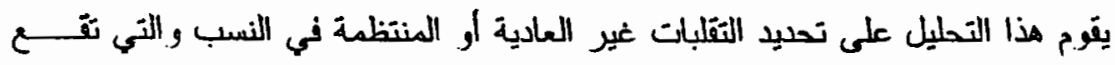

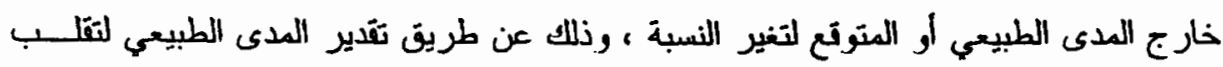

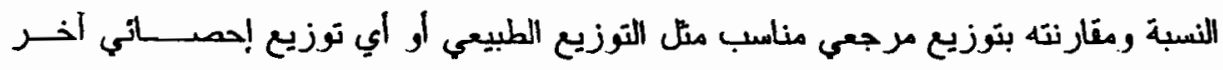
مناسبب.

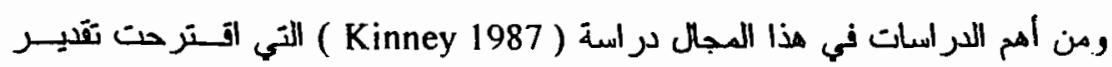

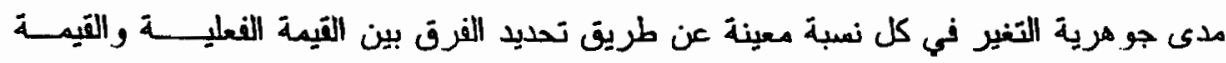

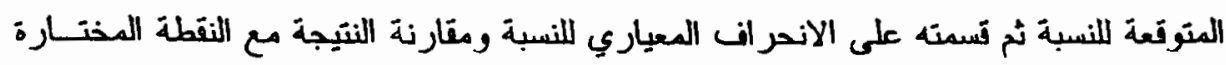

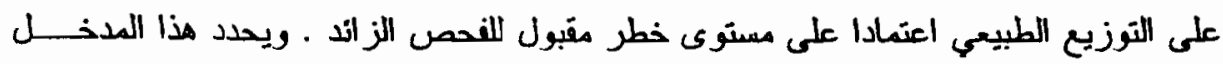

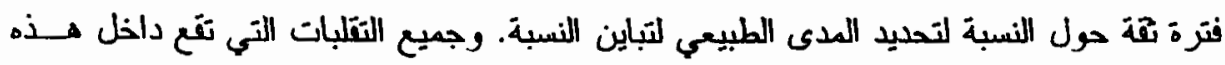

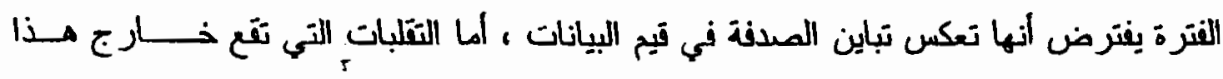

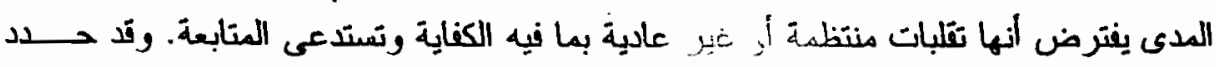
Kinney

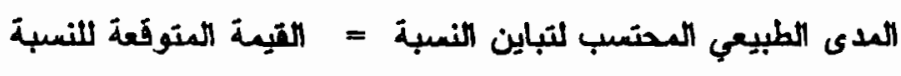
I ( قيمة التوزيع الطبيعي × الانحراف السعياري ). 


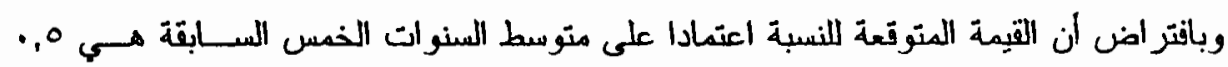

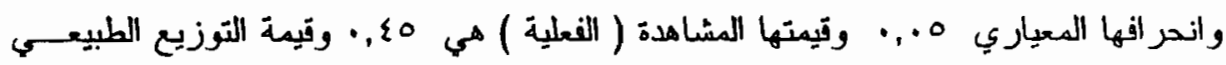

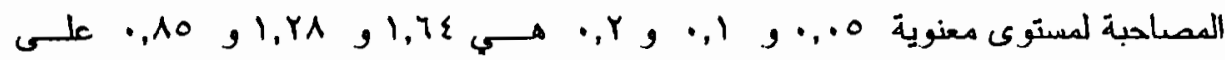

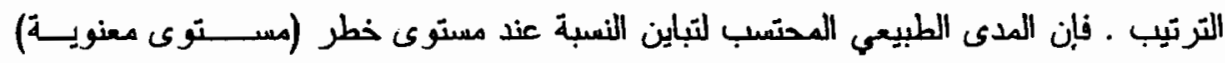
•

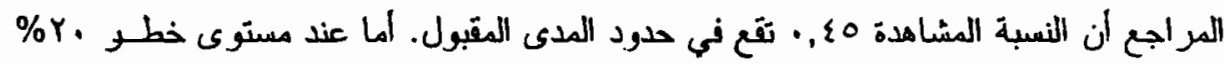

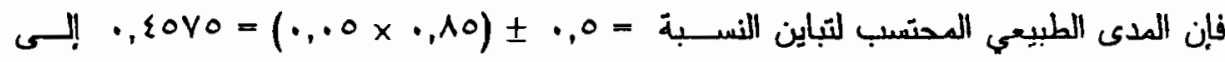

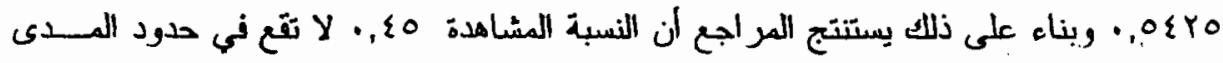

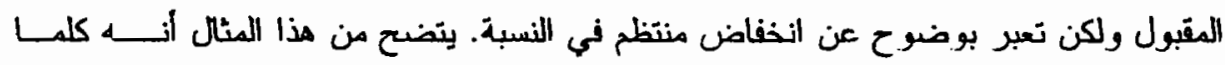

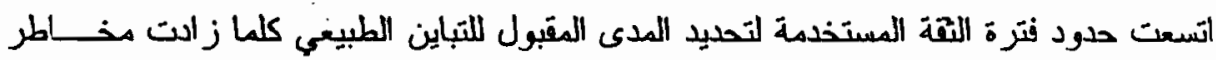

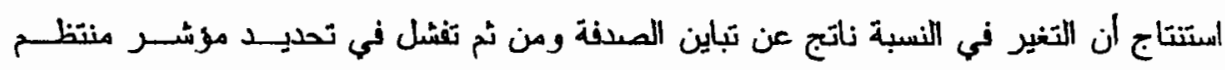

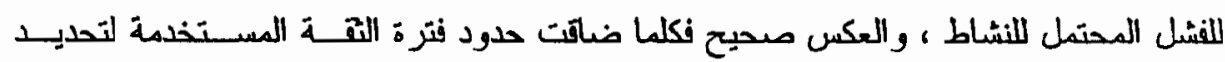

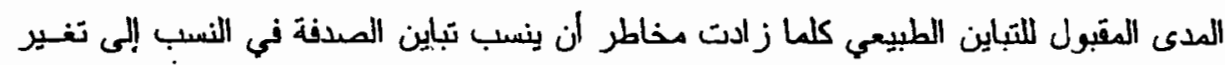

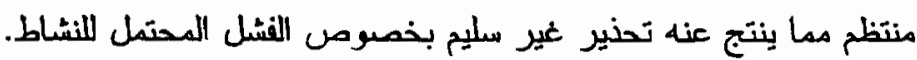

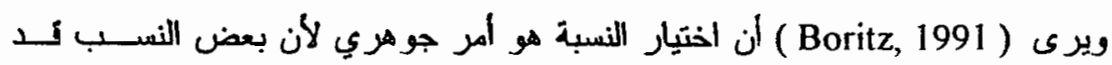

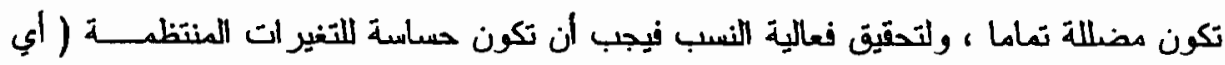

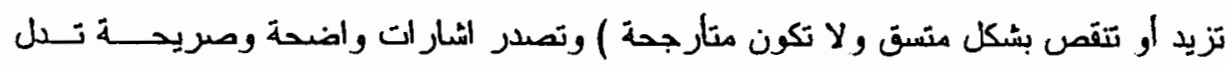

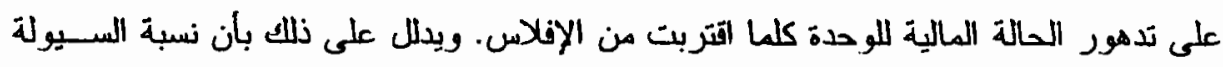

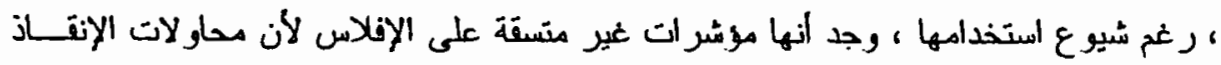

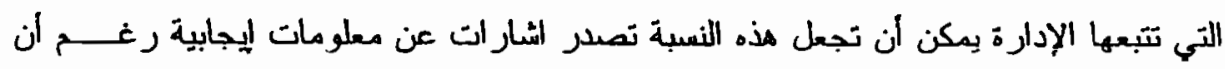

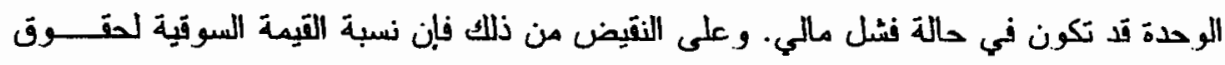

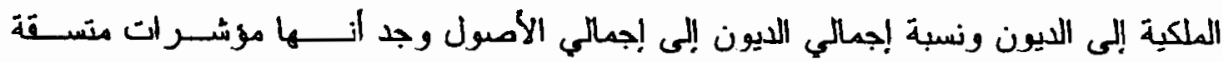

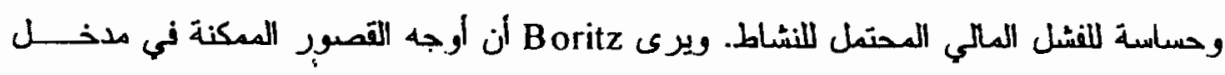
أو Kinney

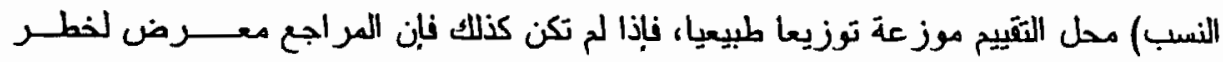

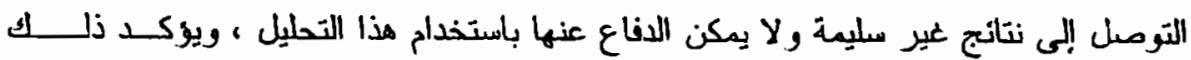


بالإشارة إلى النتائج المنضاربة اللار اسات في دجال خصائص توزيعات النسب الماليـــة التــي

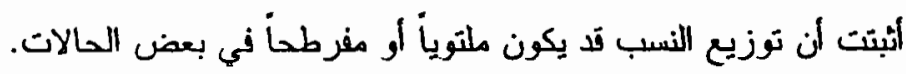

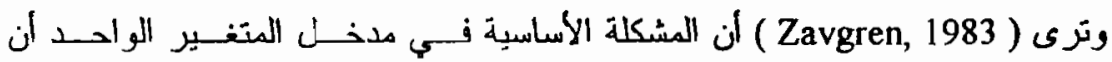
تصنيف الشركات يتم على أساس نسبة واحدة فقط كل مرة ، ومن ثم فهناك احتمال التوصــل التهل

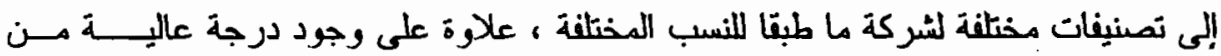

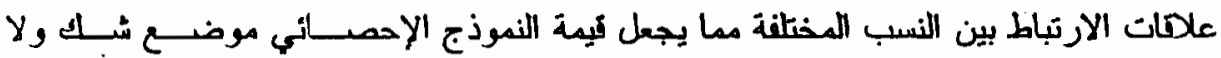
يمكن تحديد أثر كل نسبة بمنة مستخلة.

ويرى الباحث ، أن اهم عيوب مدخل المتغير الواحد أنه لا يمكن توتع أن نسبة ماليــة

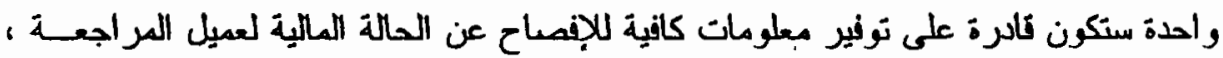
كما أن المراجع تد لا يعنطيع ، عن طريت تحليل النسب المالية واحدة تلو الأخرى ، تجميسيع

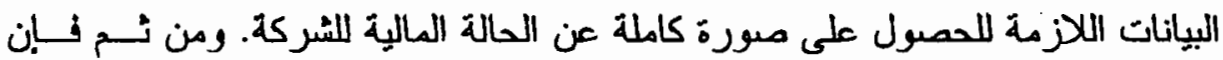

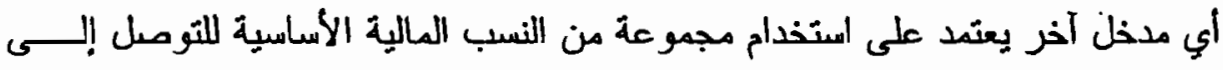
مقياس فريد للحالة المالية للعميل سيكون ، بلا شلك ، أكثر فعالية.

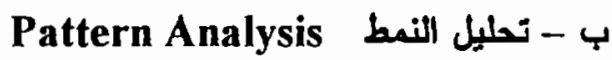
يحاول هذا الأسلوب تتقيح مدخل المتغير الواحد عن طريق استخدام عدة نسـبـ

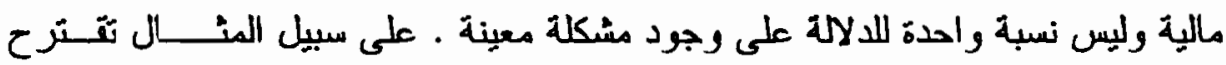

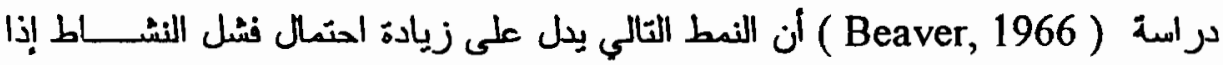
كانت نسبة : رلية تثناتص تشائص - - التدفق النقدي إلى إجمالي الديون تبز ايد

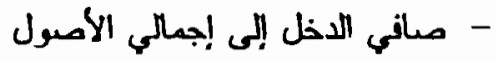
تنتاثص

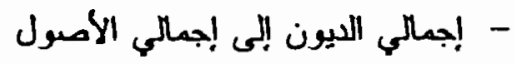
تنتاتص سنص

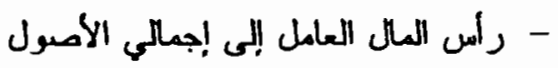
- الأصول المنداولة إلى الالتزامات المتداولة الهمبالة الهول

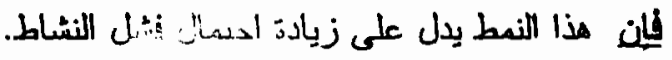

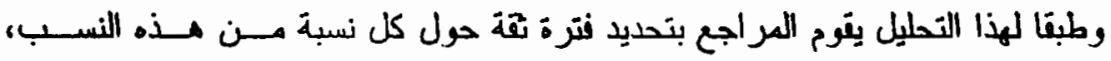

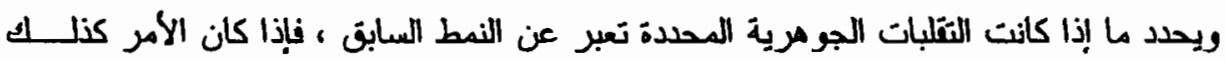

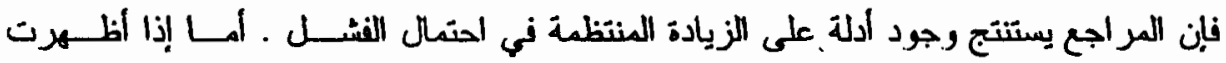


بعض النسب فقط تغير ات جو هرية او تغيرات في الاتجاه العكسي فإنه بمكن ان بعتنتج عـــدم وجود زيادة منتظمة في احتمال الفشله. وتتمثل قوة تحليل النهط في استخداهه لعدة نسب ، وليس نسبة واحدة ، ومن ثم يمكـن

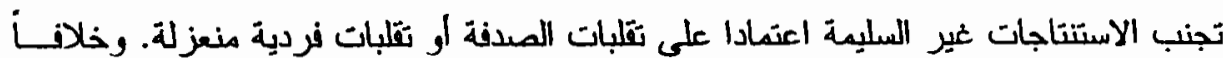

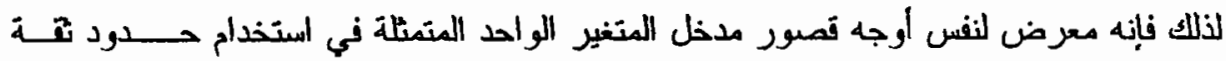

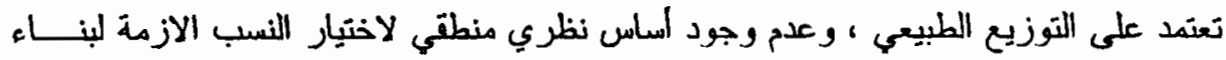
النمط واختيار النمط الذي يضع العلاهة بين النسب الفردية في شكل قاعدة بمكــنـن الســتخدامها

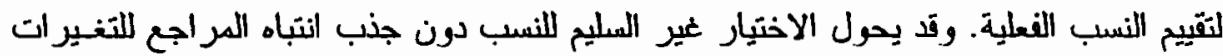

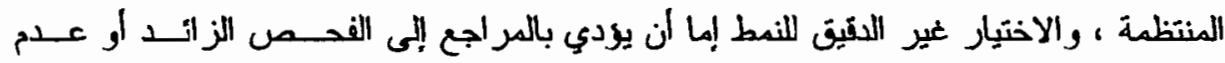
القدرة على تحيد المشاكل الجو هرية التي تستدعى الاهتمام.

Discriminant Analysis التطليل التمبيزى بينت العديد من الدر اسات أن النماذج الرياضية البسيطة التي تعنمد علـــــ البيانـات

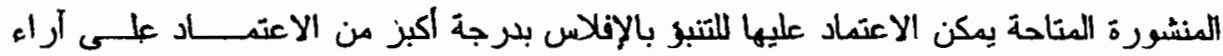

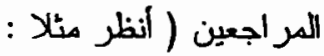

(Altman and McGough, 1974 \& Levitan and Knoblett, 1985 \& Menon and Schwartz, 1987)

وتد طبقتت معظم هذه الدر اسات التحليل التمييزى و هو. أســلـوب إحصــائي يســتخدم لتحديــد

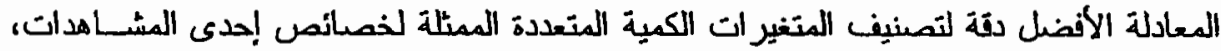

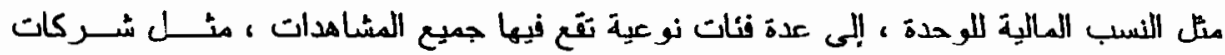

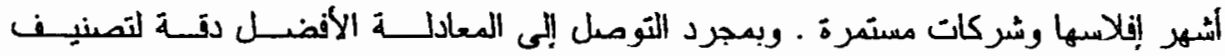

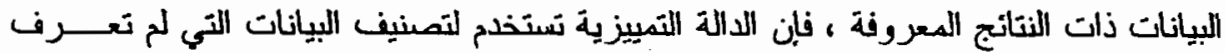

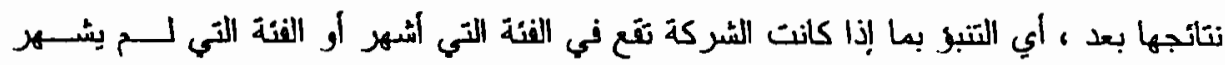
إفلاسها . نتانجها بعدا

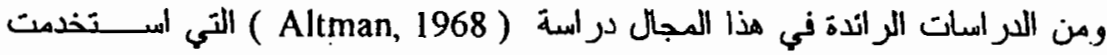

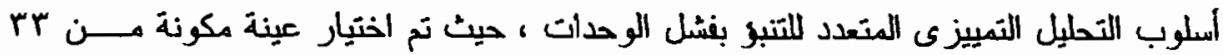
شركة صناعية تعرضت للفشل ، و عينة هن rr شركة هماتلة ( من حيث الصناعة والحجـم )

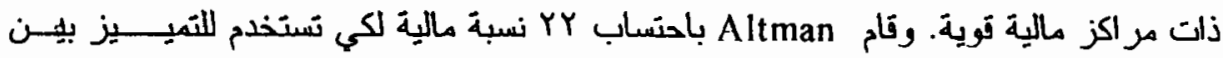

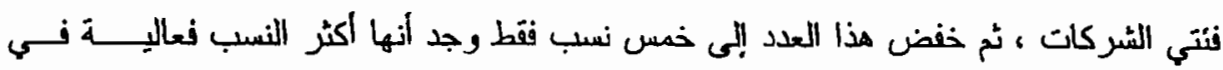


التمييز بين الفتتين. وباستخدام السلوب التحليل التمييزى توصل Altman إلى دالـــة التميـيز التالية :

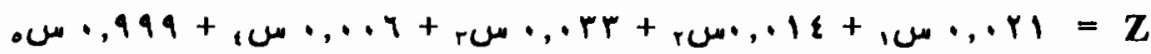
حيث Z إحصانية التمييز سار : نسبة راس المال العامل إلى إجمالهي الأصول.

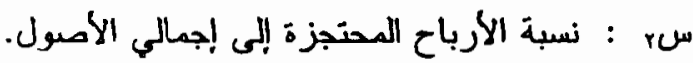

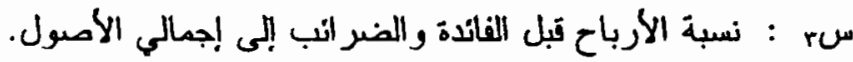
س، : نسبة القيمة السوتية إلى القيمة الدفترية لحقوق الملكية. سه : : نسبة المبيعات إلى إجمالي الأصول.

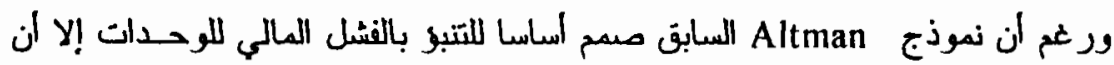
اعتقدا أنه من الممكن استخدامه اليضا لمساعدة المراجـع (Altman and McGough, 1974 )

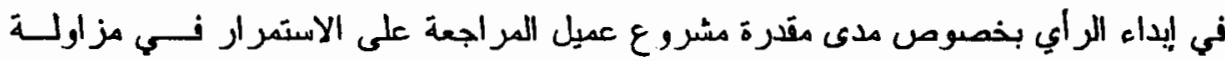

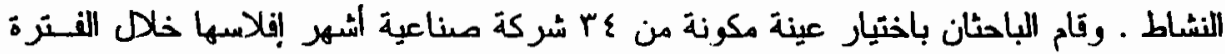

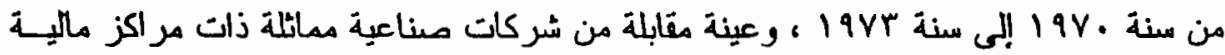

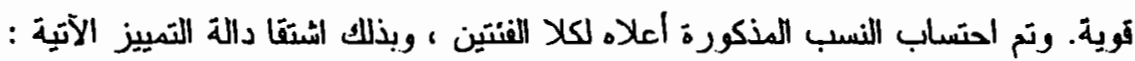

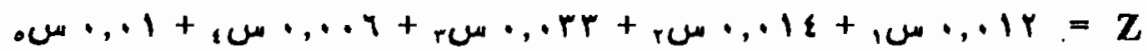

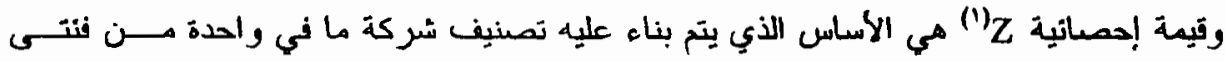

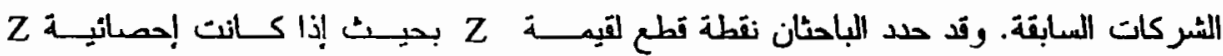

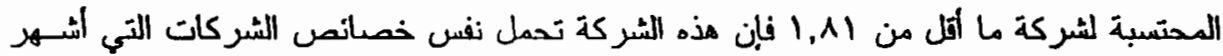

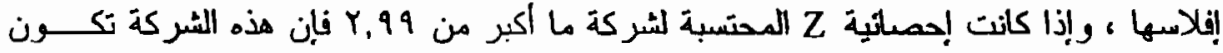

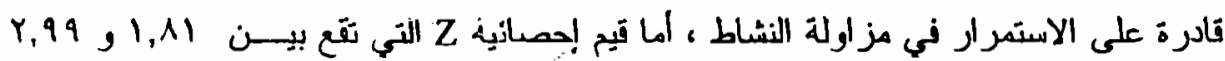

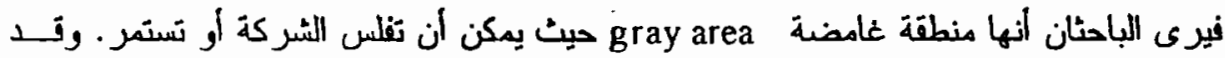

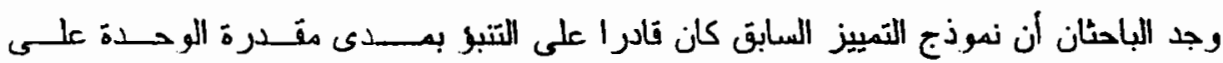

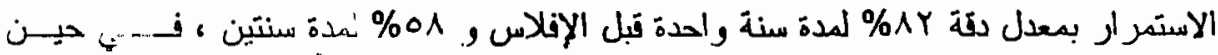

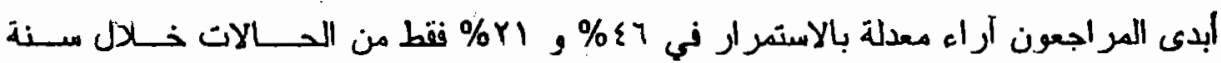

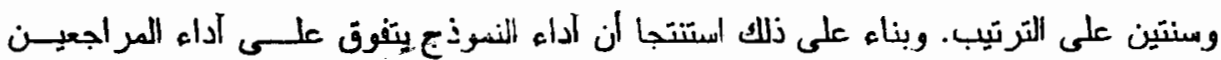

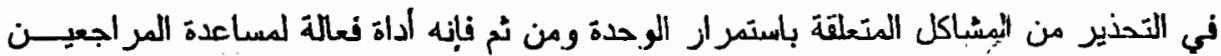

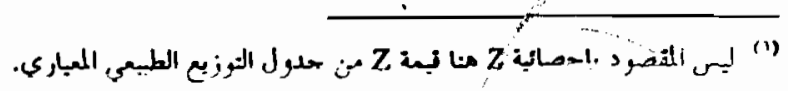


في إيداء أر اء مهنية سليهة. وفي درأسة أخرى تام التمان وزملاوه (Altman et al., 1977)

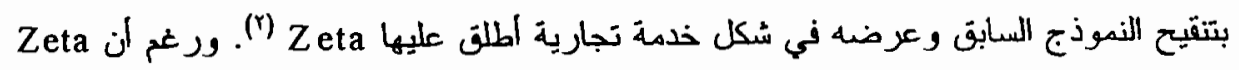

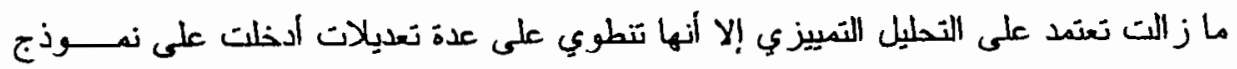

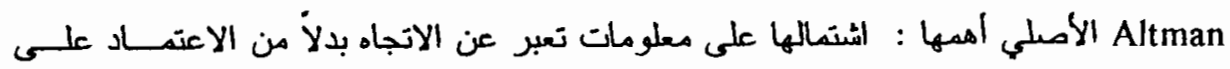

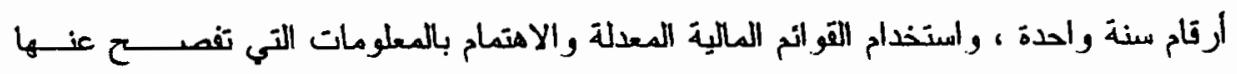

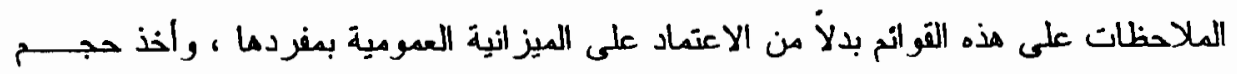

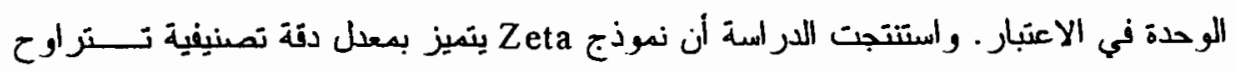

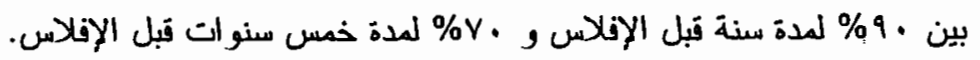

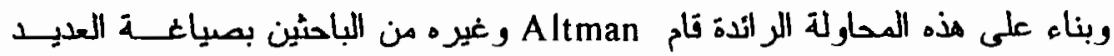

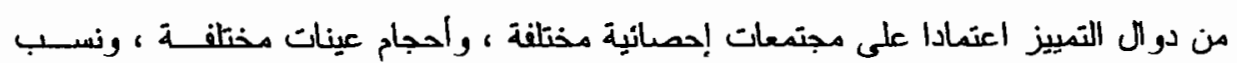

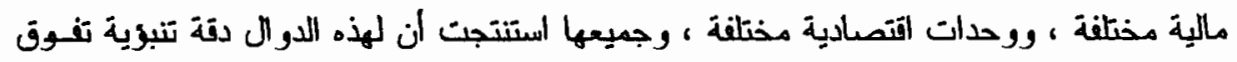

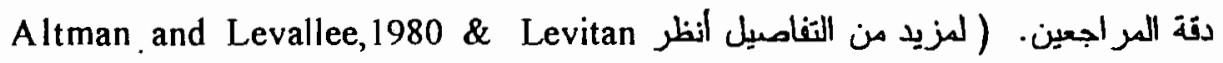
and Knoblett,1985 \& Zavgren,1983 \& Zmijewski, 1984 \& Asare, 1990 \&

Boritz, 1991 \& Koh and Killough, 1990) ومما لا شك فيه ان قوة التحليل التمييزى تتمثل في موضواتوعيته النسبية ومقدرته على

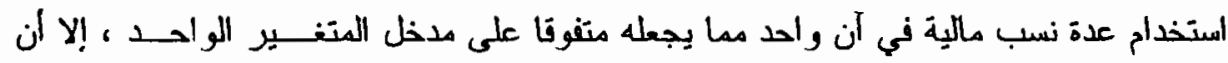

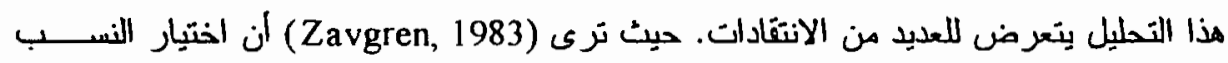

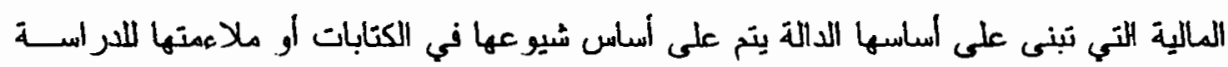

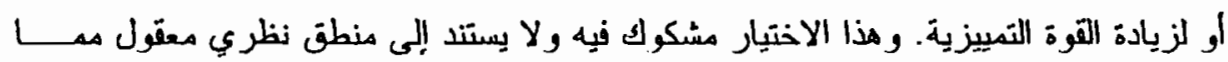

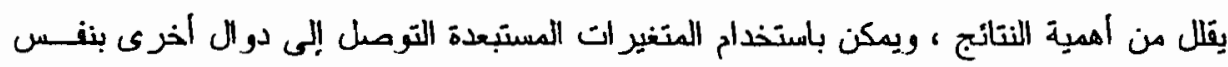

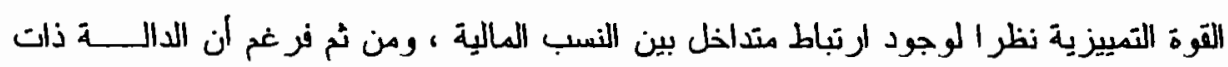

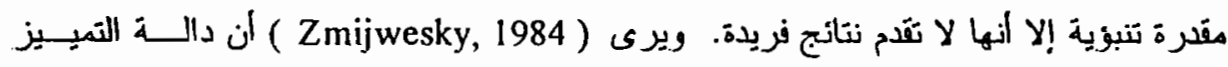

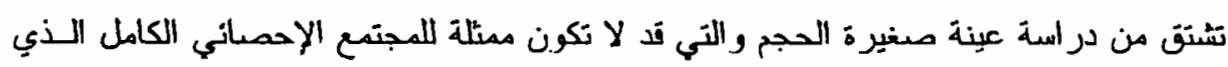

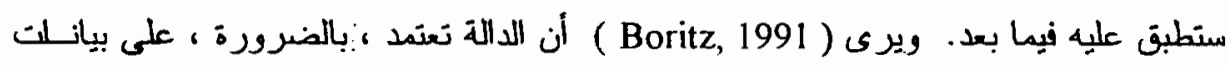

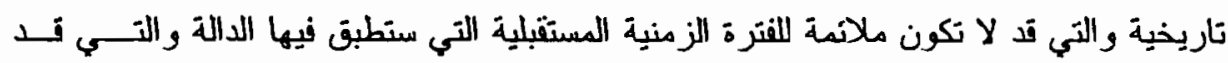

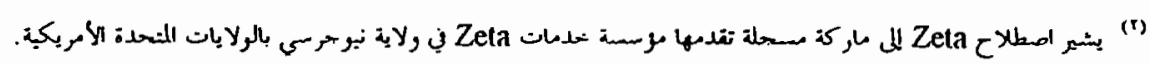


يكون لها أوز ان مختلفة بسب تغير المناخ الآتصادي و الحالة السياسية , الاجنماعية ... الـــخ ،

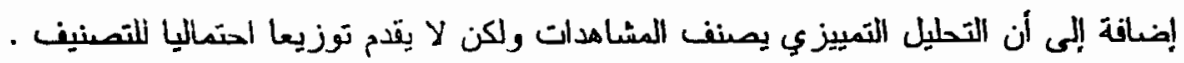

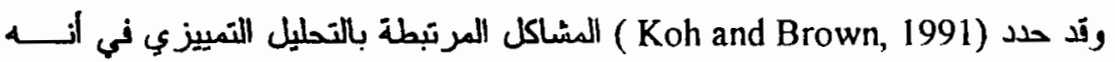

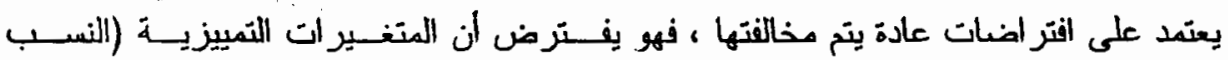

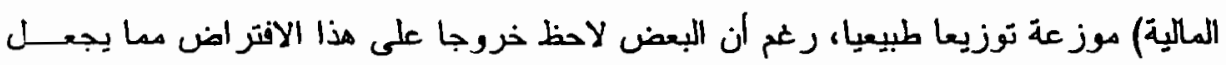

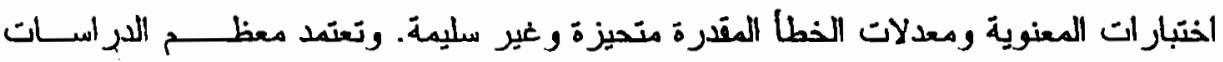

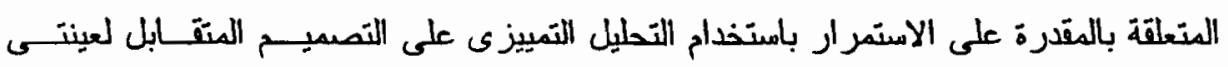

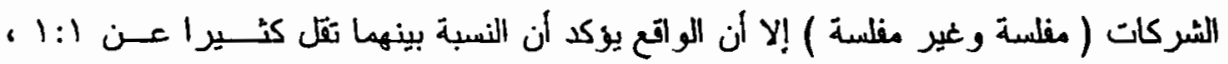

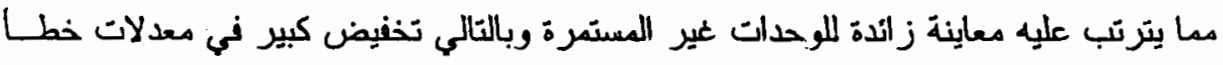

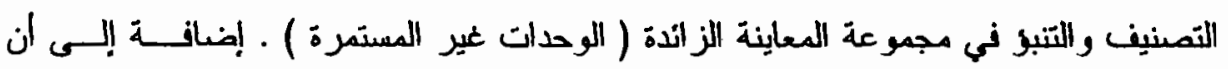

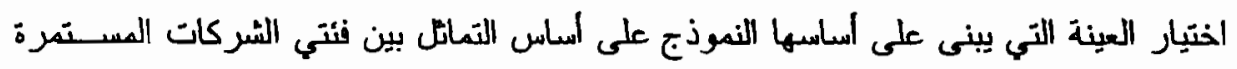

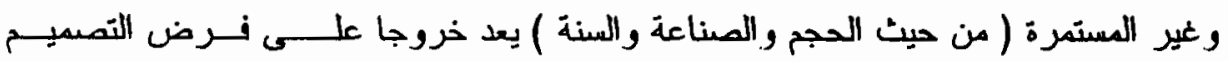

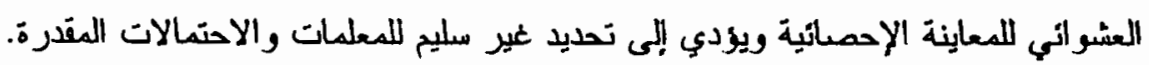

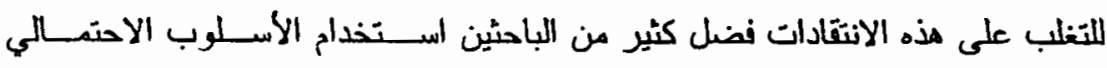

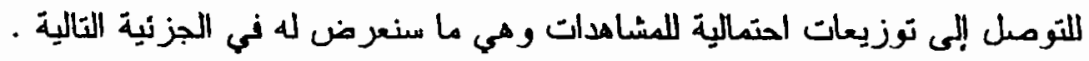

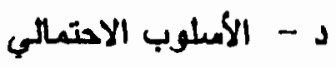

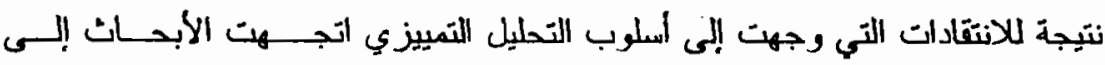

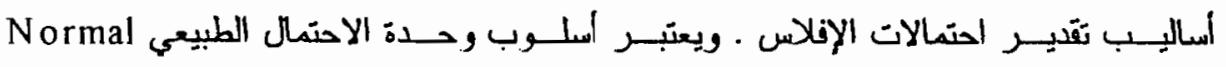
Logistic Probability واسلوب وحدة الاحتمال اللو عاريتمي Probability Unit (Probit)

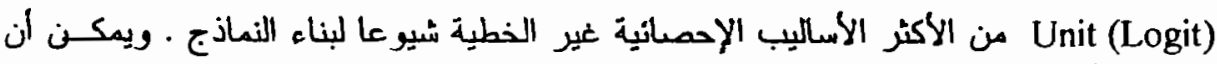

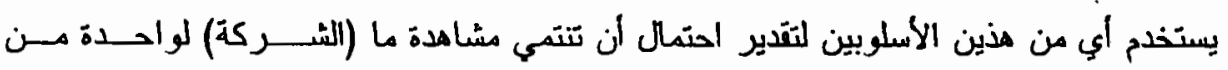

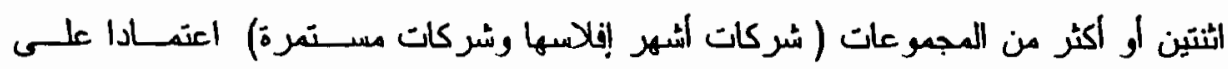

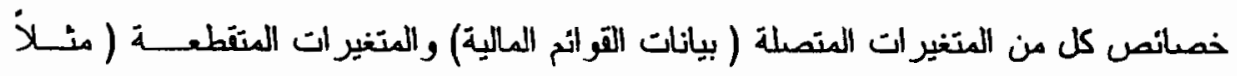

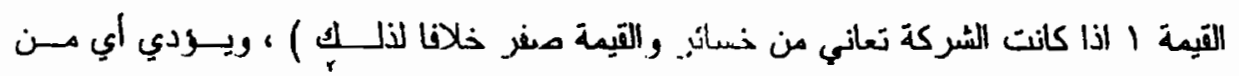

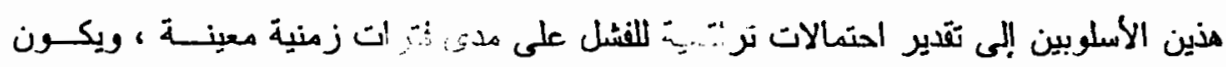
لنماذج التصنيف المشتَّة بامتفدامهها معاملات فريدة وينتج عنها توزيعات احتمالية مديحة 


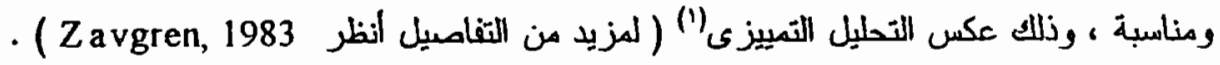

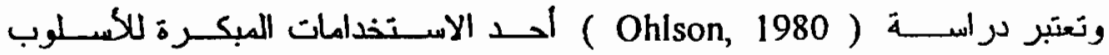

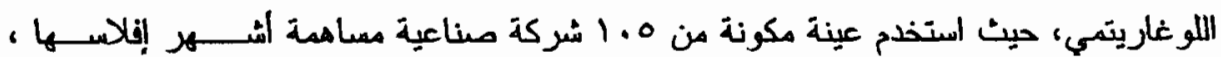

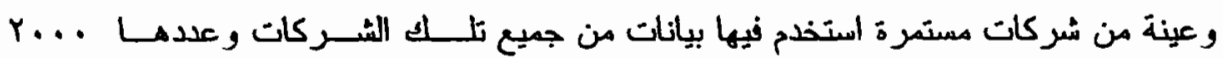

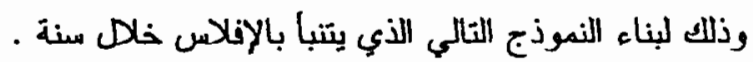
W Y,rV - w -

حيث :

س1, = اللوغاريتم الطبيعي لاجمالمي الأمول معدلا بالتغيرات في المستوى العام للكسعار.

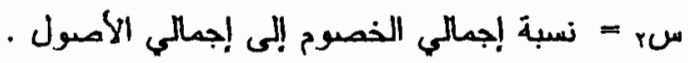
سبr = نسبة راس الملل العامل إلى إجمالمي الأصول.

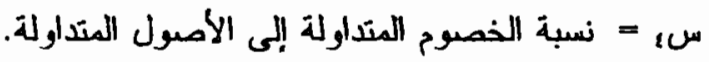
سه = نسبة صافي الاخل إلى إجمالمي الأصول.

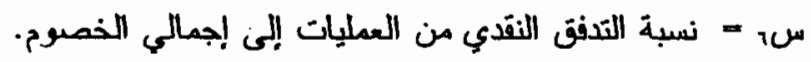

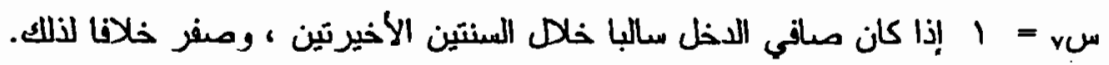

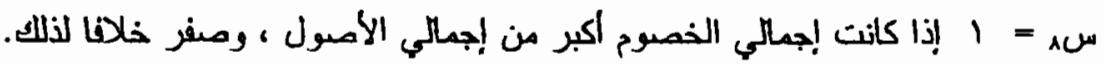

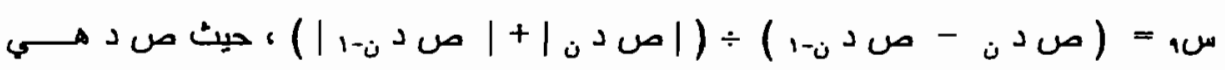
مافي الاخل و ن هي نهاية السنة التي تم فيها تقدير احتملال الفتل.

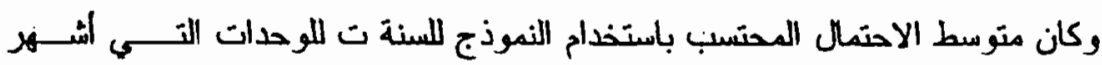

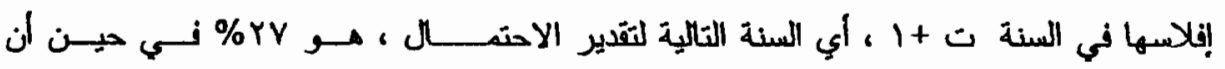

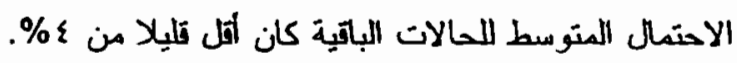

:

(1) يثم التوصل إلم استعال الإفلالى باسنخدام الدالة اللوغاريتمبة كما يلي :

$$
P_{j} t=\frac{1}{1+e^{-Z}}=\frac{1}{1+e^{-(a+b|x|+b 2 \times 2+\ldots . .+b p \times p)}}
$$

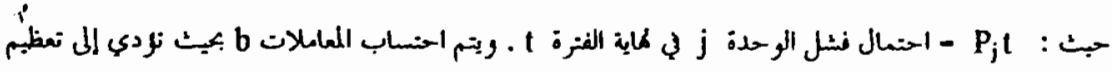

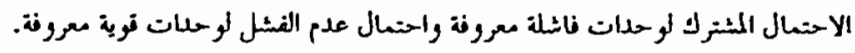




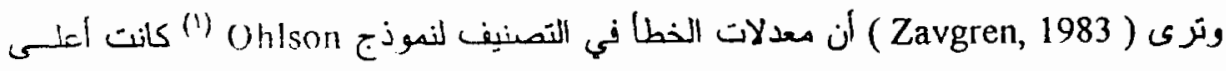

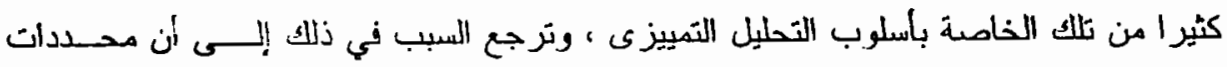

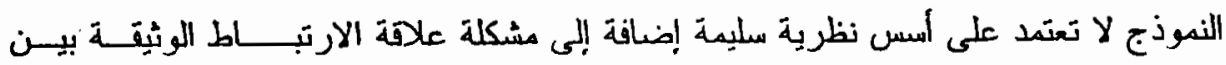

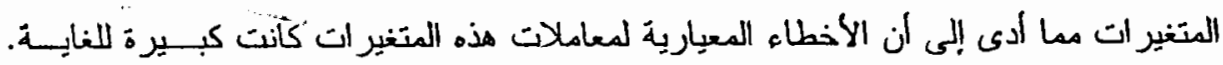

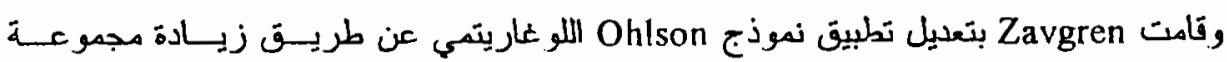

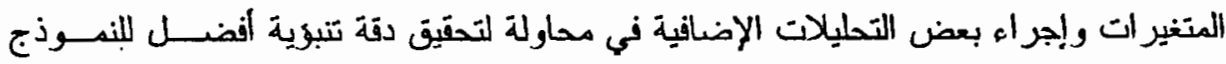

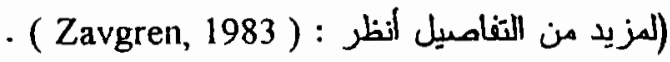

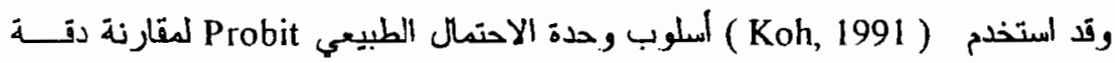

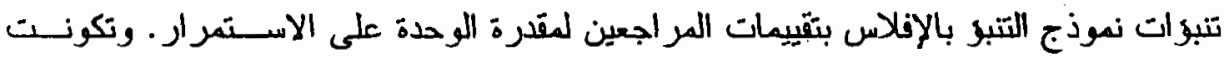

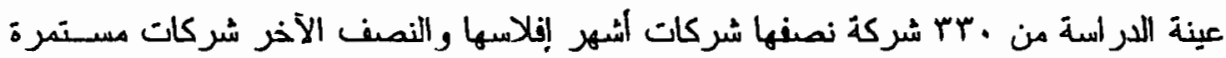

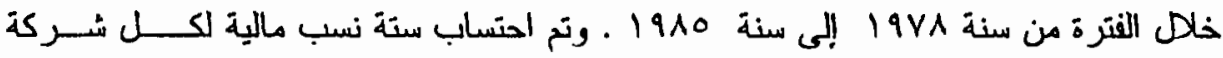

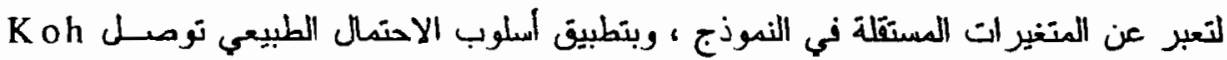

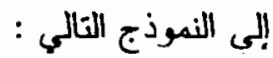
(Z)

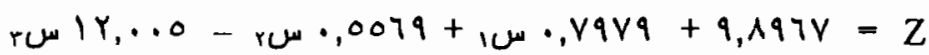
(Y)... س. حيث : ص م الاحتمال الشرطي لعدم الإفلاس ن (.) الح الحتمال طبيعي تر اكمية.

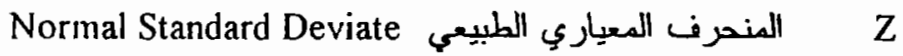
سا نسبة الأمول السريعة إلى الذصوم المتداولة. سr سبة القيمة السوقية لحقوق الملكية إلى إجمالمي الأصول. سr سبة إجمالي الالتز امات إلى إجمالي الأصول. سع: نسبة مدفوعات الفائدة إلى الأرباح قبل الفائدة والضريبة.

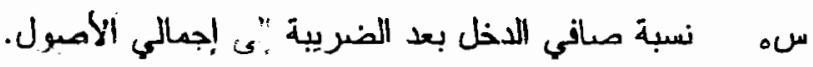

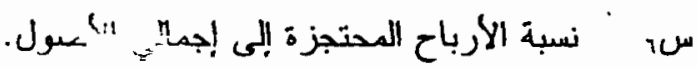

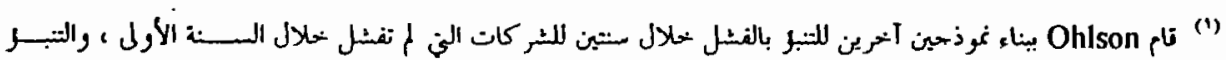

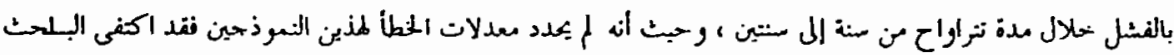
بعرض النموذج الأول كمئل على اسلوب التحليل اللوغارينشي. 


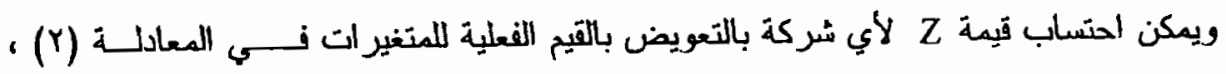

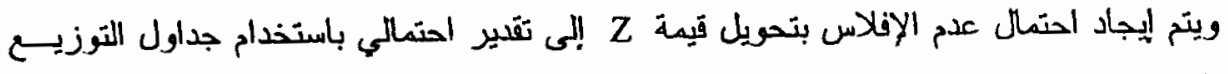
الطبيعي ( وهذا هو المقصود بالمعاللة (1) ).

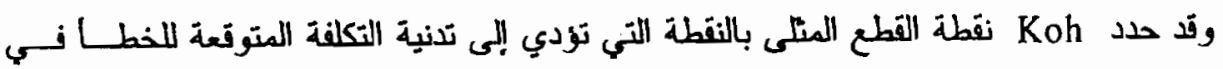

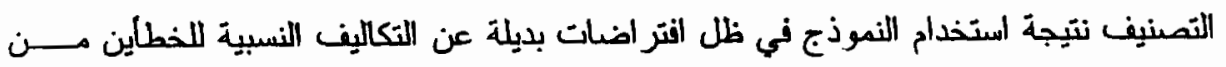

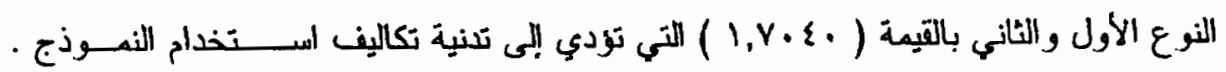

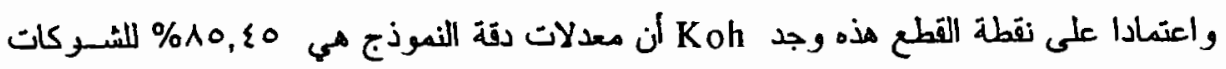

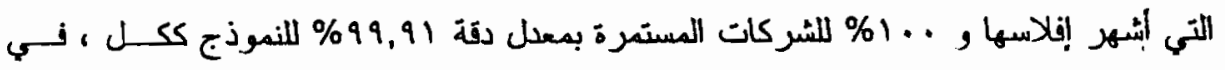

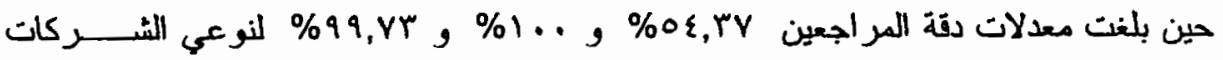

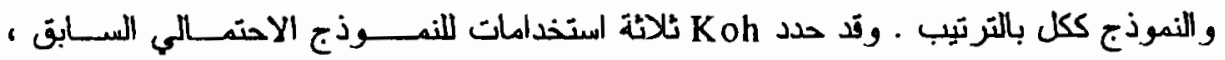
تتلخص في الآتي :

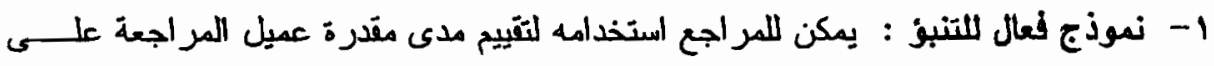

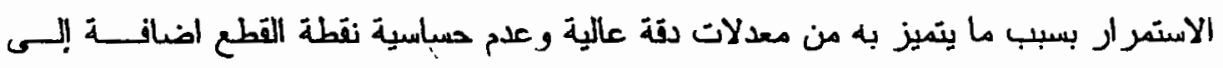

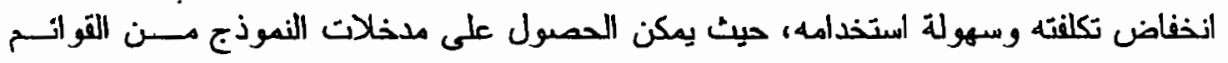

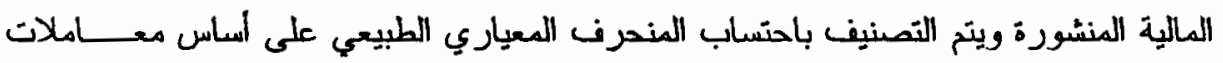

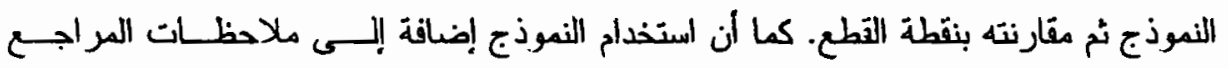

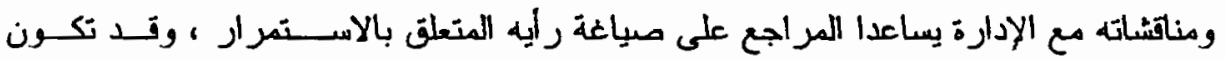

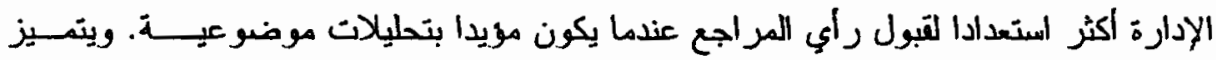

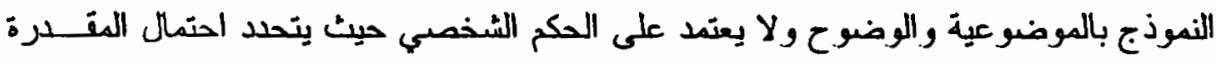

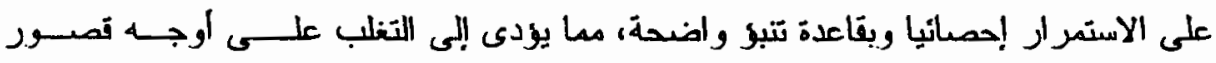
المعيار ه المتمثلة في عموميته و وعموضنه .

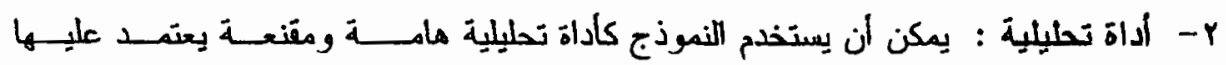

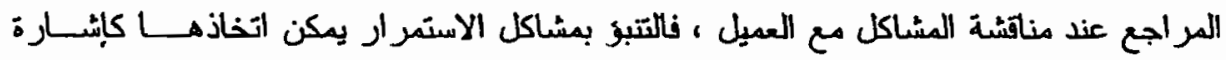

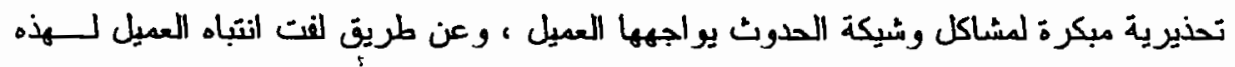

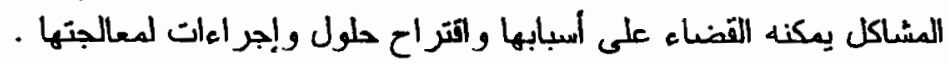

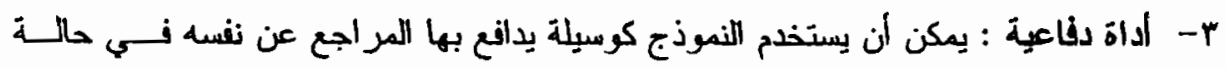

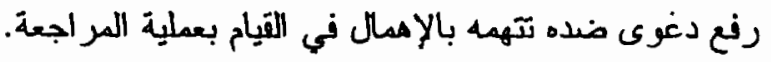


وفي در اسة أخرى استخدم ( Koh and Brown, 1991 ) نف س الأسـلوب لبنــاء

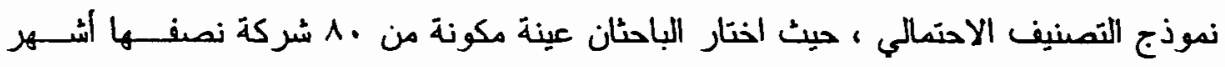

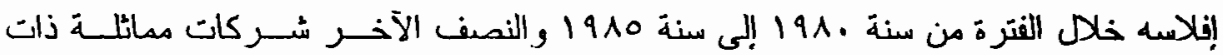

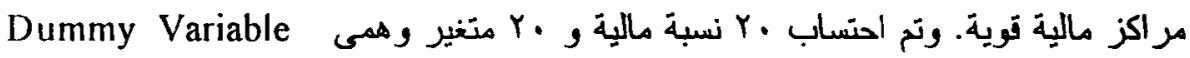

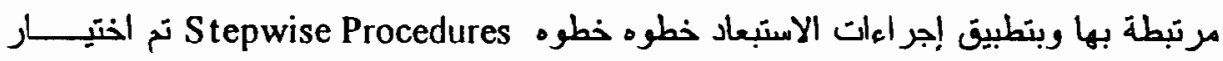

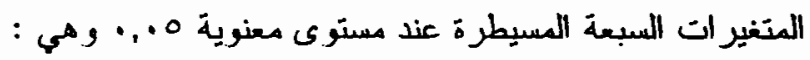

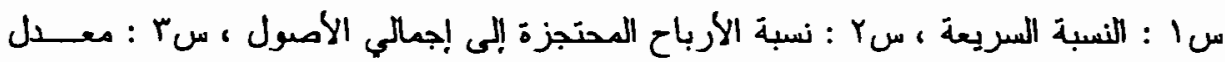

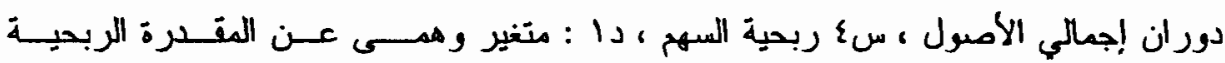

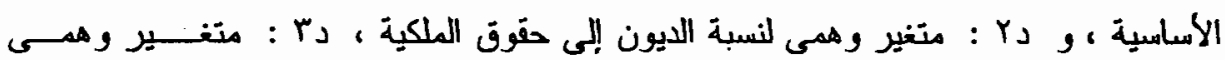

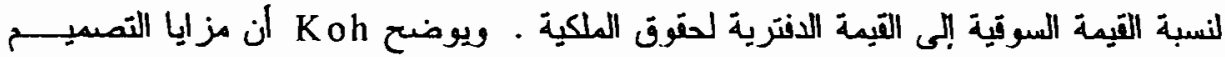

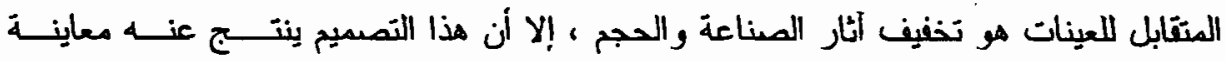

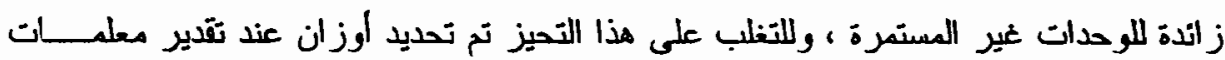

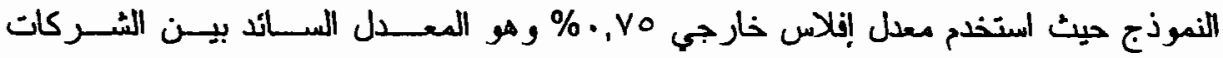

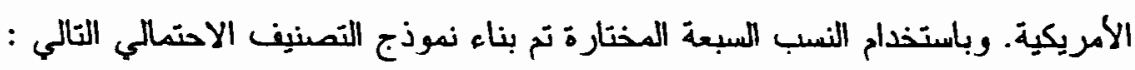

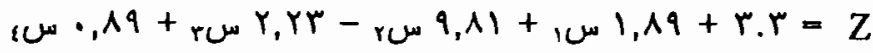

$$
\begin{aligned}
& \text { rدY,VI + Y Y,Yq - .21.11 - }
\end{aligned}
$$

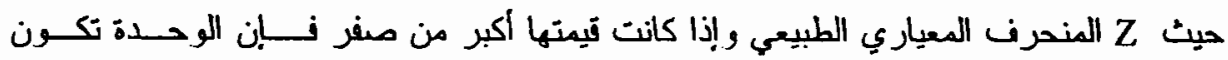

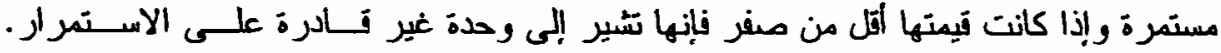

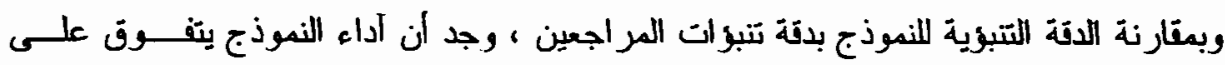

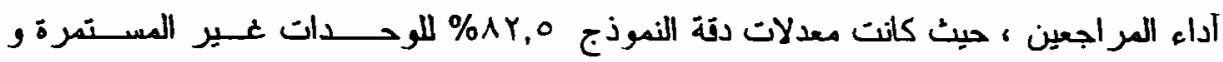

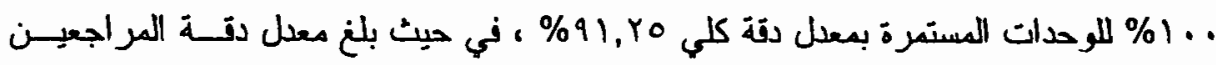

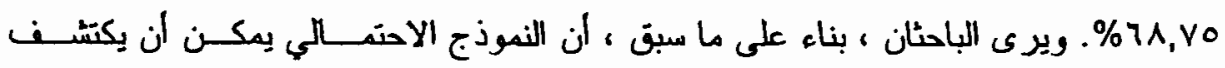

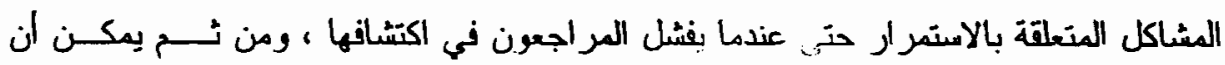

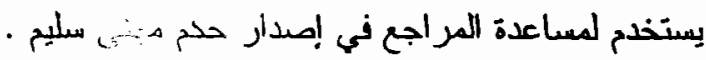

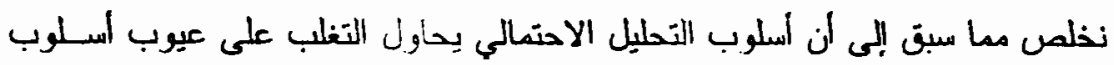

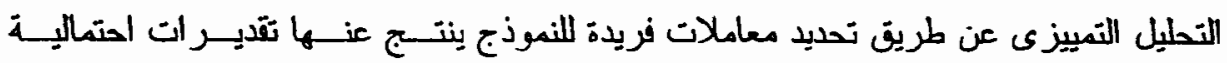

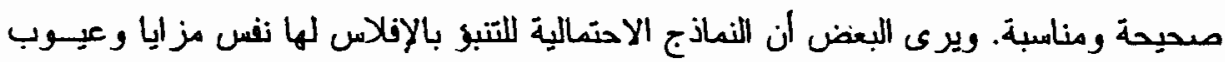




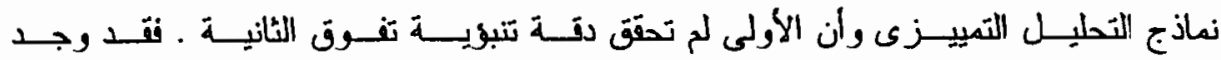
(Hamer, 1983 )

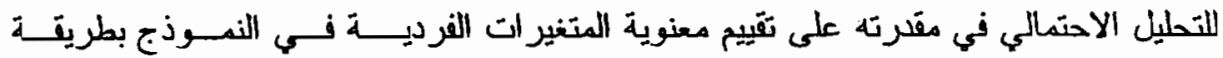

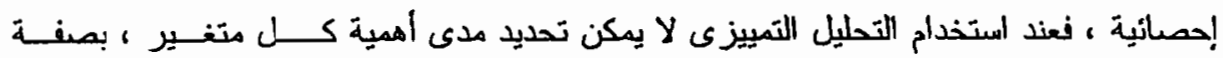

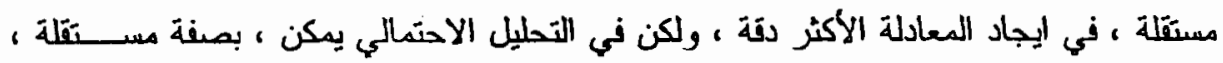

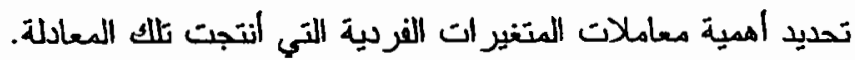
تقيبيم نماذج التنبوز بالإفلاس يلاحظ من العرض السابق أن العلامة بين إفلاس عميل المر اجعة وإصـــــدار تقريــر

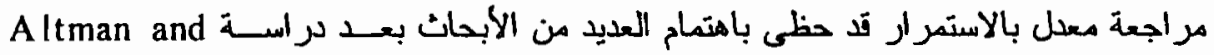
سنة ع McGough

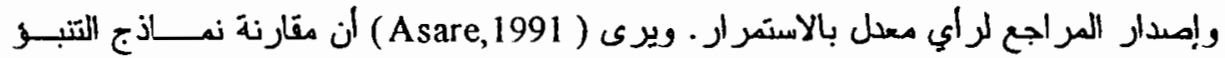

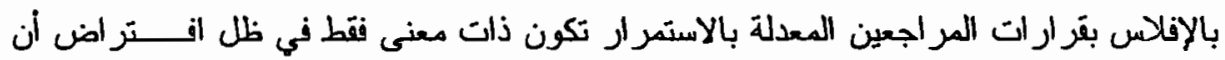

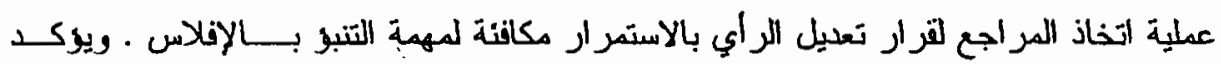

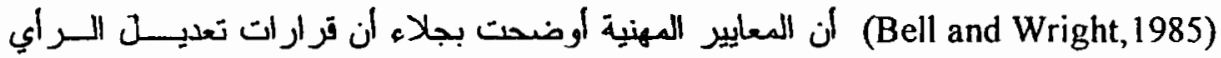

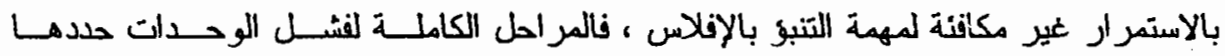
(Boritz,1991)

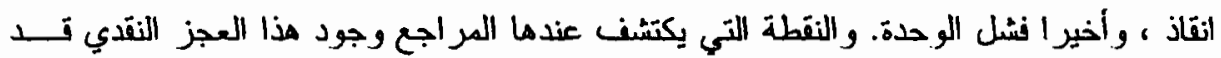

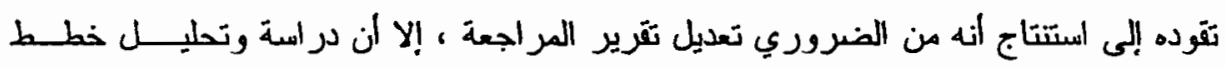

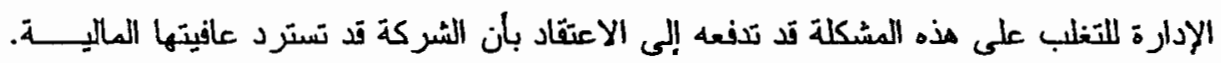

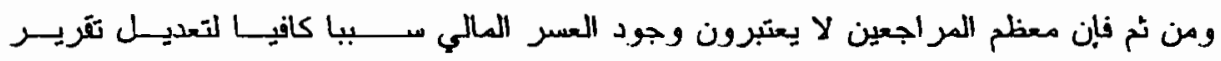

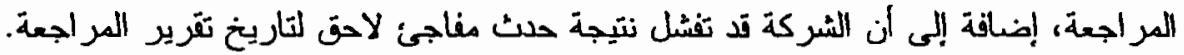

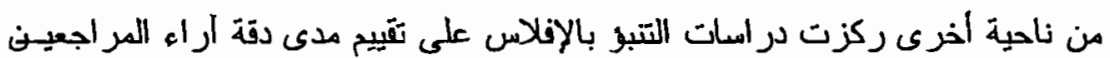

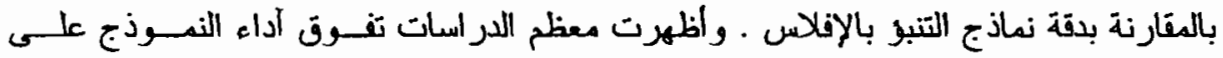

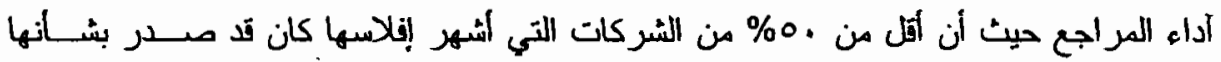

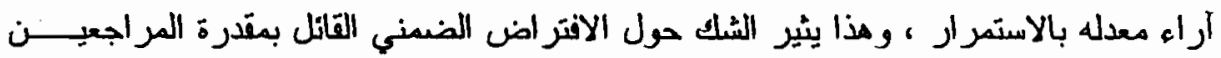

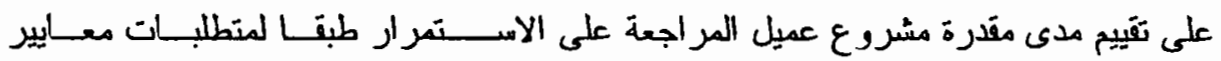

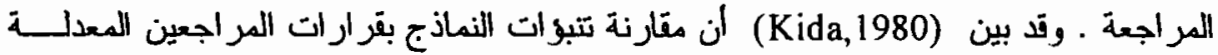

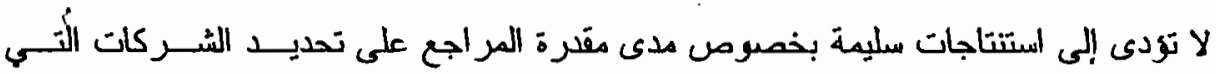




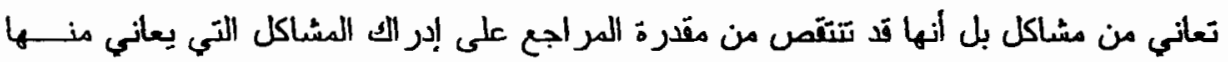

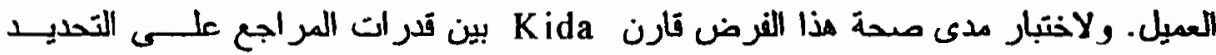

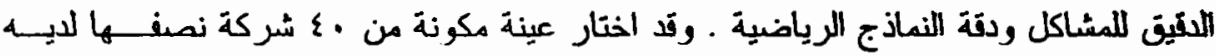

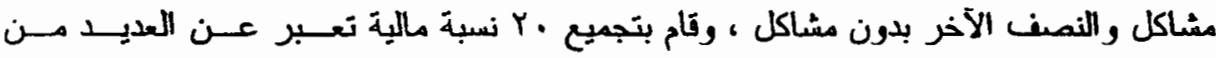

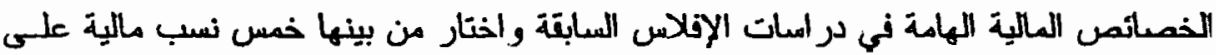

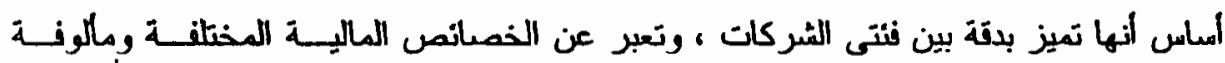

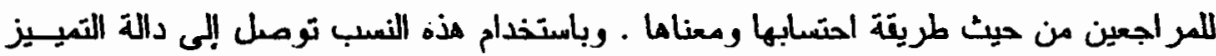
الآتية : حيث سار : نسبة صافي الاخل إلى إجمالي الأصول ( الربحية ) ، سه : نسبة صافي الـثروة

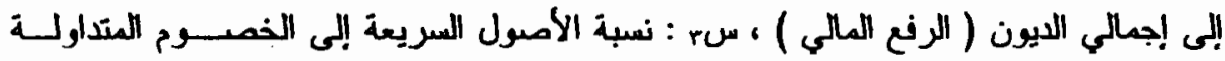

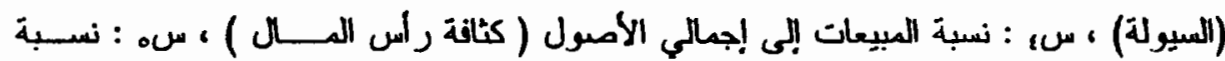

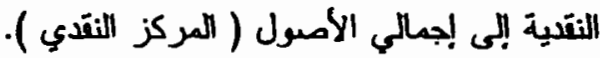

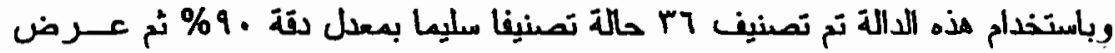
Kida

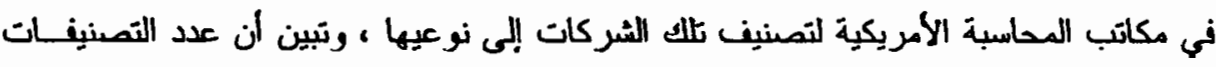

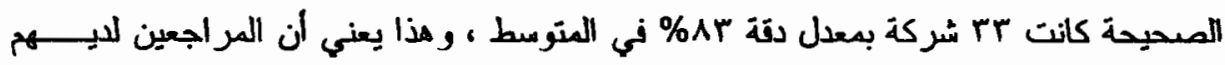

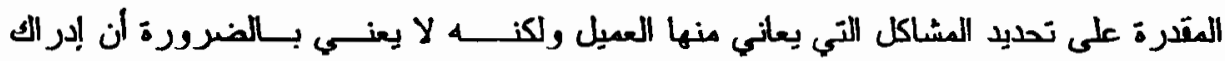

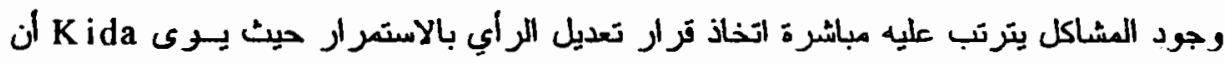

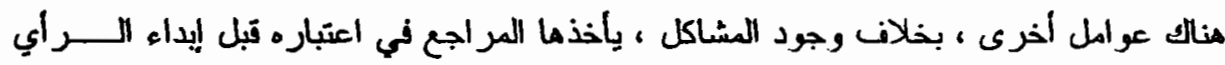

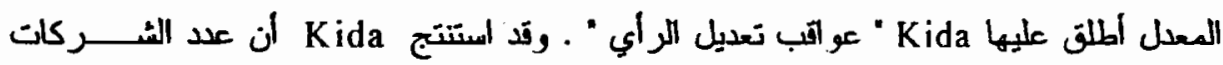

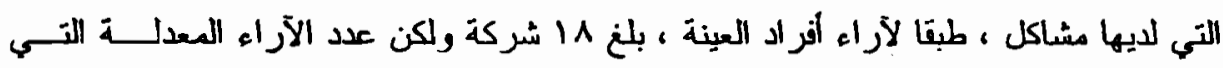

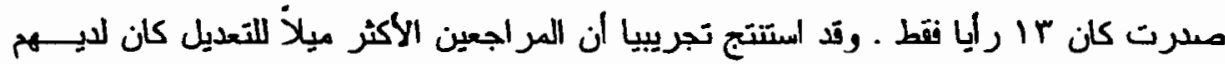

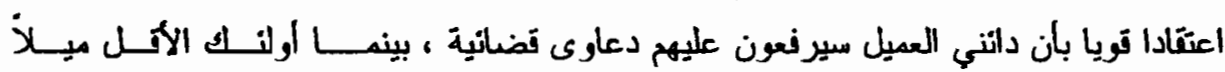

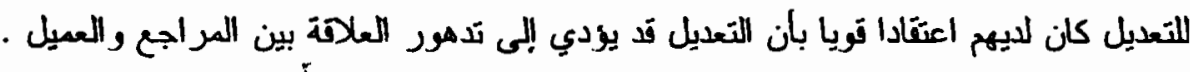

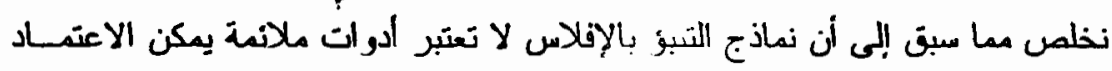

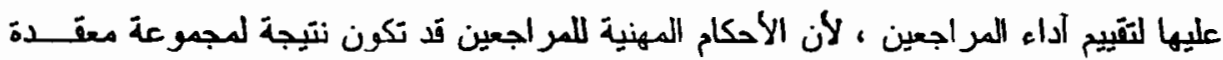

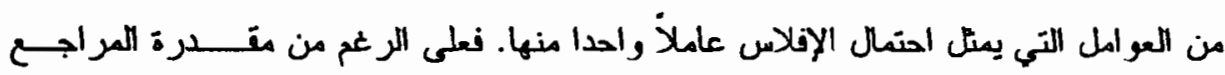

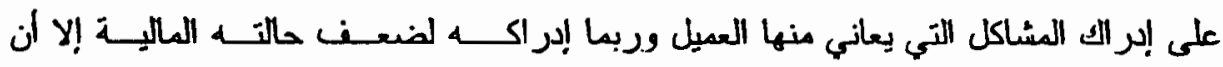




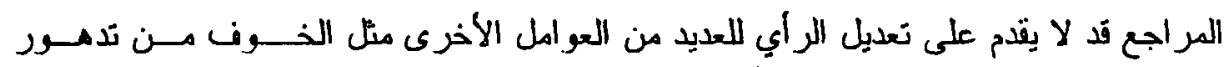

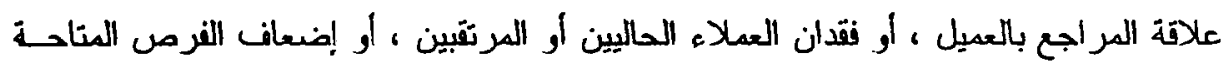

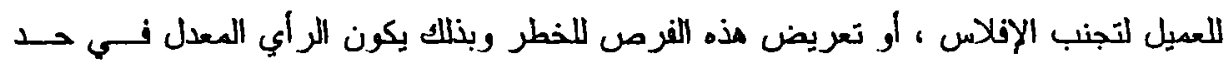

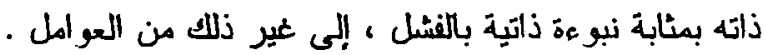

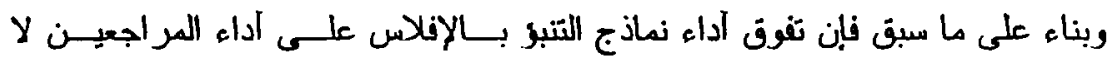

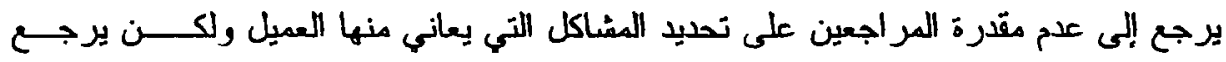

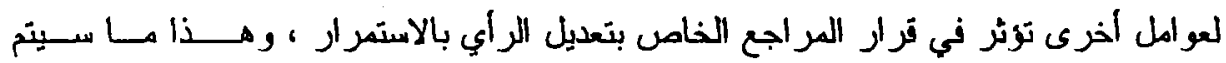

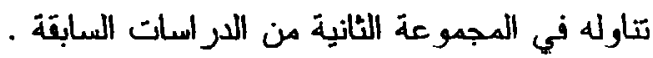

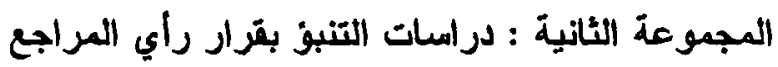

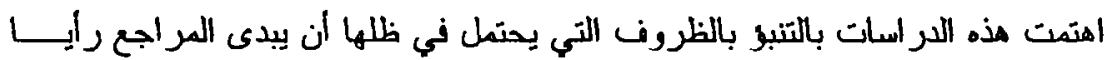

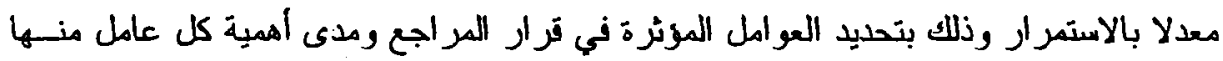

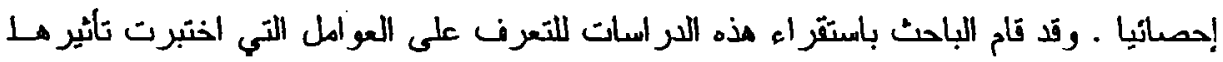

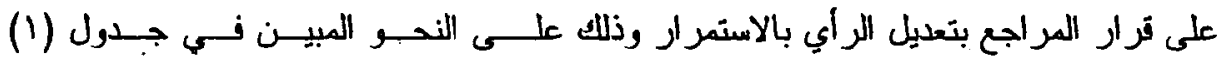

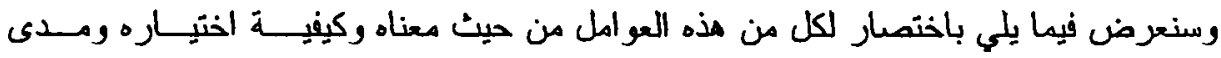
أهميته من وجهة نظر الدراسات التي تناولته . 


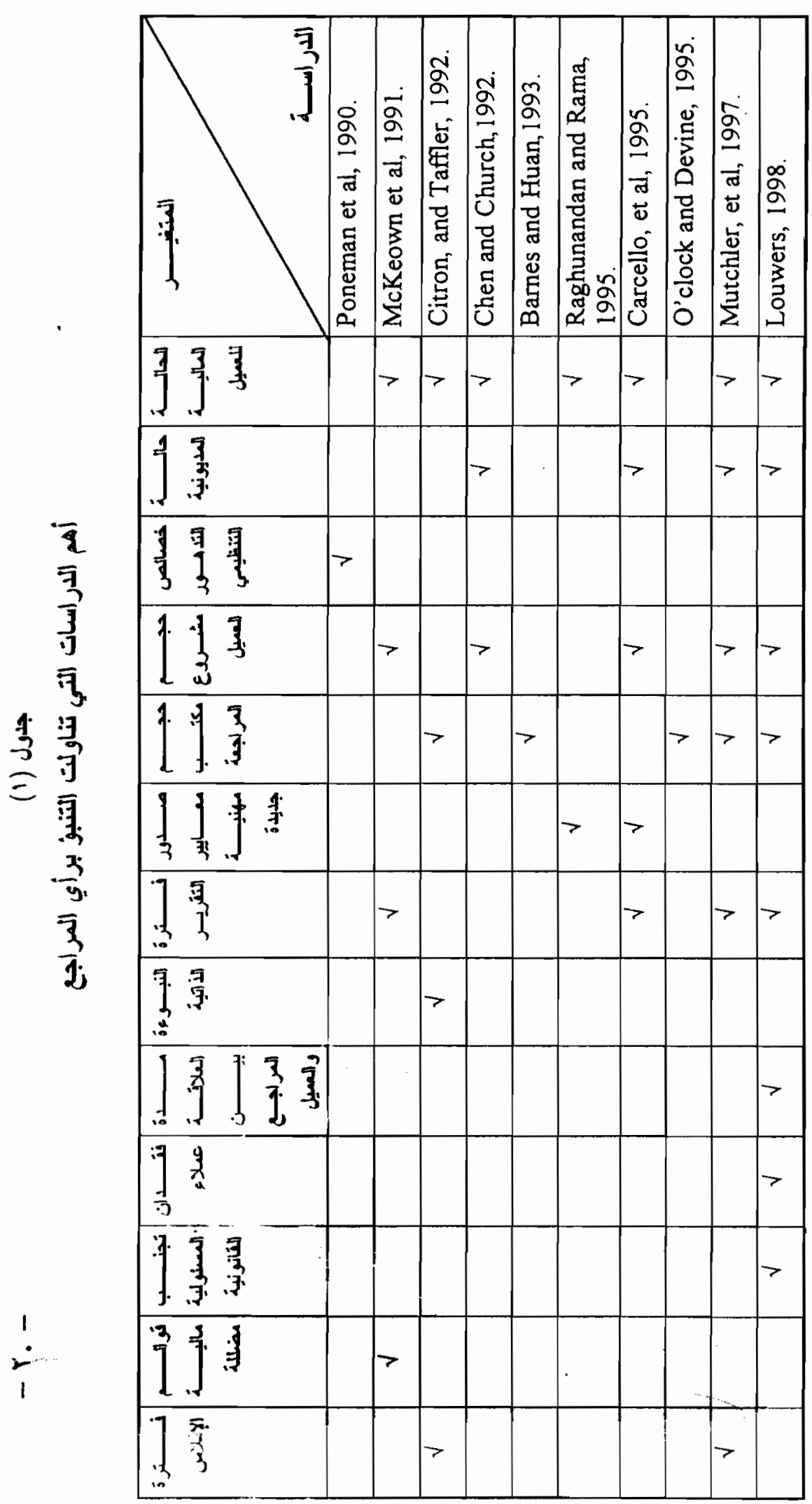




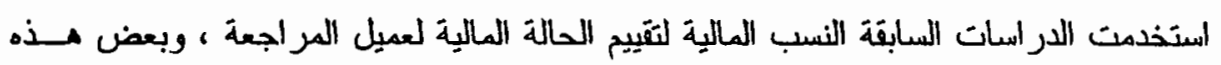

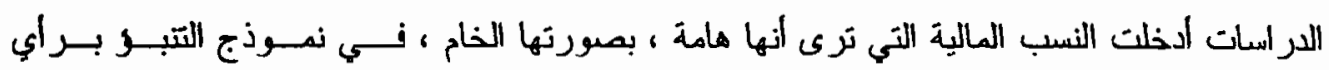
الدراجع مثل : در اسة (McKeown et al. 1991) التي توصلت إلى الربعة نسب مالية هامة انفر اديــا

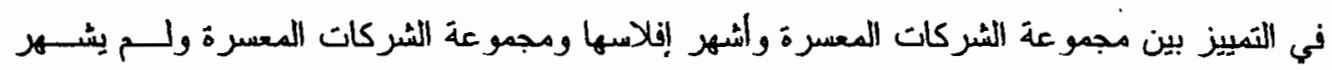

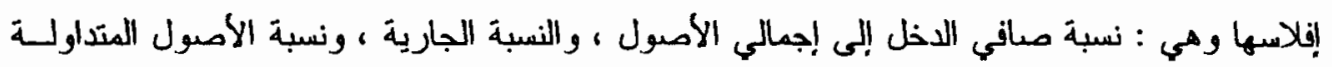

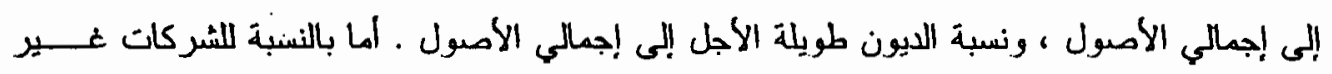

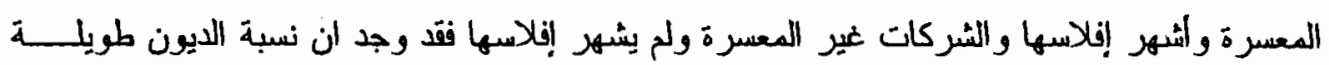

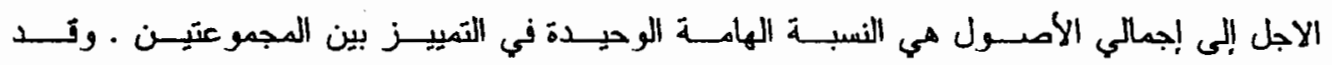

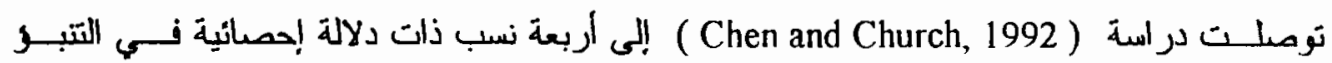

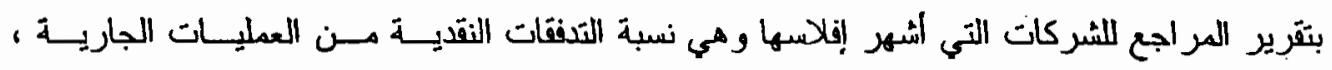

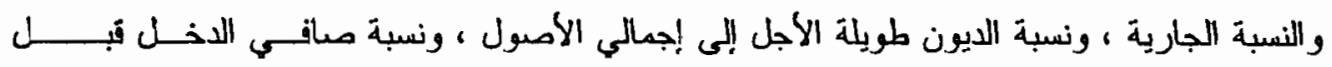

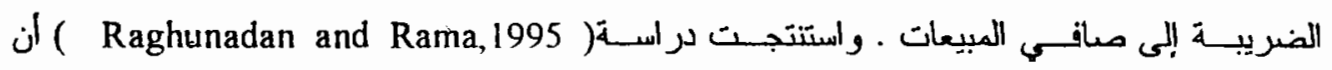

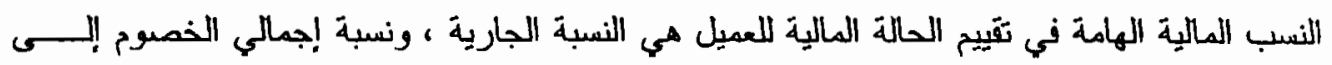

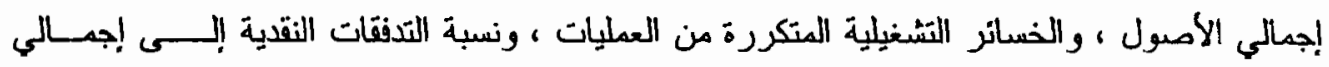
الالتز امات.

من ناحية أخرى ، الستخدمت بعض الدراسات النسب الهامة التي حددتها الدراســات المسابقة

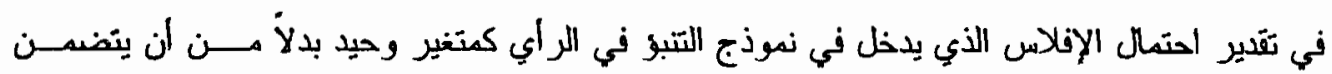

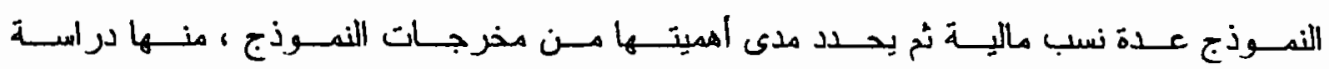

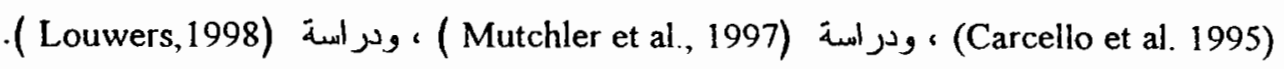

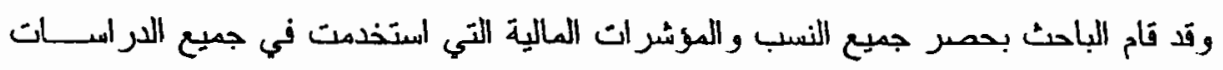

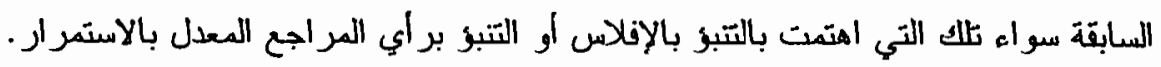

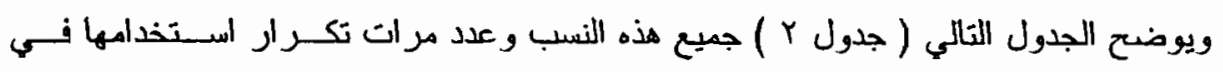
الدر اسات السابقة. 
ملاحظات على الجدول (Y) (1) (1)

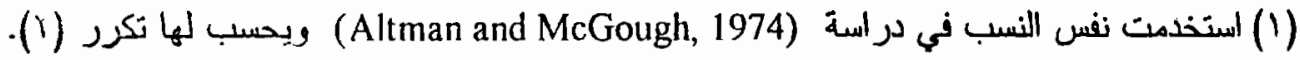

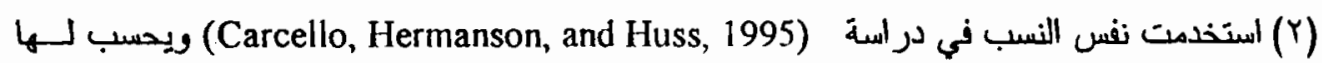
تكر ار (Y) (Y)

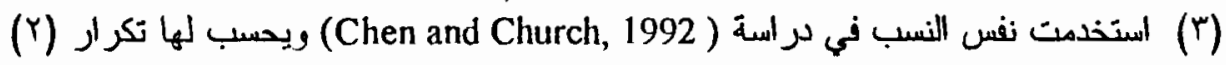

$$
\text { أستخدت نفس النسب في الدراسات التالية : }
$$

McKeown et al., 1991 \& Muthchler et al., 1997 \& Louwers, 1998.

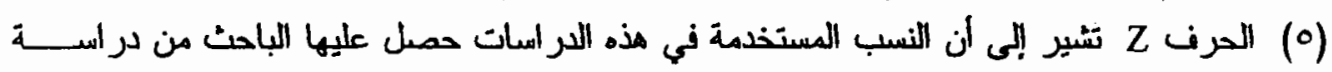

(Zavgren, 1983 ) 


\section{جاول (r)}

أهم النسب المالية التي استخدمت في الدراسات العابقة لتتييم العالة المالية لعيل المراجعة

\begin{tabular}{|c|c|c|c|c|c|c|}
\hline 10880 & toriting & 1972, & $\begin{array}{l}\text { Dalkin } \\
1972(2)\end{array}$ & $1968(1)$ & $\begin{array}{l}\text { Beaver } \\
1966(2)\end{array}$ & 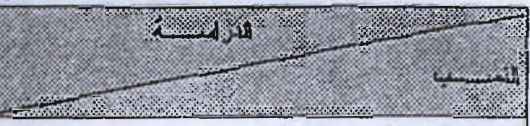 \\
\hline & $\sqrt{ }$ & & $\sqrt{3}$ & & $\sqrt{ }$ & التفنَ النّدي إلى إجمالب الليون \\
\hline \multirow[t]{5}{*}{$\sqrt{ }$} & $\sqrt{ }$ & & $\sqrt{ }$ & $\sqrt{ }$ & $\sqrt{ }$ & صاني الدخل ل!ي لجمالى الأمول \\
\hline & $\sqrt{ }$ & & $\sqrt{ }$ & & $\sqrt{ }$ & إجمالي الكيون بلى إجمالي الأمول \\
\hline & $\sqrt{ }$ & & $\sqrt{ }$ & $\sqrt{ }$ & $\sqrt{ }$ & رلس لامال العامل إلى إجمالي الأمرل \\
\hline & $\sqrt{ }$ & : & $\sqrt{ }$ & & $\sqrt{ }$ & الأمبول المتارولة إلى الخمبوم المندارول2 \\
\hline & & & & $\sqrt{ }$ & & الأرباع المنجز : بلى إبملالي الأمسول \\
\hline$\sqrt{1}$ & & & 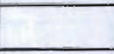 & $\sqrt{ }$ & & القيمح الهبونيح لحقون الملكية إلى إجمالى الديون \\
\hline$\sqrt{ }$ & & & 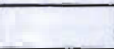 & $\sqrt{ }$ & & المبيعات إلي إجمالي الأمبول \\
\hline$\therefore$ & & & $\sqrt{1}$ & & & الأمسول العريعُ إلى لجمالى الأهمرل \\
\hline & & & $\sqrt{ }$ & & & الأمول المتاراكل إلى إجمالي الأمول \\
\hline$\sqrt{ }$ & & & $\sqrt{ }$ & & & النتبية لبي إجمالي الأمسور \\
\hline \multirow[t]{24}{*}{$\sqrt{ }$} & & $\sqrt{ }$ & $\sqrt{ }$ & & & 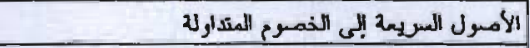 \\
\hline & & $\sqrt{ }$ & $\sqrt{ }$ & & & التقبيح إيى الخصوم المتدرولرح \\
\hline & & $\sqrt{ }$ & & & & الذهوب المثار رلم إلى حترن الملكيح \\
\hline & & & & & & لبجمالي الدخل بيى إجمالى رلس المال \\
\hline & & & & & & الديون ليى إبمالمي رلس المال \\
\hline & & & & & & 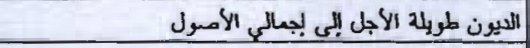 \\
\hline & & & & & & مافي الدذل تبل الضر بيح إلى مساني للمبيعات \\
\hline & & $\sqrt{ }$ & & & & الأمبول المدارول إلى المبيعات \\
\hline & & & & & & رِبعية الههم \\
\hline & & & & & & الترزيعات للبهم \\
\hline & & & & & & 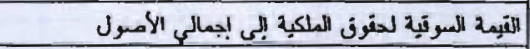 \\
\hline & & & & & & 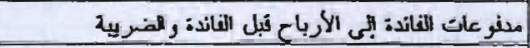 \\
\hline & & & & & & معطل دور نن إجمالي الأمبول \\
\hline & & & & & & إجمالعى الديون إلى هنون الملكية \\
\hline & & & & & & 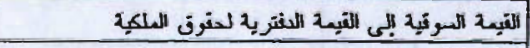 \\
\hline & & & & & & التنير في إجملالي الأصول \\
\hline & & & & & & التنير نى إجمالى الدخل إلى لجمالى الأمسول \\
\hline & & & & & & 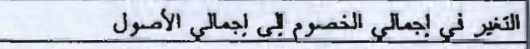 \\
\hline & & $\sqrt{ }$ & & & & حقون الملكية إلى المبيهات \\
\hline & & & $\sqrt{1}$ & & & الأمسول السريع إلى المبيعات \\
\hline & & $\sqrt{ }$ & $\sqrt{ }$ & & & رلس لالمال العامل إلى المبيمات \\
\hline & & & $\sqrt{ }$ & & & 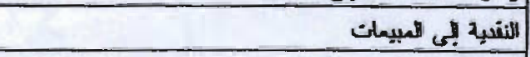 \\
\hline & & $\sqrt{ }$ & & & & المخزون إلى المبريعات \\
\hline & & & & & & هنون الملكيح بلى المبيعات \\
\hline
\end{tabular}


تابع جدول (Y)

\begin{tabular}{|c|c|c|c|c|c|c|c|c|c|}
\hline , & Noplet & 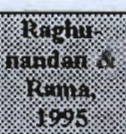 & . & $\begin{array}{l}\text { Konitind } \\
\text { Brongn } \\
1003\end{array}$ & $\begin{array}{l}\mathrm{K}, \mathrm{w} \\
1090\end{array}$ & 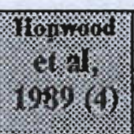 & $\begin{array}{l}\text { Mrin } \\
618591\end{array}$ & $\begin{array}{l}25 \\
1084 \\
198\end{array}$ & 1982 \\
\hline V & $\sqrt{ }$ & $\sqrt{ }$ & & & & & $\sqrt{ }$ & & \\
\hline 18 & $\sqrt{ }$ & ( & $\sqrt{ }$ & & & $\sqrt{1}$ & & $\sqrt{ }$ & \\
\hline$\wedge$ & $\sqrt{ }$ & $\sqrt{ }$ & $\sqrt{ }$ & & & 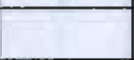 & & $\sqrt{ }$ & \\
\hline 0 & & & & & & 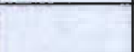 & & & \\
\hline ir & $\sqrt{ }$ & $\sqrt{ }$ & & & & $\sqrt{1}$ & $\sqrt{1}$ & $\sqrt{ }$ & \\
\hline 9 & $\sqrt{ }$ & & $\sqrt{ }$ & $\sqrt{ }$ & $\sqrt{ }$ & & & & \\
\hline$q$ & $\sqrt{ }$ & & & & & & & & \\
\hline 8 & & & & & & & & & $\sqrt{ }$ \\
\hline$r$ & & & & & $\sqrt{1}$ & 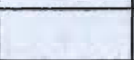 & & & te \\
\hline 0 & & & & & & $\sqrt{ }$ & & & \\
\hline$v$ & 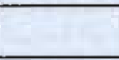 & & & & & $\sqrt{ }$ & & & $\sqrt{ }$ \\
\hline 7 & & & $\sqrt{ }$ & $\sqrt{ }$ & & & & & $\sqrt{ }$ \\
\hline$r$ & & & & & & & & & \\
\hline 1 & & & & & & & & & \\
\hline 1 & & & & & & & & & $\sqrt{ }$ \\
\hline 1 & & & & & & & & & $\sqrt{ }$ \\
\hline 9 & 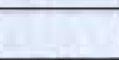 & & & & & $\sqrt{ }$ & T & & \\
\hline$r$ & J & & & . & & & $\sqrt{ }$ & & \\
\hline$\circ$ & & & & & & $\checkmark$ & & & \\
\hline$r$ & & & & $\sqrt{ }$ & $\sqrt{ }$ & & & & \\
\hline 1 & & & & & $\sqrt{ }$ & & & & \\
\hline 1 & & & $\sqrt{ }$ & & & & & & \\
\hline 1 & & 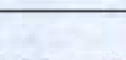 & & $\sqrt{ }$ & & & & & \\
\hline i & 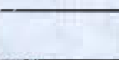 & & & $\sqrt{ }$ & & & & & \\
\hline 1 & & & & $\sqrt{1}$ & $\cdot$ & & & & \\
\hline 1 & & & & $\sqrt{1}$ & & & & & \\
\hline 1 & $\sqrt{ }$ & & & & & & & & \\
\hline 1 & $\sqrt{ }$ & & & & & & & & \\
\hline 1 & v & & & & & & & & \\
\hline 1 & & & & & & & & & \\
\hline 1 & & & & & & & & & \\
\hline$r$ & & $r$ & & & & & & & \\
\hline 1 & & & & & & & & & \\
\hline 1 & & & & & & & & & $\checkmark$ \\
\hline 1 & & & & & & & & & 1 \\
\hline
\end{tabular}


ثانياً : حالة المديونية

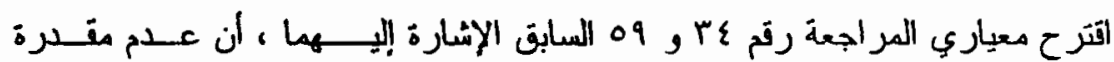

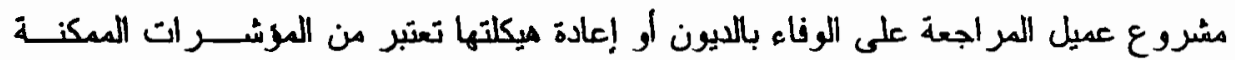

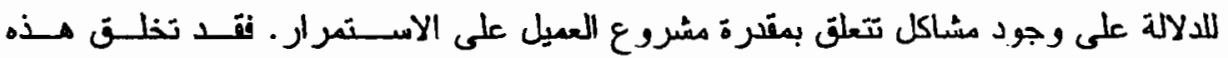

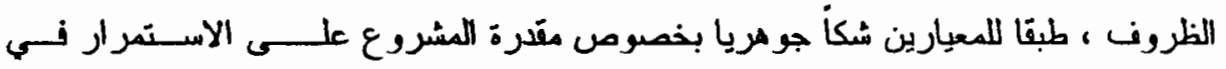

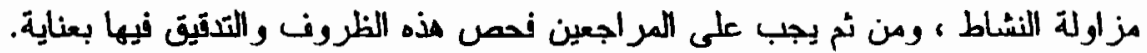

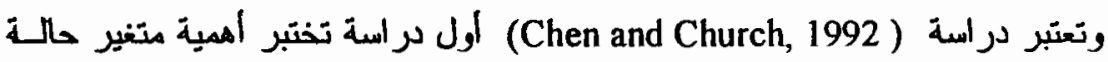

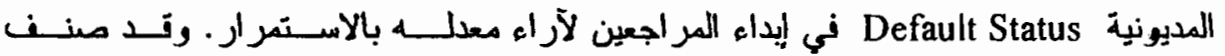

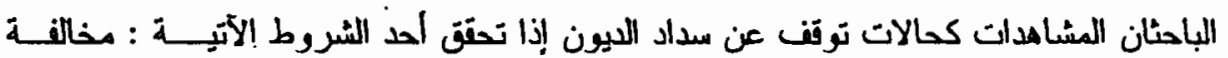

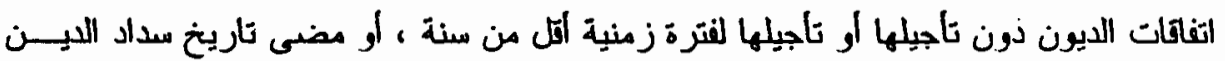

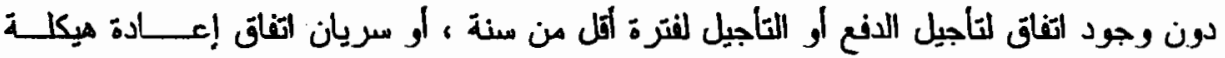
الديون.

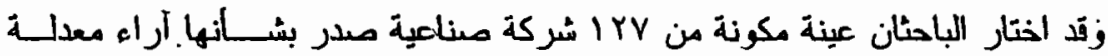

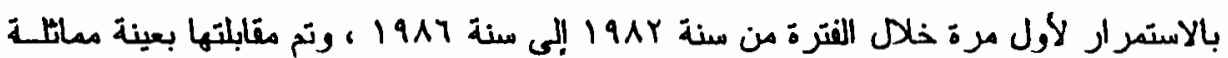

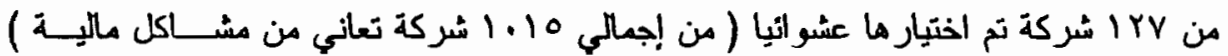

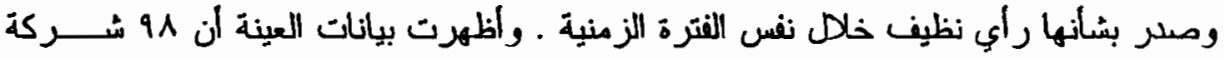
(\%VV)

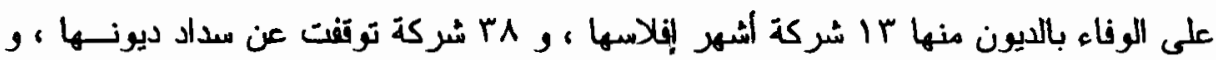

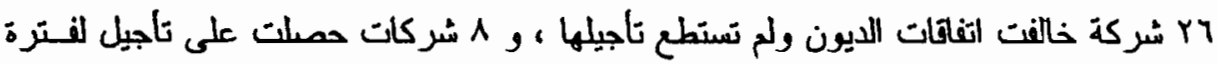

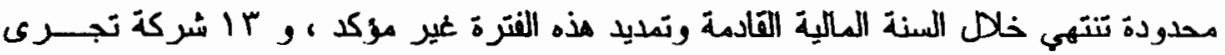

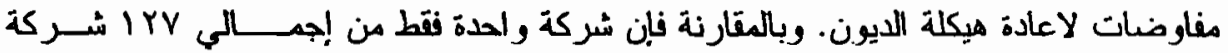

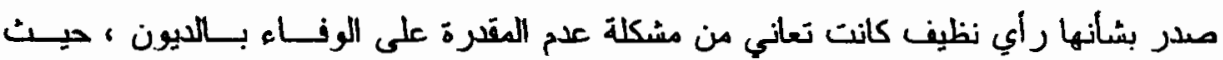

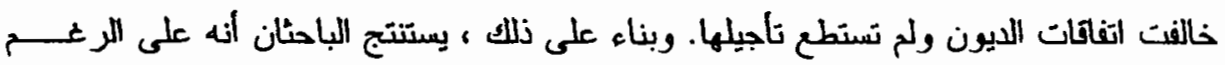

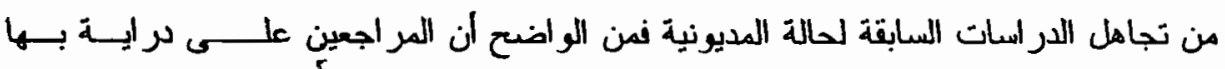
ويعتبرونها مؤشرا أساسيا لإبداء رالي معدل بالاستمرار .

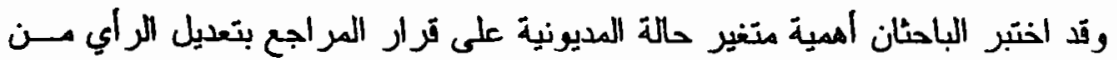

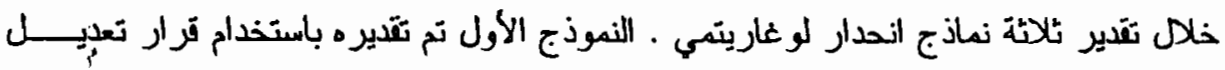

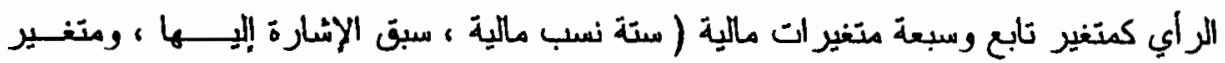


الحجم ) كمتغير ات مستخلة. واظهرت نتائج النموذج دلالة إحصائية ( عنــد مسـتوى ( ., ) )

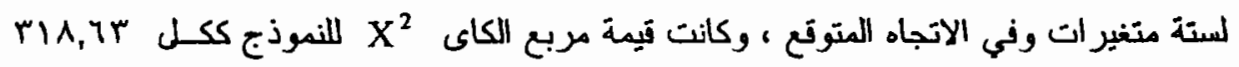

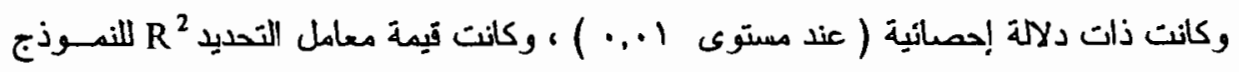

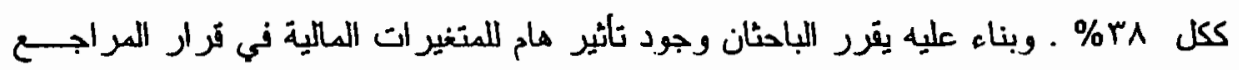

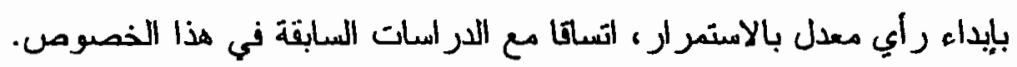

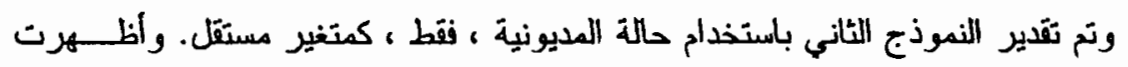

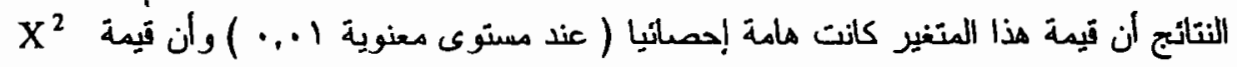

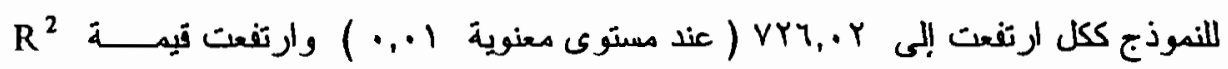

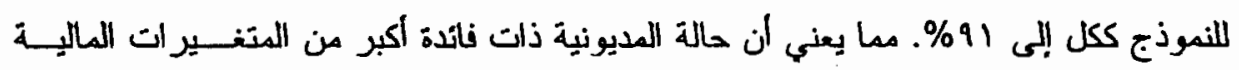

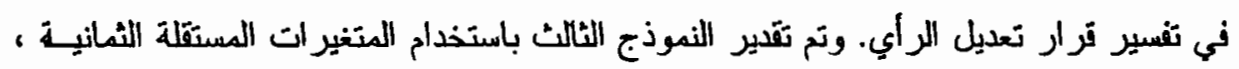

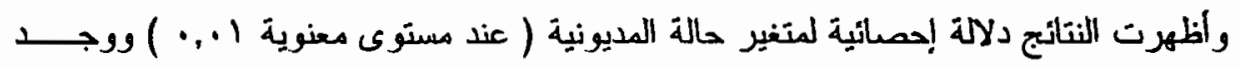

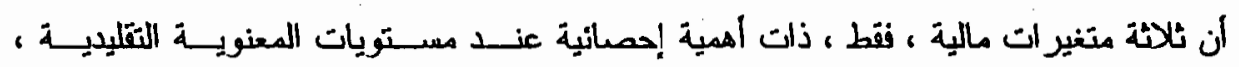

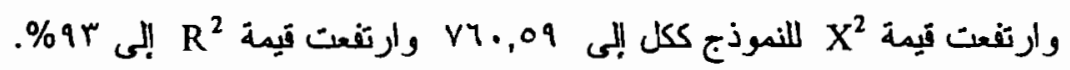

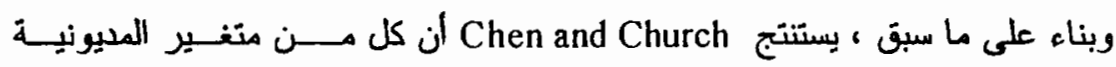

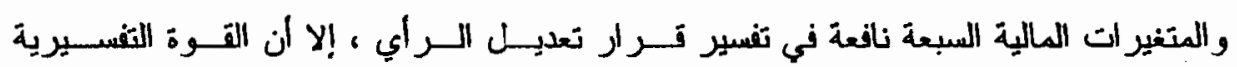

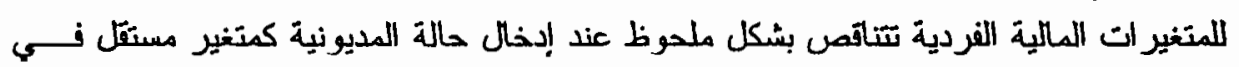
النموذج.

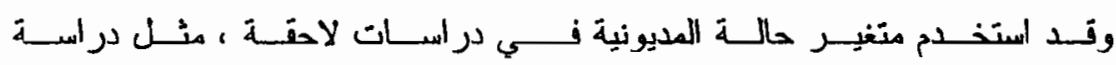
(Carcello et al. , 1995)

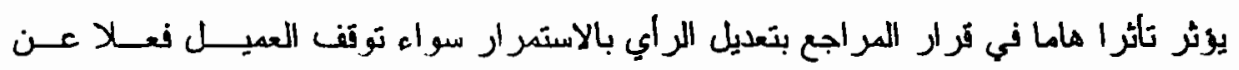

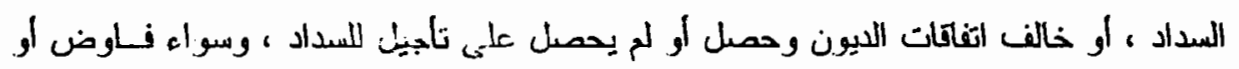
بعيد التفاوض مع الداننين لجدولة هدفو عات الايون.

وتد امتدت دراسة (Mutchler et al., 1997) بتحليل لأهميـة Chen and Church

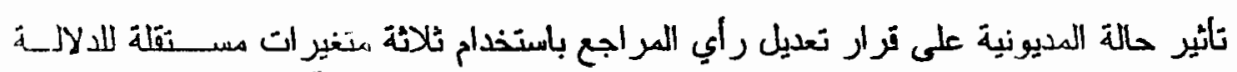

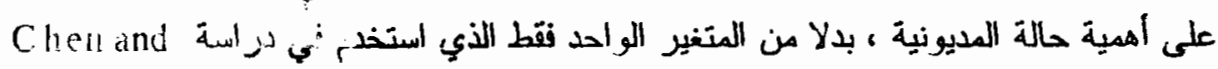

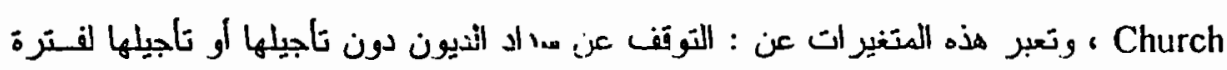

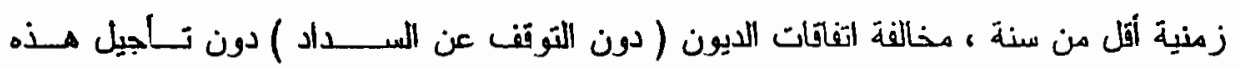

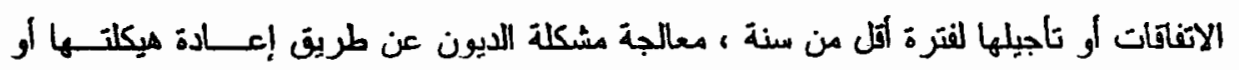




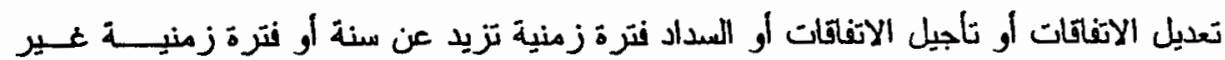

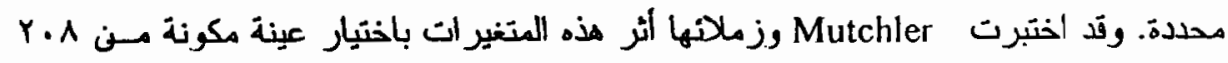

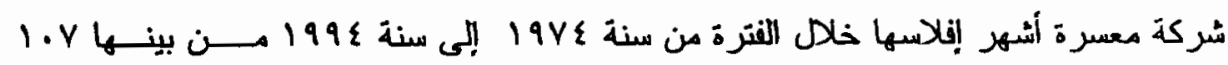

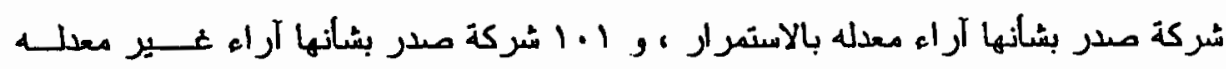

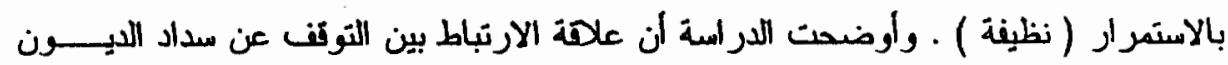

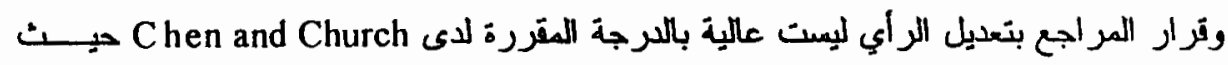

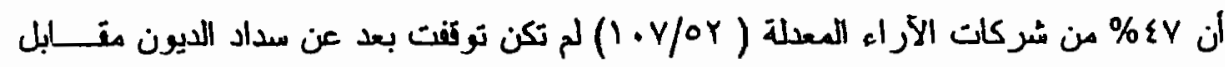

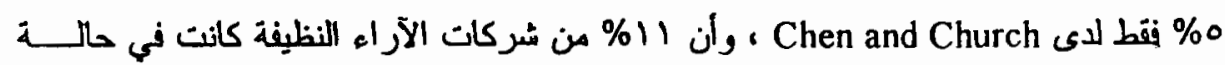

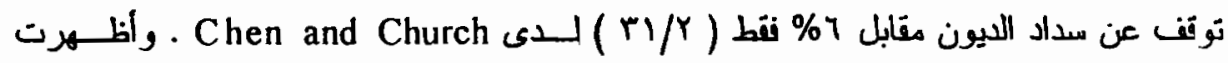

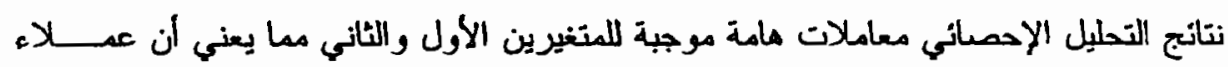

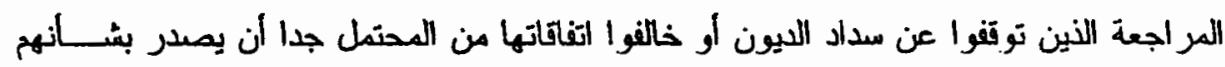

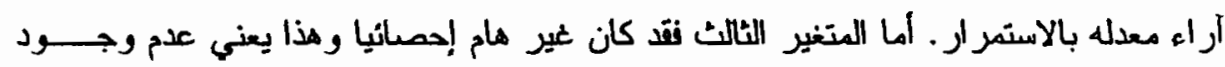

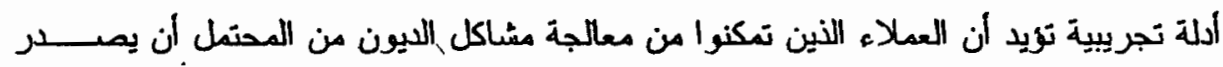

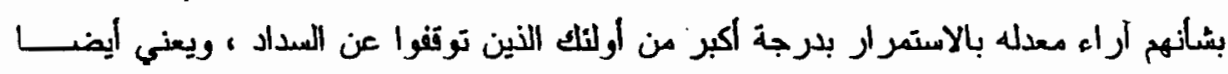
أن المراجعين لإيهتمن بالديون التي عولجت إلا إذا كانت توثر في الاحتمال المقدر للإفلاس.

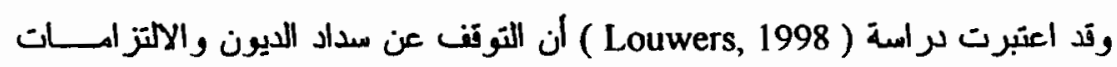

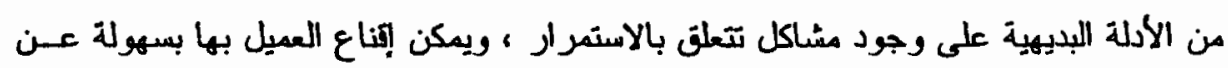

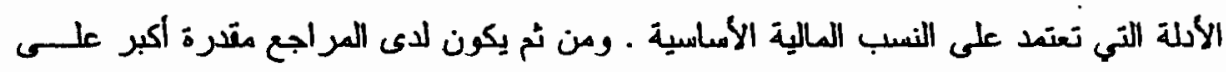

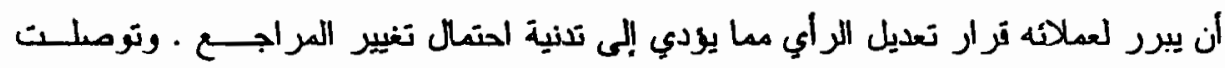

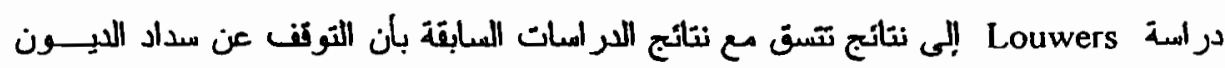

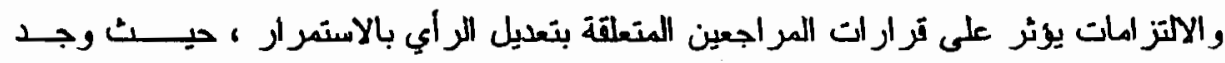
عاهة ارتباط توية هوجبة بين التوتن عن العداد وئر ار تعديل الراي.

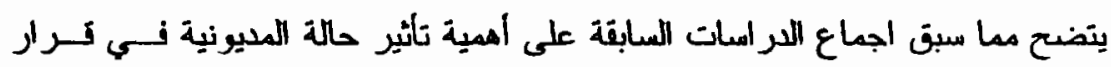

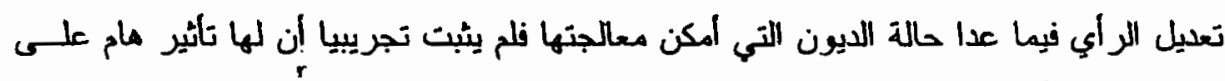

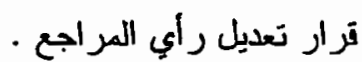

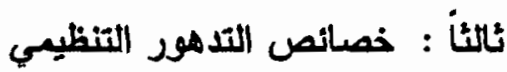

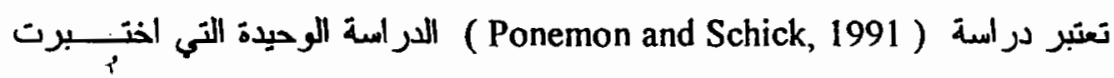

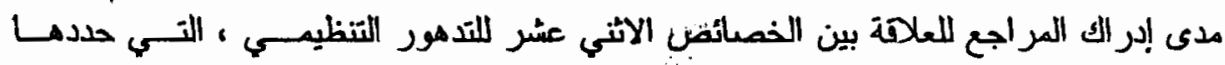


الباحتُون في مجال العلوك التنظيمي ، ورحدات عملاء المر اجعة التي تعـــاني مــن مشـــاكل

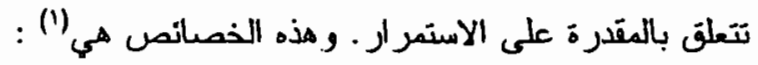

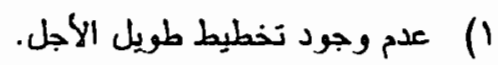
r) انخفاض دعنويات العاملين بالمشروع. r) تهرب المديرون من المسنولية بالقانها على الآخرين. ع) حدوث توقف أو تخفيض في الانتاج دون وجود أسس أو أولويات مخططة مسبقلا.

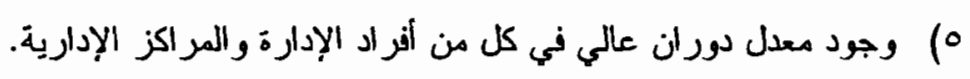

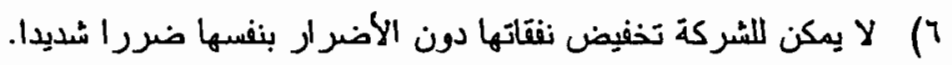

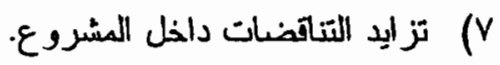
ه) وجود تدر كبير من مقاومة التغيير.

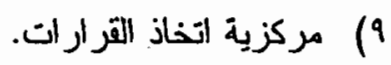

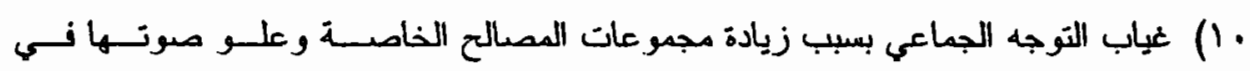
المشروع.

1) انخفاض مصداقية رجال الادارة و المديرين.

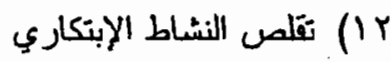

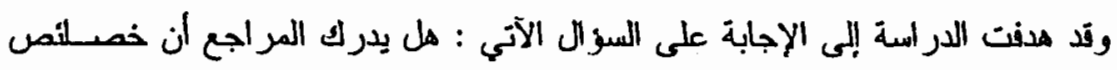

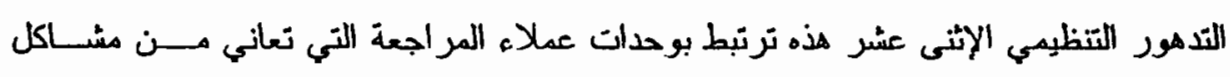

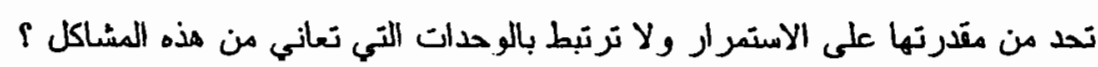

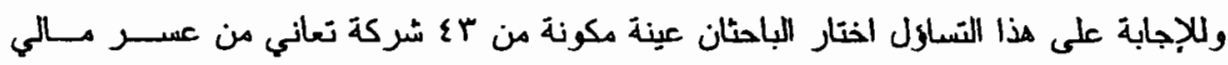

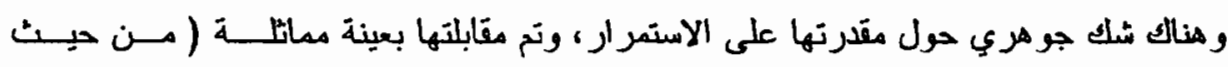

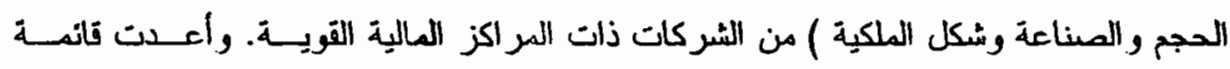

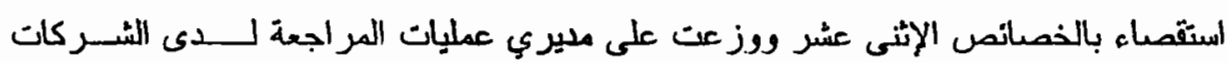
المختارة. وتد الظهرت الإحصاءات الوصفية أن المتوسط الحسابي للعديد من الخصائص كــــان

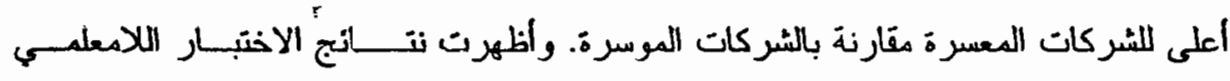

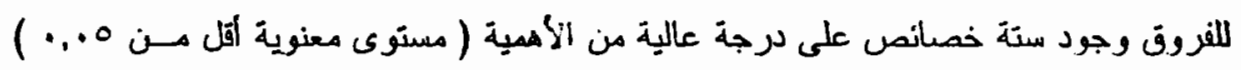

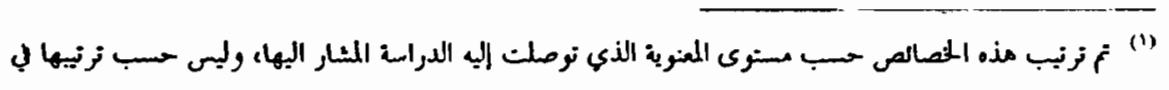


تتميز بها الشركات المعسرة و.هي الخصائص من الأولى إلى السادسة السابق الإشارة إليـــها ـ

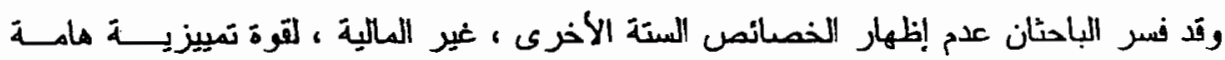

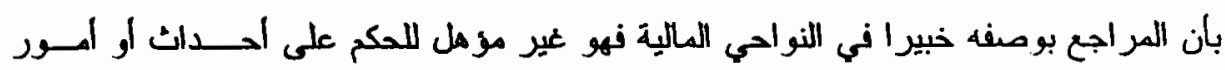

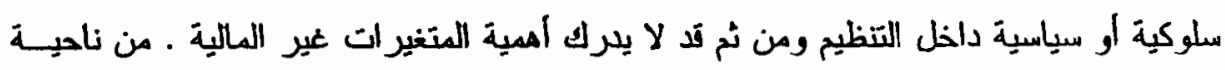

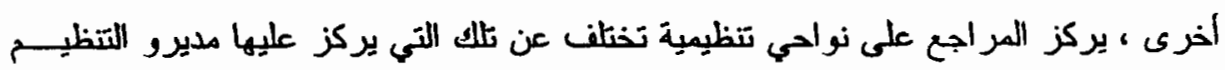

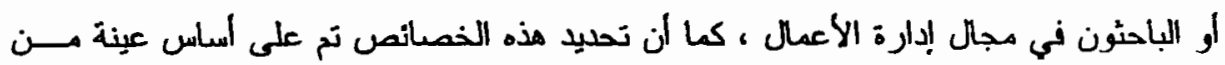

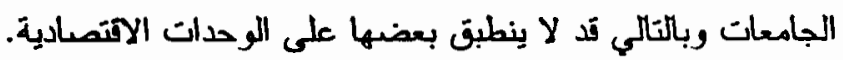

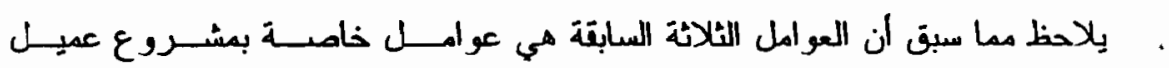

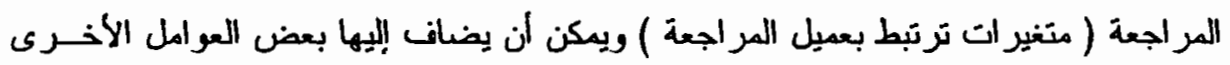

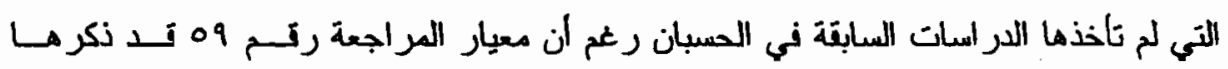

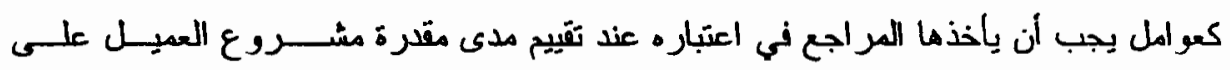

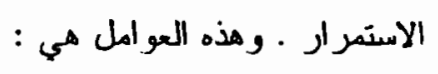

1) توتف المشُروع عن نفع التوزيعات او التأخر في دفعها.

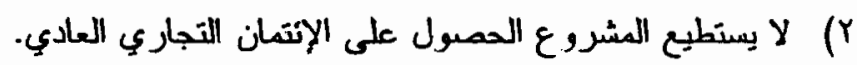

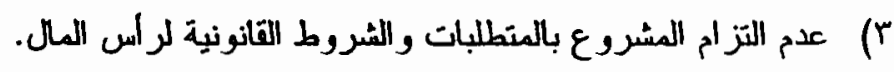
ع) احتياج المشروع لمصادر وطرن تمويل جديدة. 0) احتياج المشروع للتخلص هن جزء كبير من الأصول.

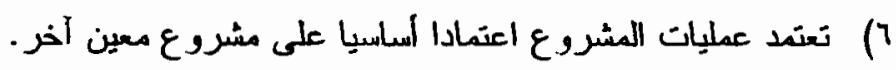
) وجود ارتباط (تعهدات ) طويلة الأجل غير اتتصادية. 1) احتياج المشروع لادخال تغيرات جومرية على العمليات الإنتاجية.

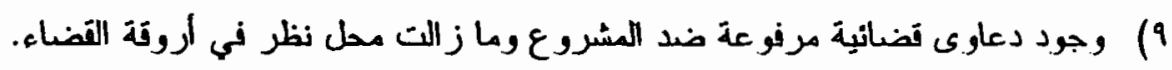

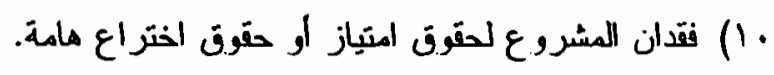

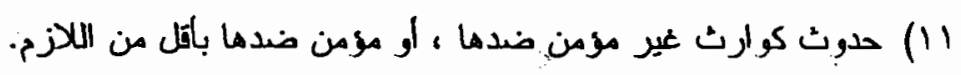

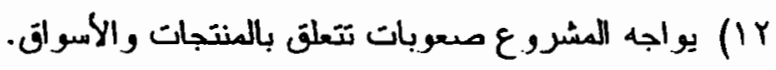

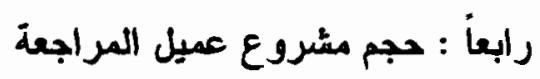

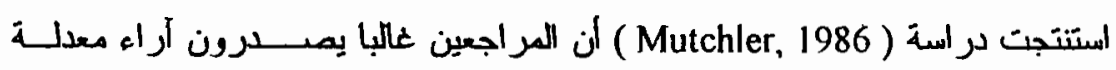

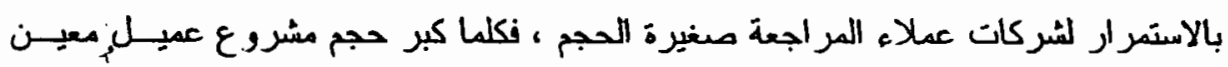

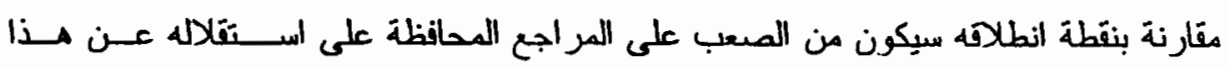


العميل وإيداء رابي معدل بالاستمر ار بسبب علامته بالعميل والضنغوط التــي تسـببها أتعـاب

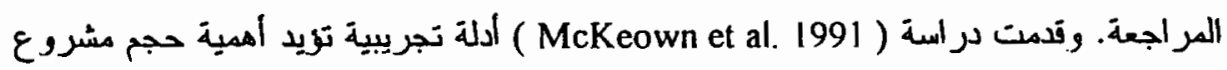

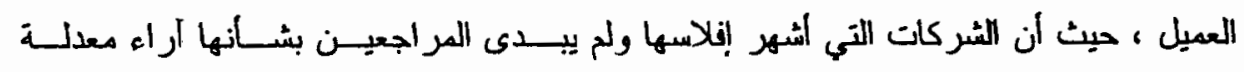

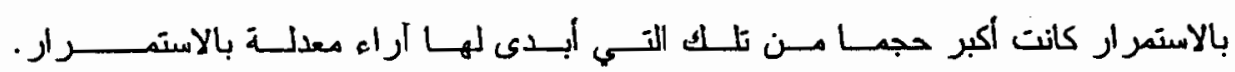

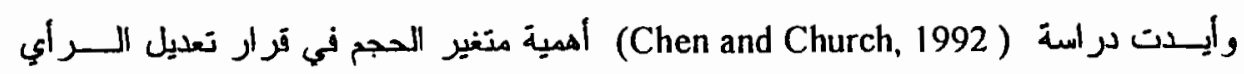

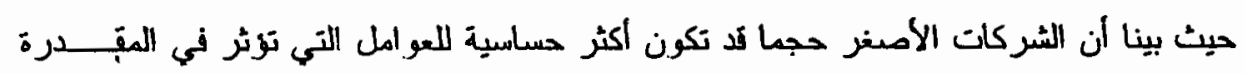

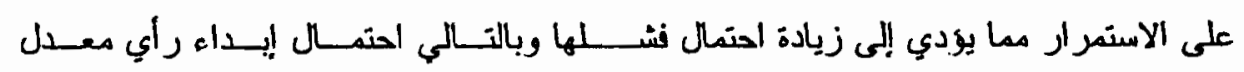

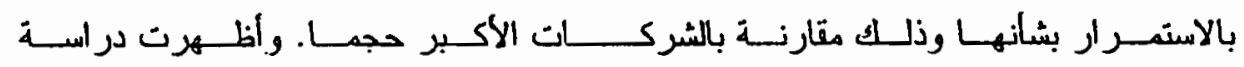
(Carcello et al., 1995)

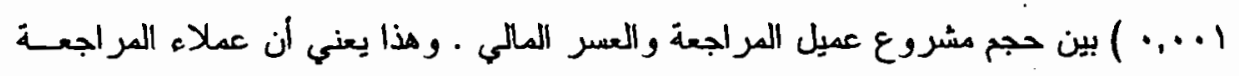

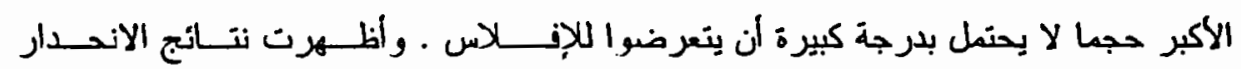

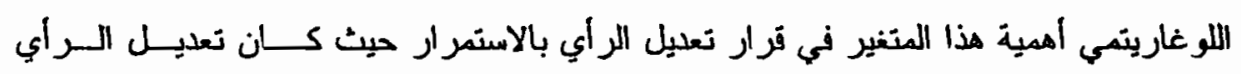

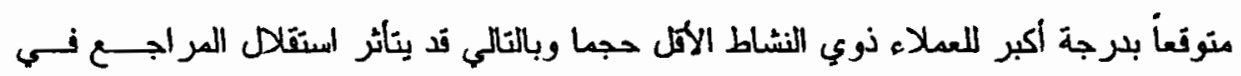
عمليات المر اجعة الكبيرة بسبب ما تنطوي عليه من أتعاب مراجعة ذات فيمة كبيرة. وأظهرت دراسة ( Mutchler et al. 1997 ) ان حجم هشروع المعيل يرنبط عكسيسيا

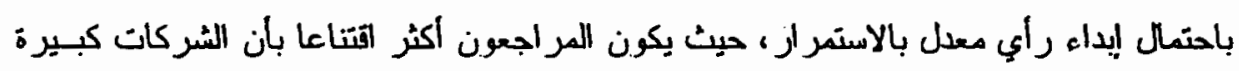

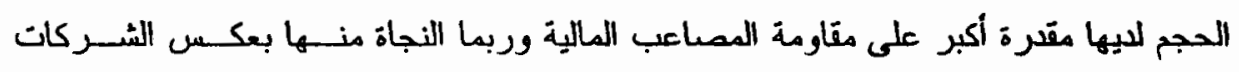

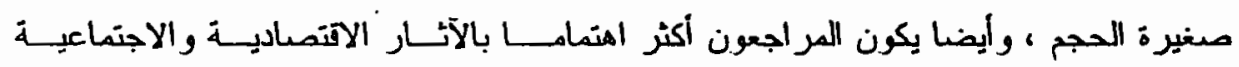
لاشهار إنلاس الشركات كبيرة الحجم والذي تد يحدث جزنياً بسبب الرأي المعدل ذاته.

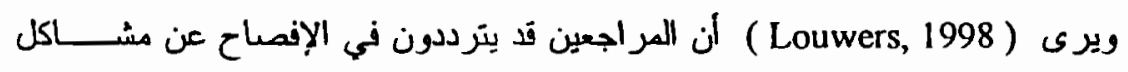

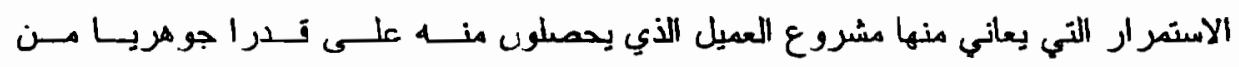

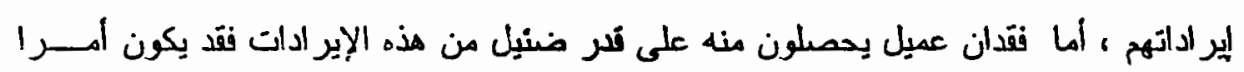
عديم الأهمية. خامساً : حجم مكتب المراجعة وتغيير المراجع

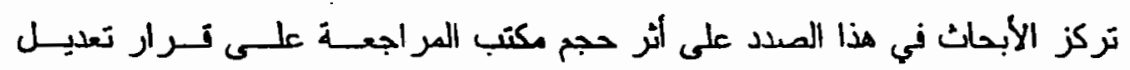

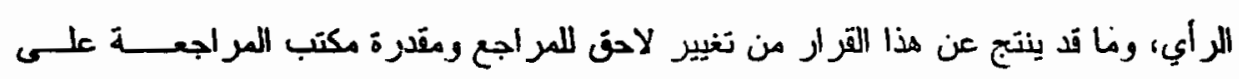

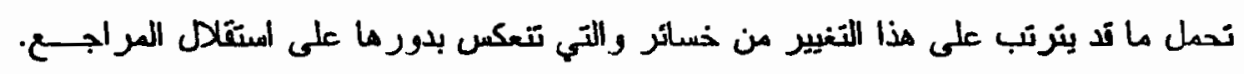

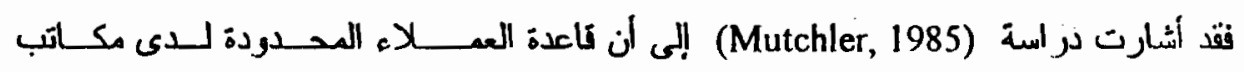




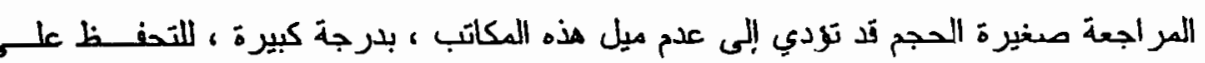

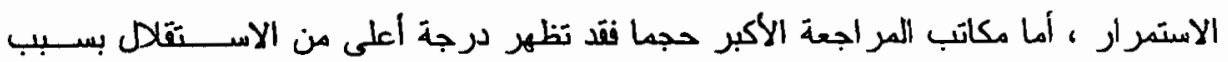

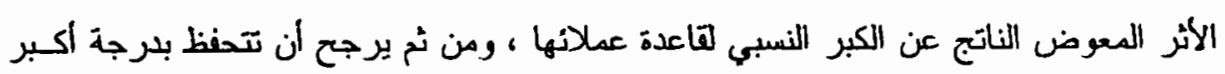
من المكاتب صغيرة الحجم.

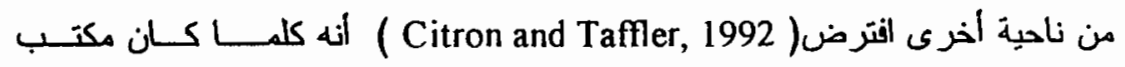

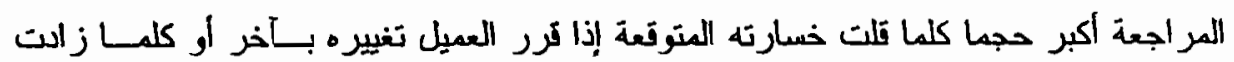

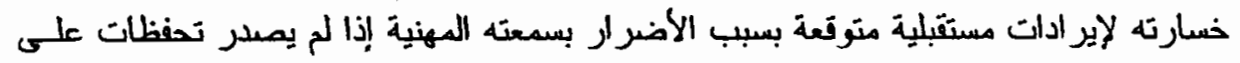

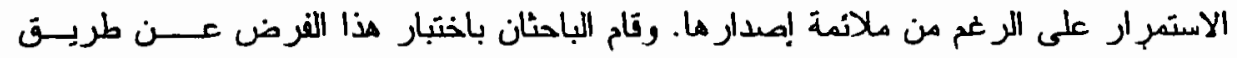

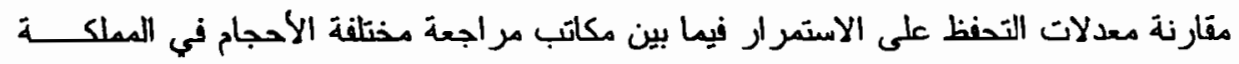

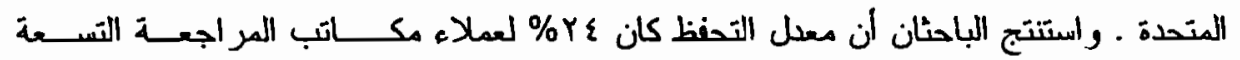

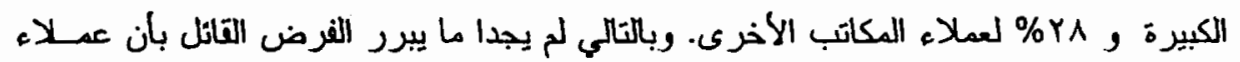

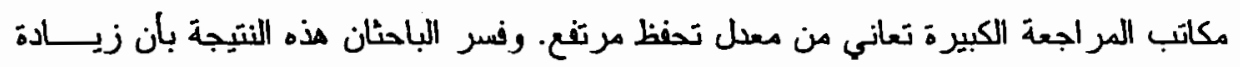

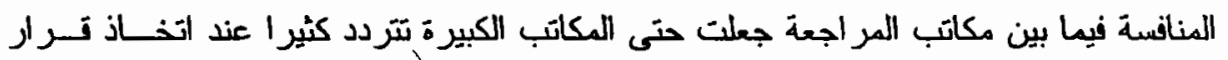

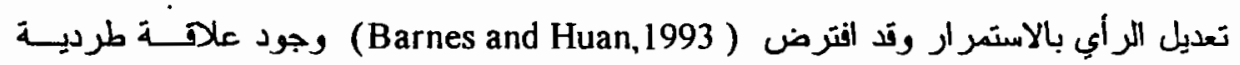

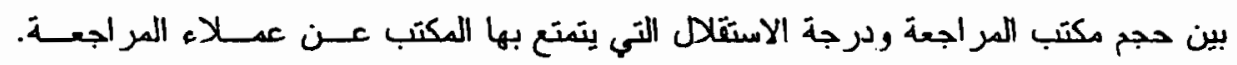

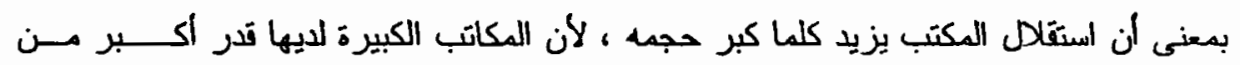

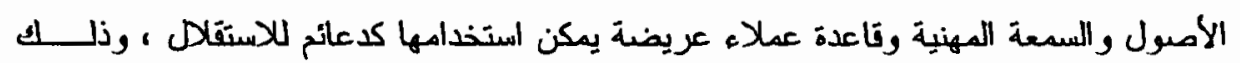
عكس مكاتب المر اجعة صغيرة الحجم.

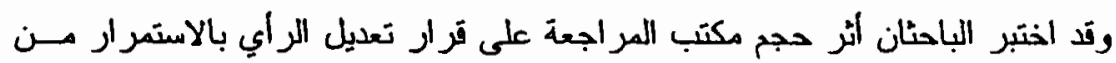

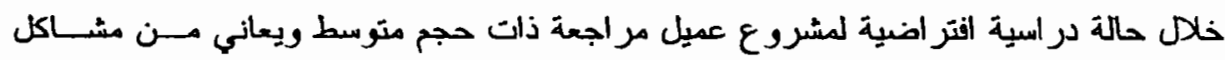

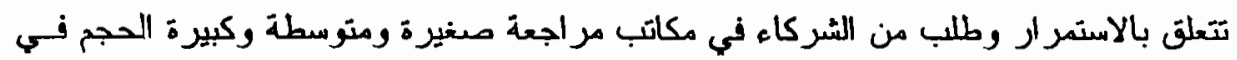

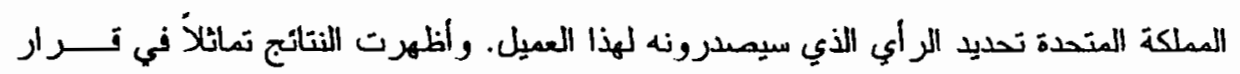

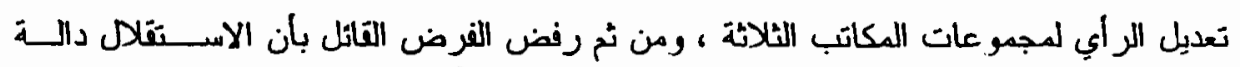

$$
\text { في حجم مكتب المر اجعة. }
$$

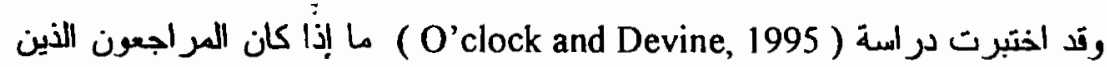

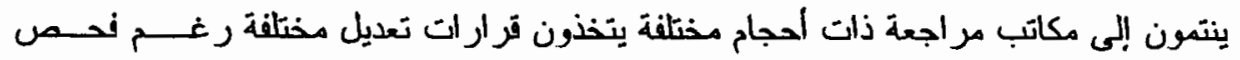

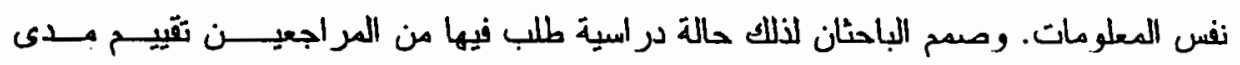

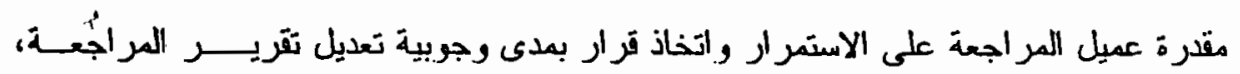


وتوضيح ما يعتقدونه نتاتج معينة إيجابية أو سلبية يمكن أن تترتب على اتخاذ او عدم اتخــــاذ

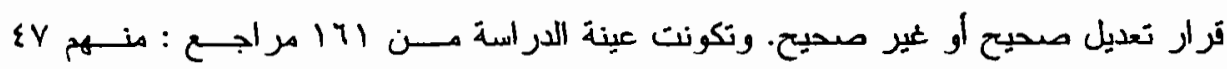

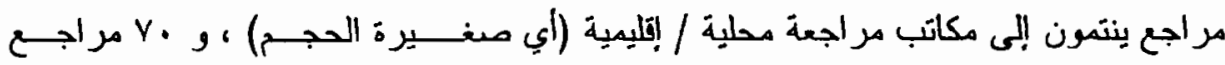

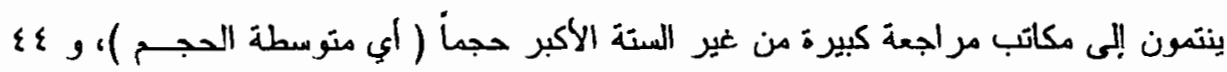

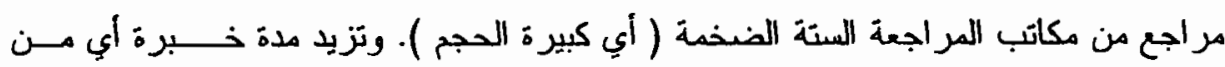

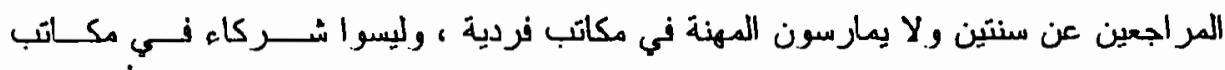

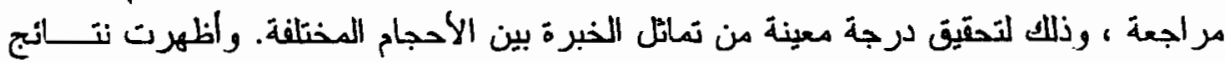

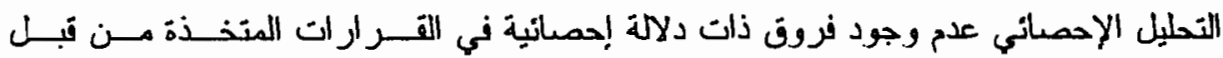

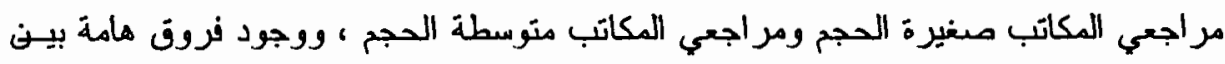

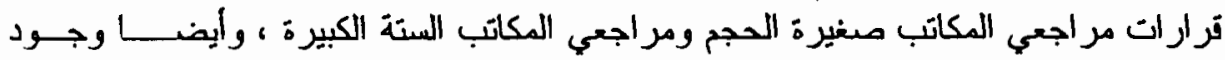

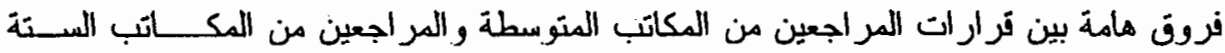

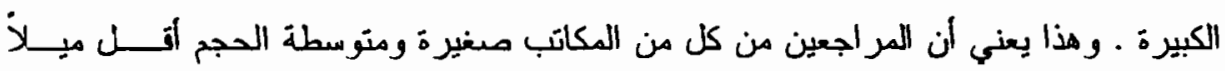

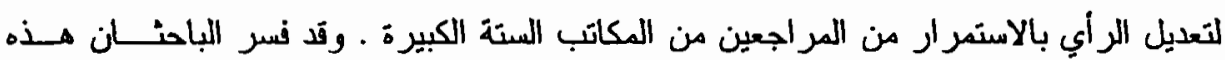

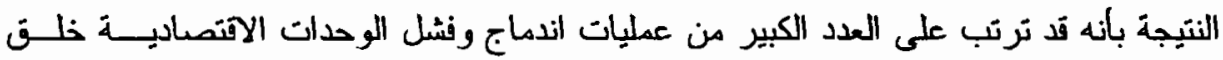

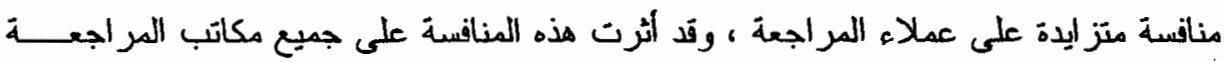

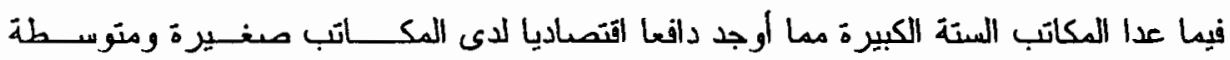

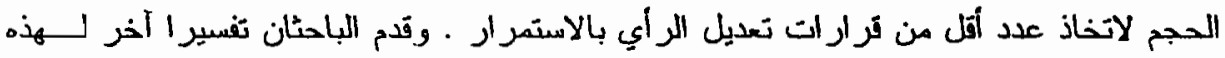

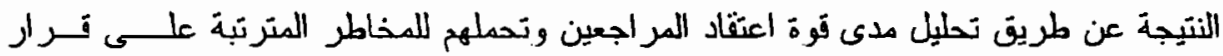

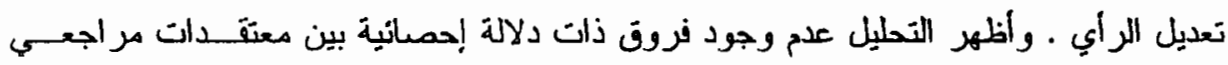

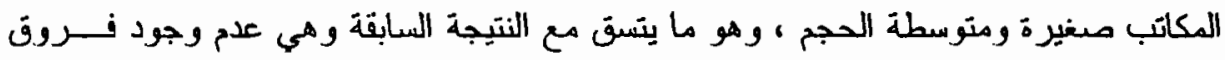

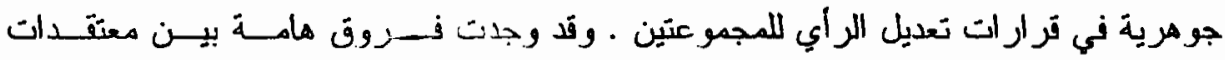

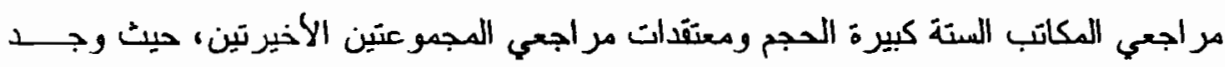

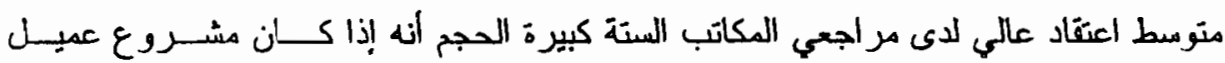

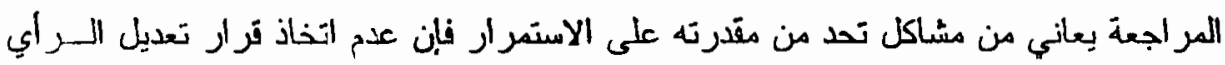

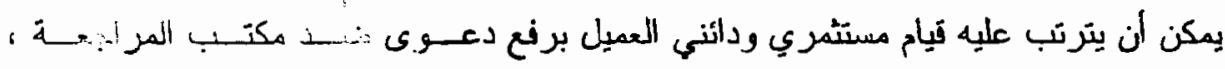

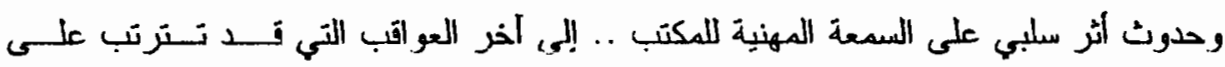

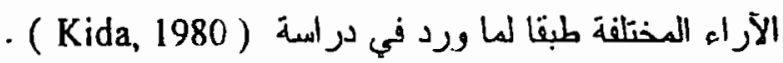




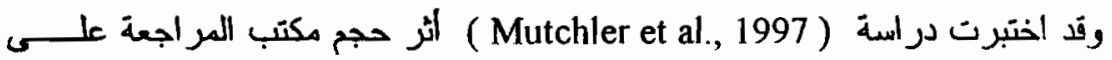

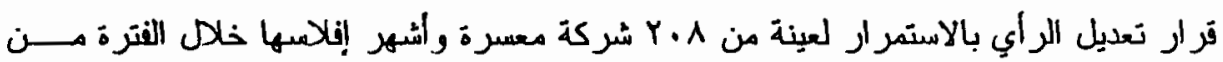

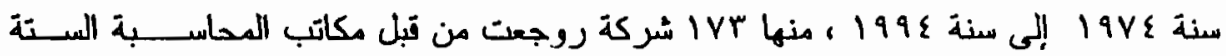

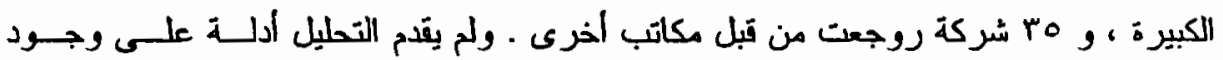

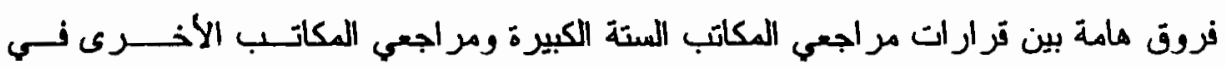

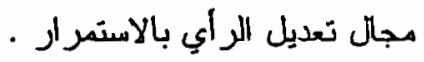
وقد حلل (Citron and Taffler, 1992) ) العلاحة بين إبداء راي معدل بالاستـترار

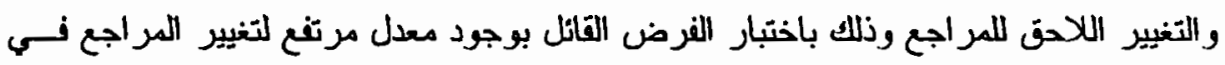

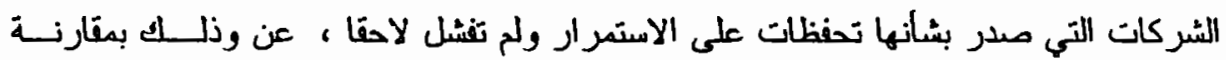

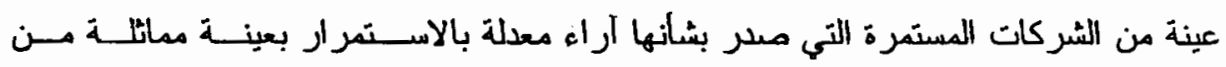

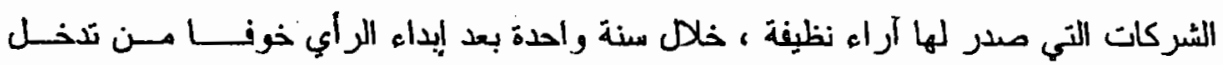

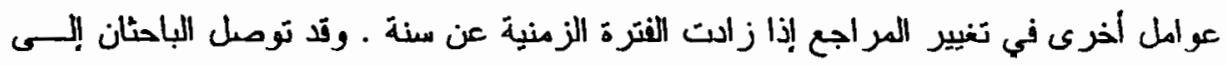

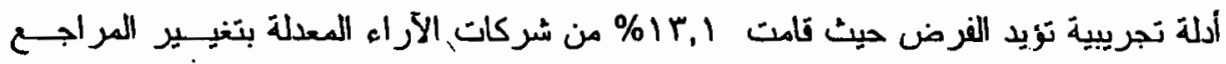

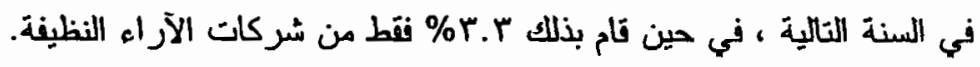

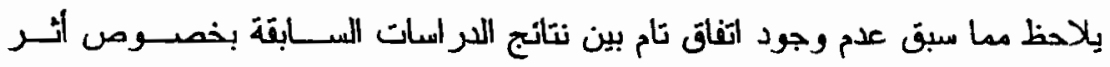

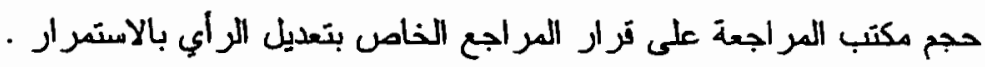

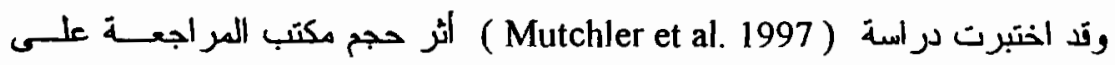

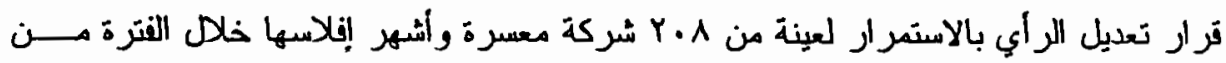

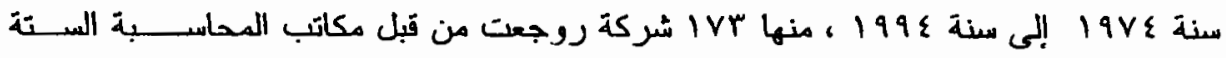

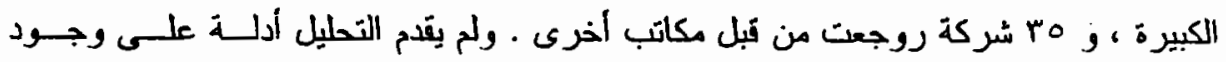

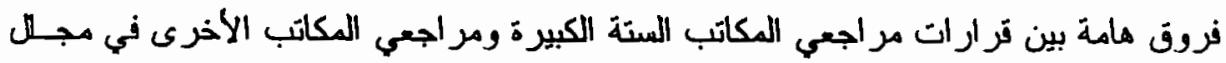

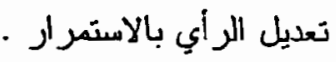
وقد حلل (Citron and Taffler, 1992) العلاقة بين إيداء براي معدل بالاســمرار

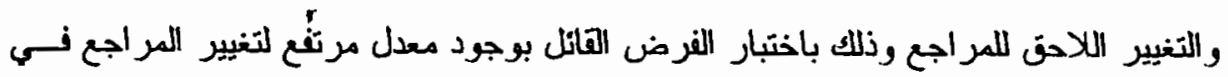

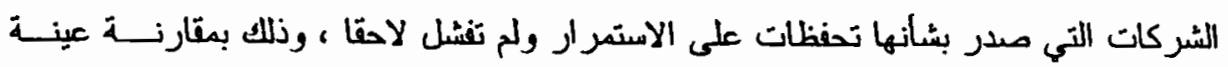

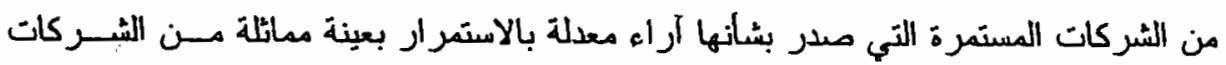

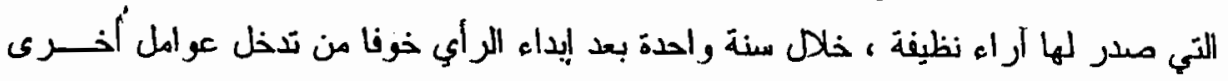


في تغيير المراجع إذا زادت الفترة الزمنية عن سنة ـ وتد توصل الباحثان إلى أدلة نجريبيــــة

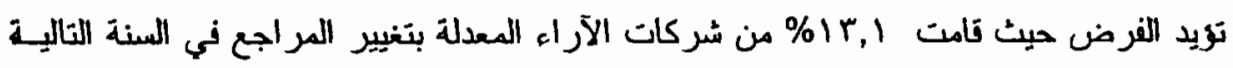

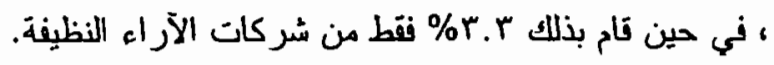

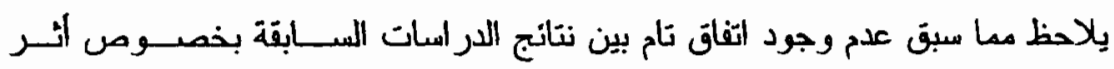

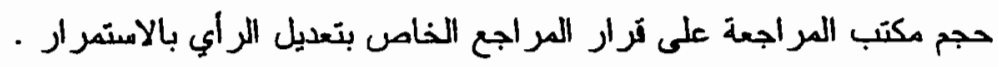

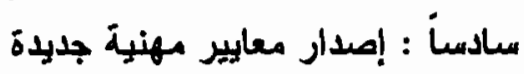

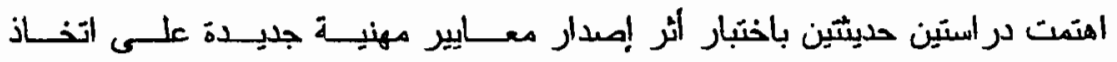
المر اجعين لقر ارات تعديل الرأي بالاستمر ار.

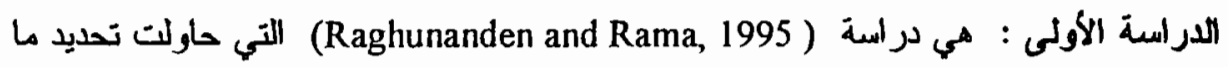

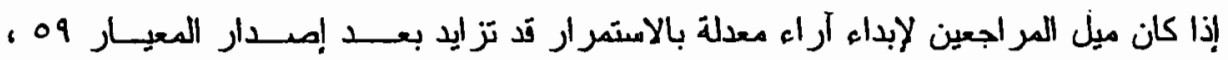

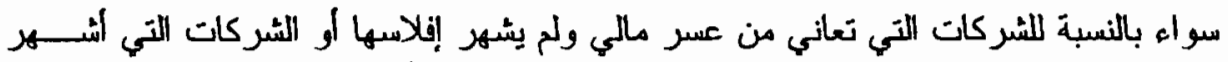

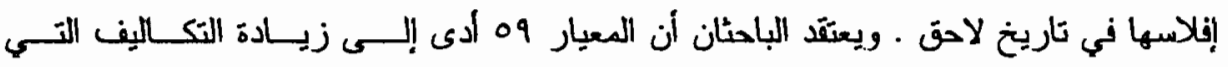

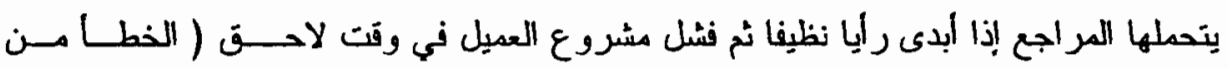

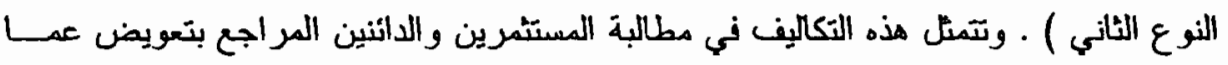

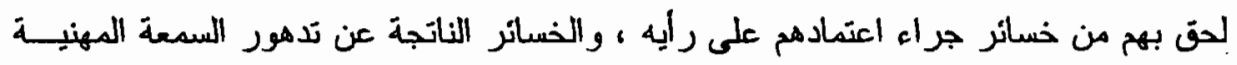

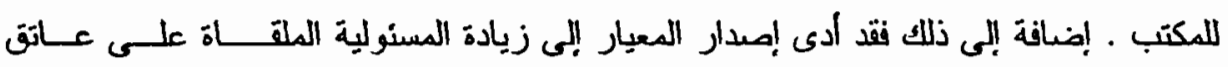

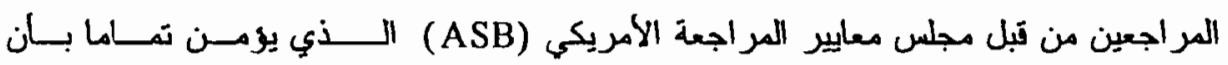

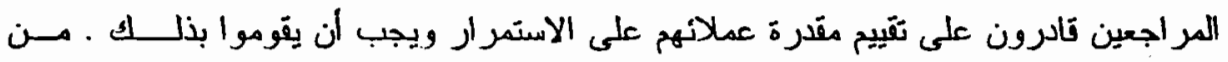

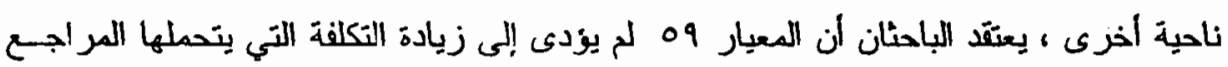

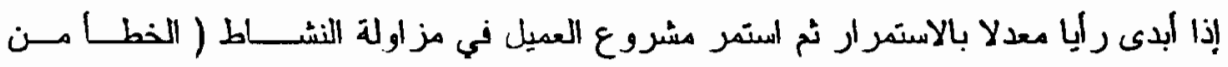

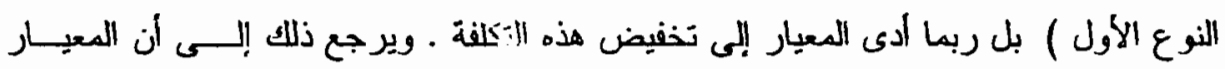

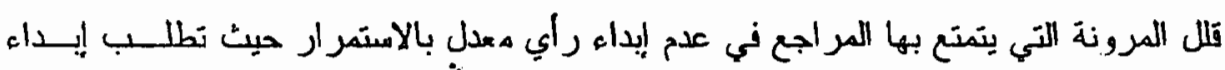

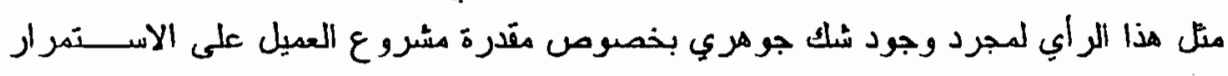

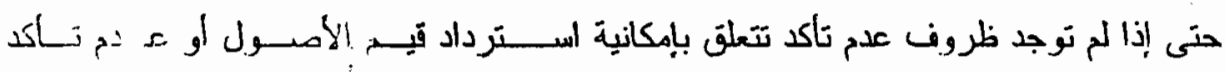

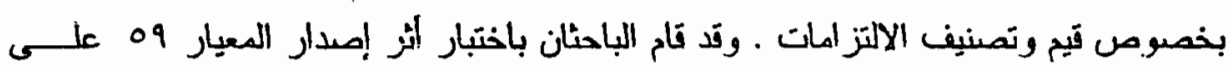

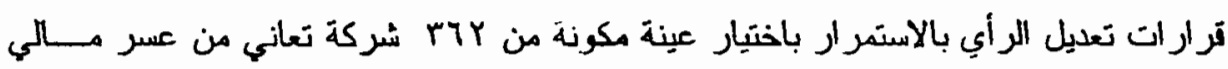

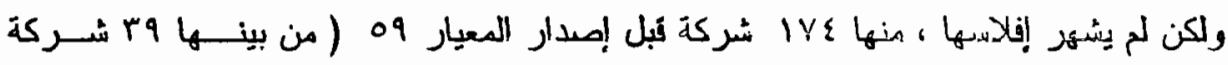




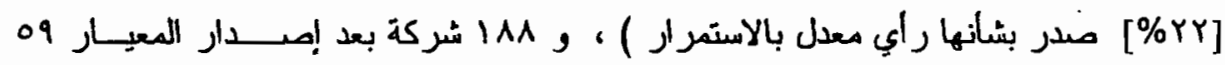

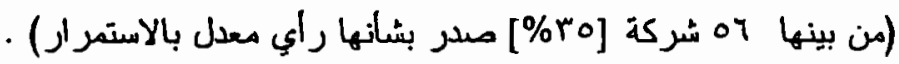

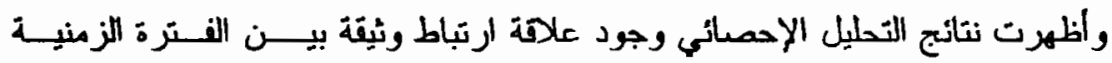

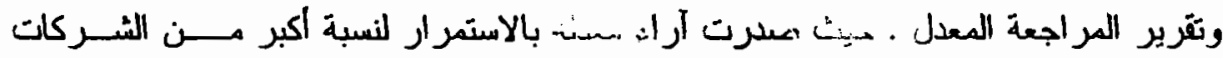

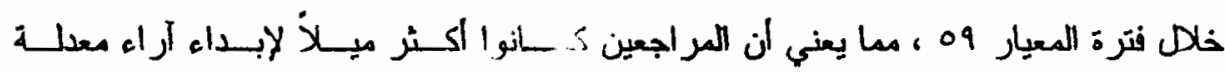

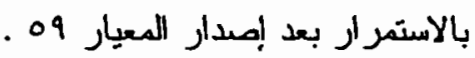

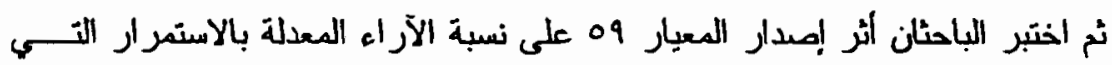

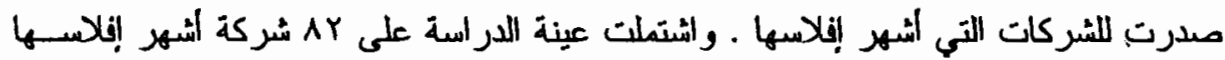

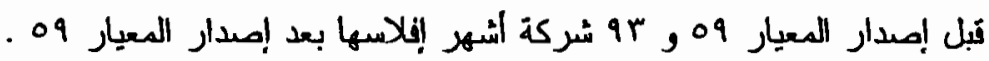

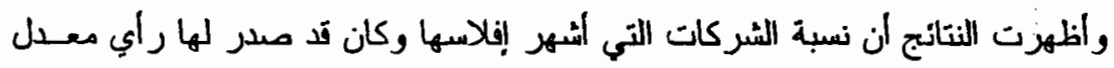

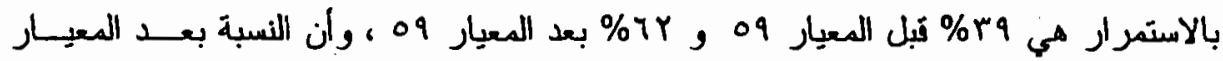

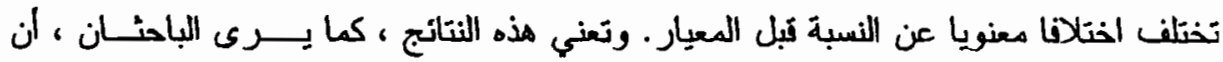

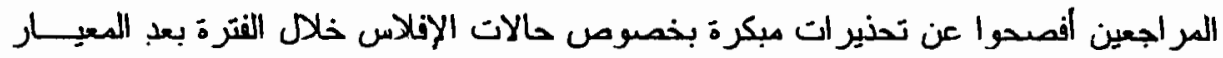

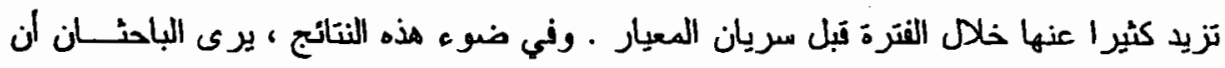

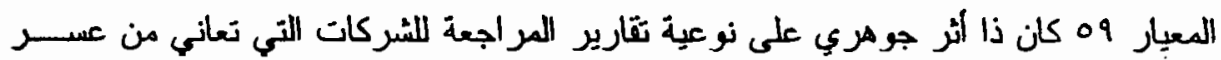

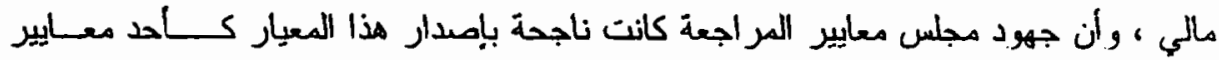
فجوة التوقع.

واهتمت المراسة الثانية هي الأخرى باختبار الثر إحكام المعايير المهنيــــة المتعلتــة

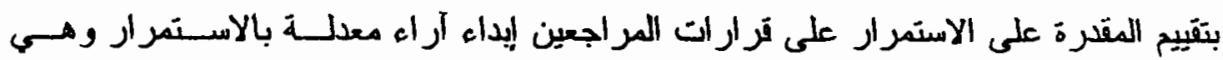

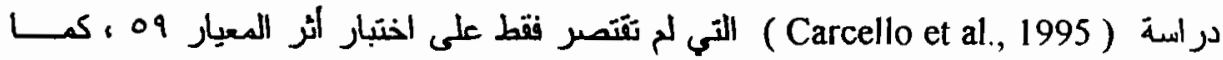

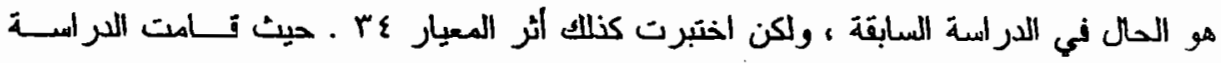

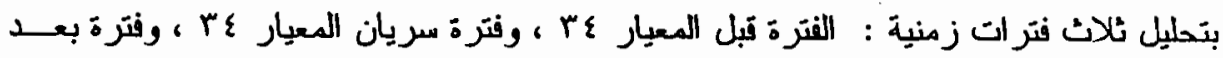

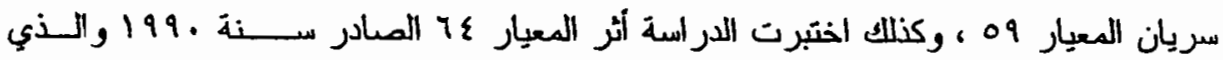

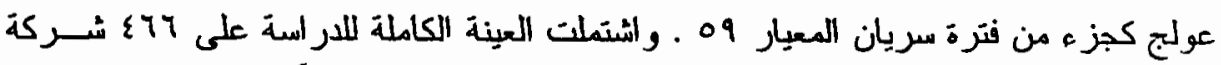

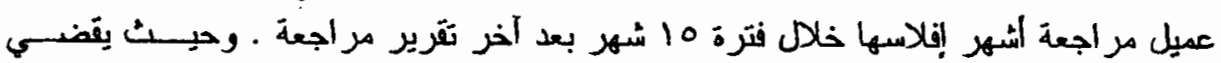

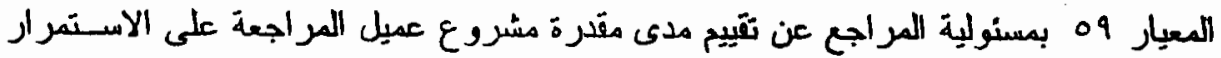

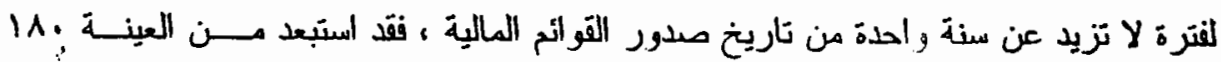

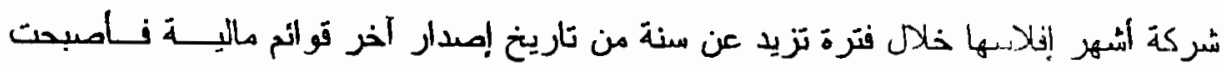




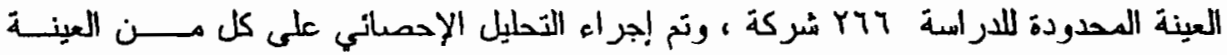
الكاملة والعينة المحدودة .

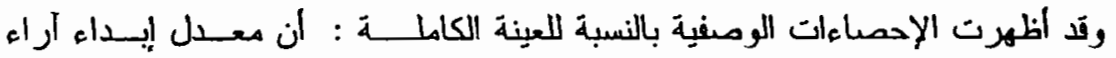

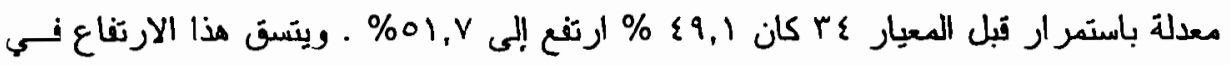

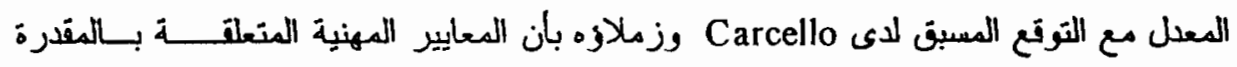

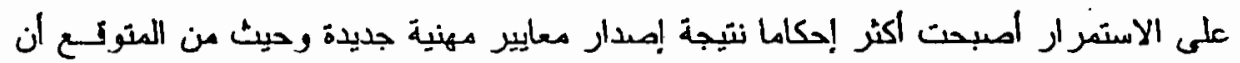

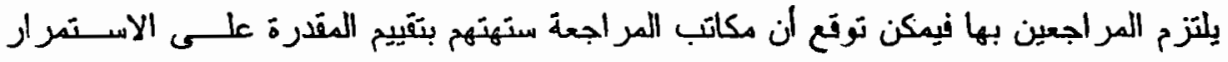

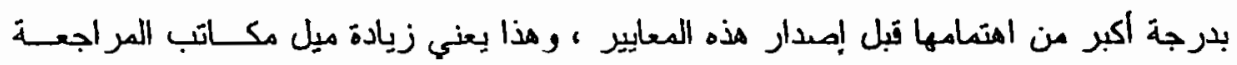

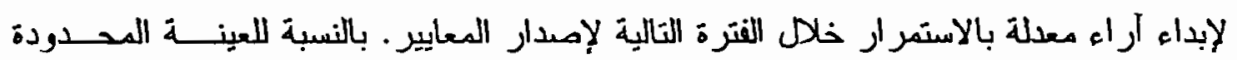
كانت نعبة إبداء ار اء معدلة بالاستمرار (

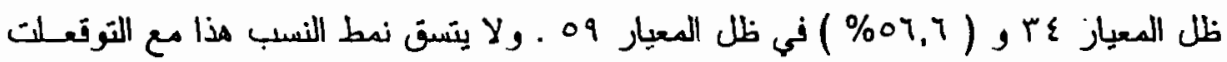
المسبقة المذكورة عالية .

وقد أظهرت نتاتج التحليل اللو عاريتمي للعينة الكاملة دعاملات مامة موجبة للمعيــار

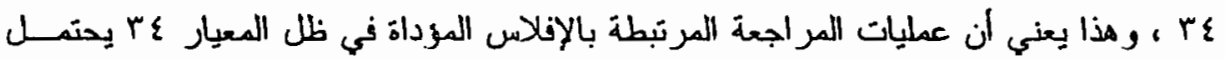

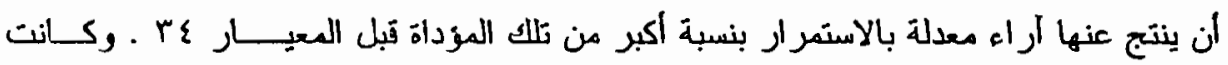

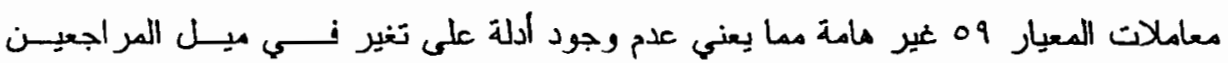

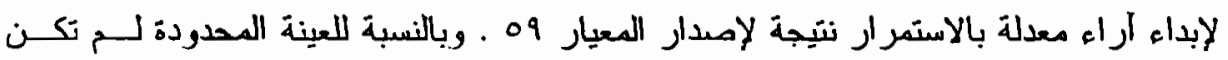

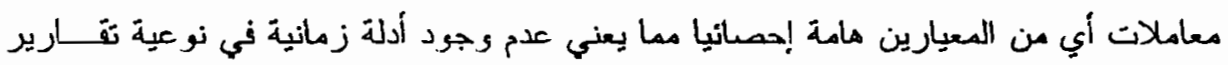

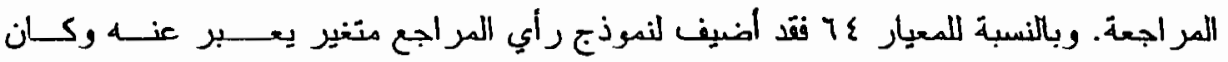

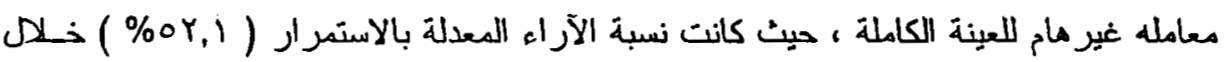

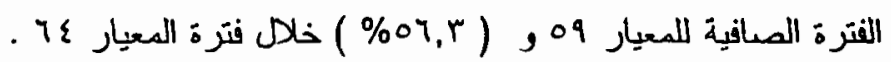

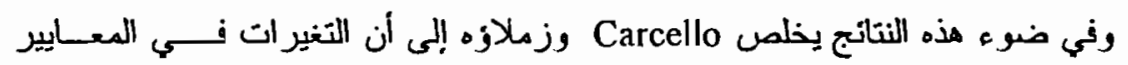

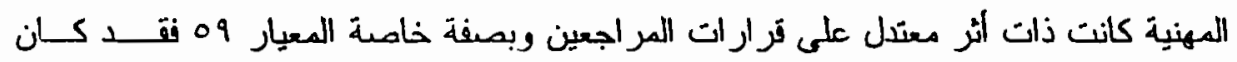

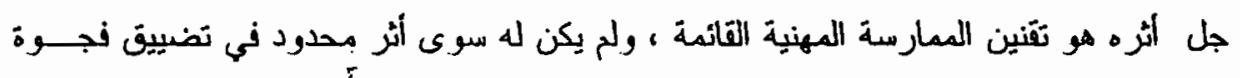

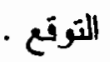

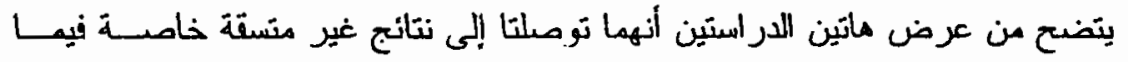

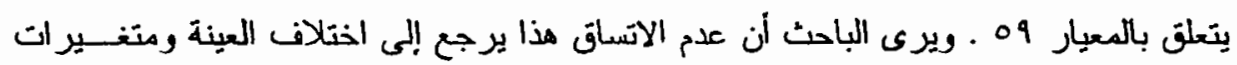

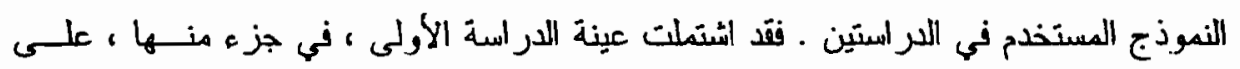




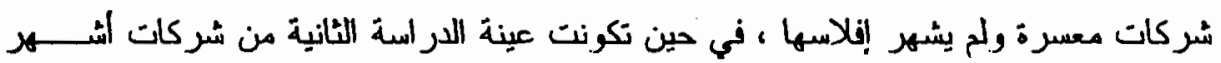

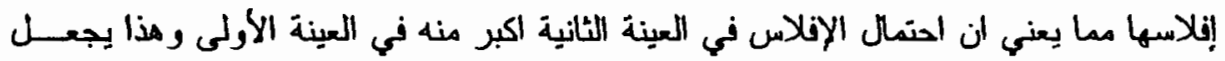

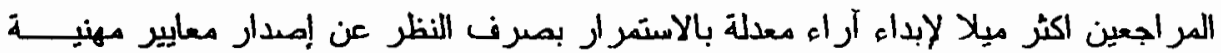

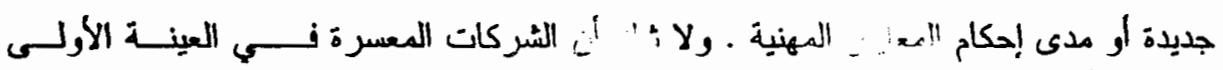

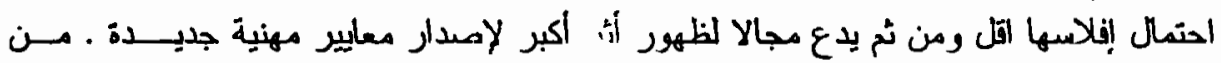

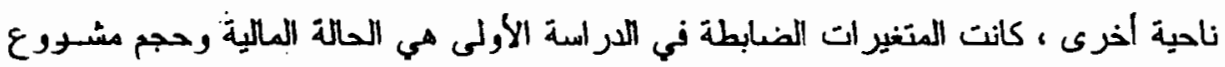

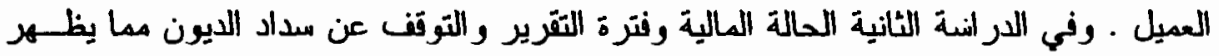

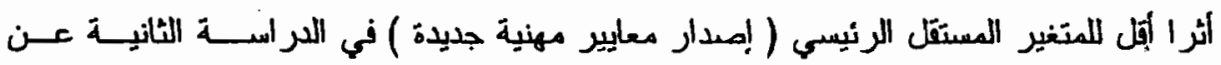

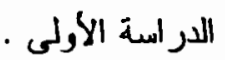

سابعا : فقدان بعض الأف العملاء حليثا

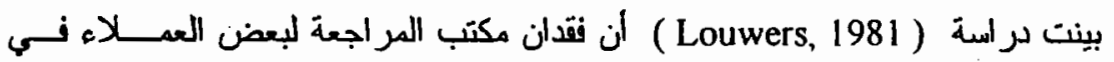

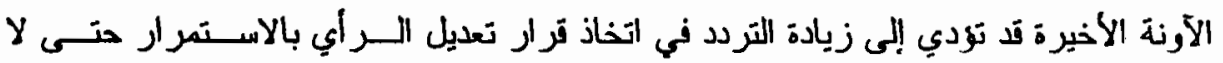

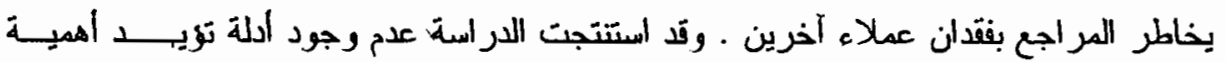
تأثير هذا العنصر على ترار تعديل الرأي بالاستمر ار. ثامنا : فترة التخرير يقصد بها الفترة من تاريخ نهاية السنة المالية حتى تاريخ إمدار تقرير المراجعـــة .

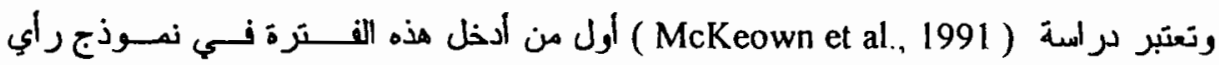

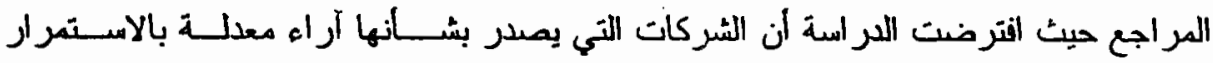

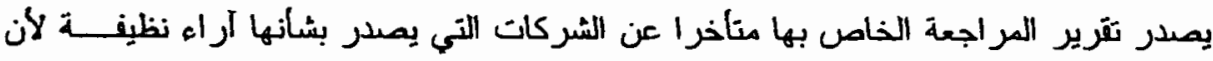

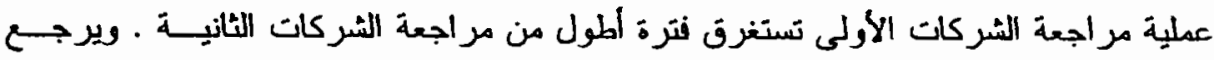

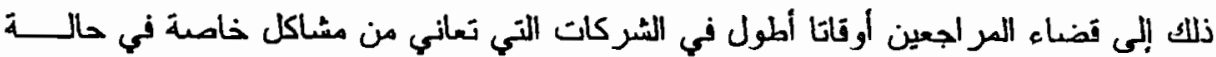

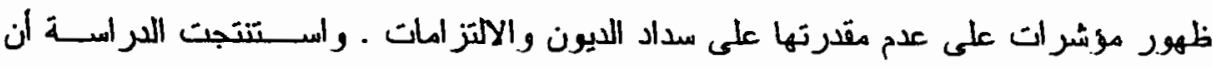

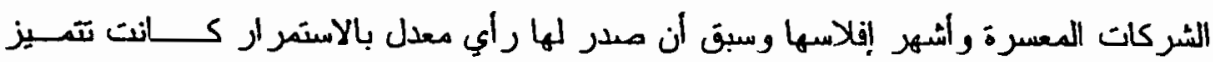

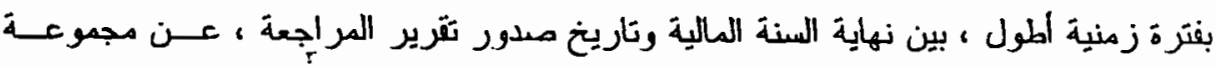
الشركات المعسرة وأشهر إفلاسها ولم يسبق ذلك معدور رأي معدل بالاستمرار .

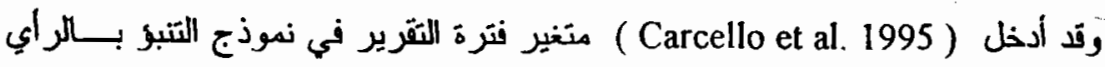

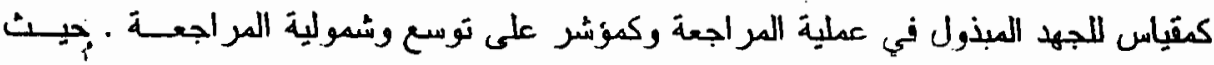

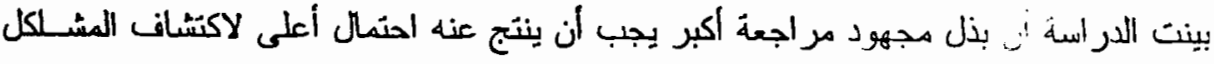




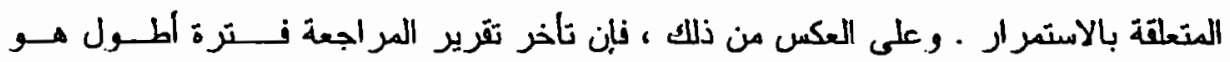

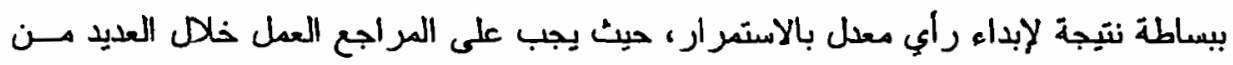

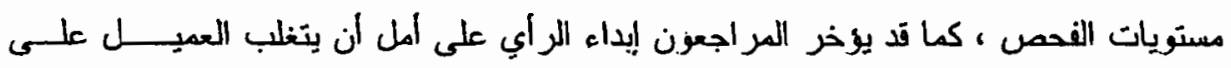

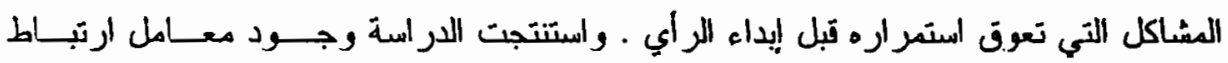

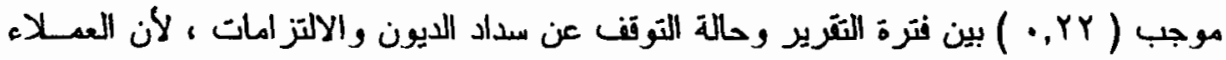

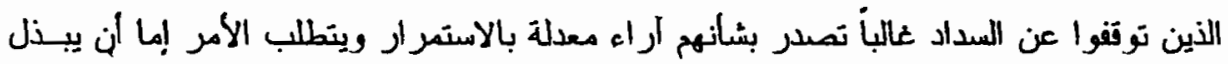

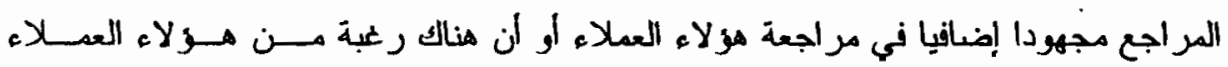

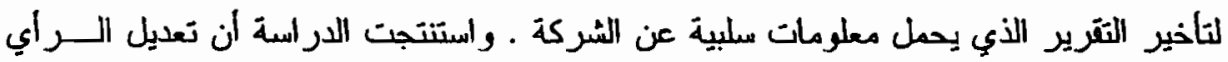

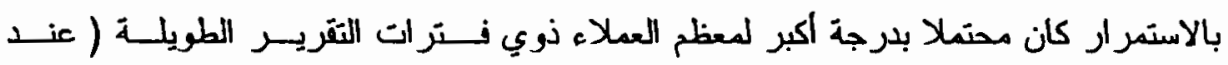

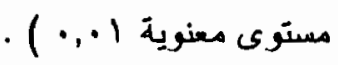

وتدمت مر اسة (Mutchler et al. 1997) ادلة تجريبية تفيد بان فترة التقرير كاتت

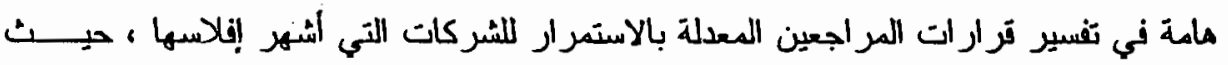

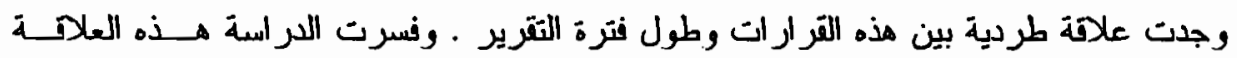

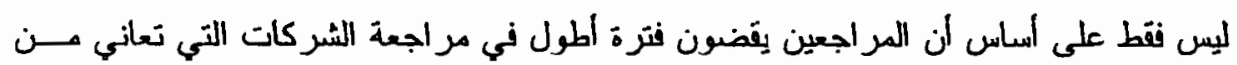

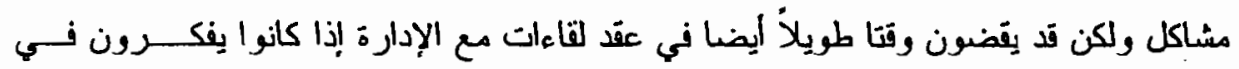

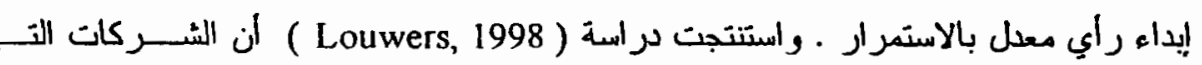

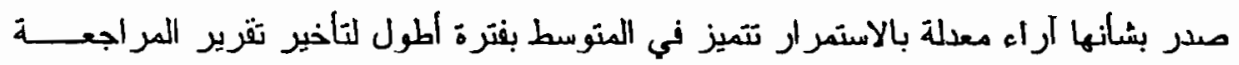

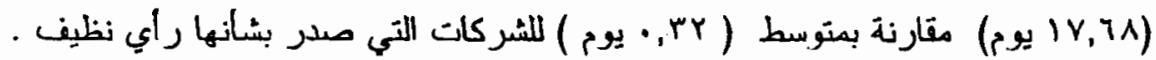

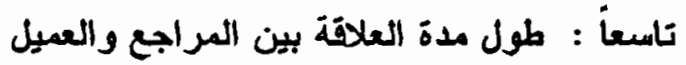

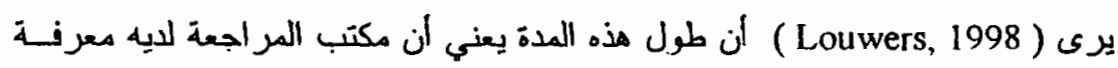

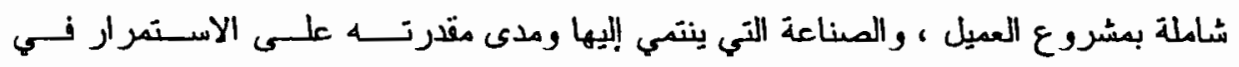

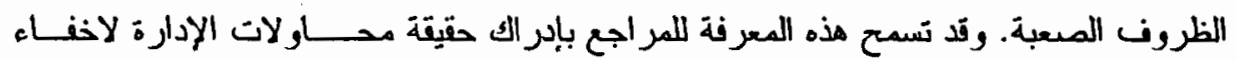

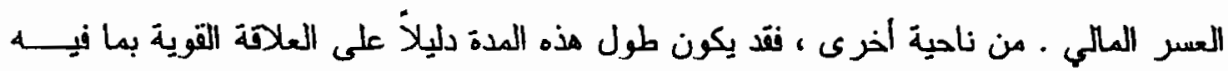

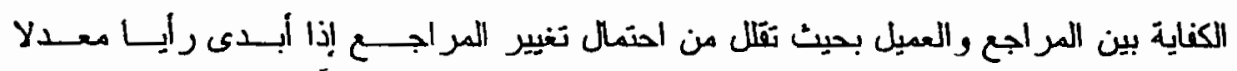

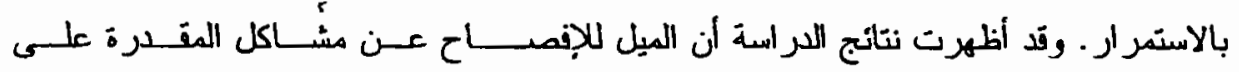

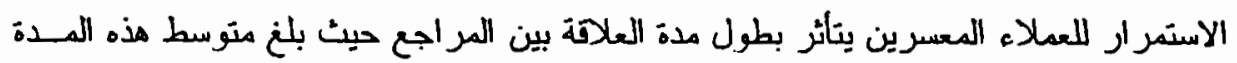

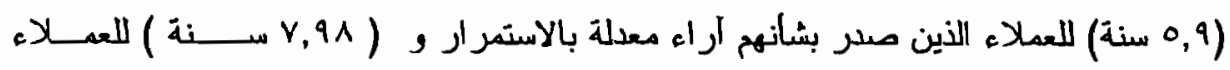

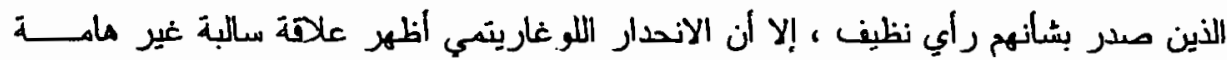


بين طول المدة وإبداء راي معدل بالاستمر ار ، هما يعني أن هذا العامل يوثر تـــاثير معتــلا

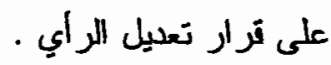

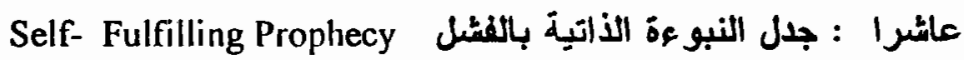

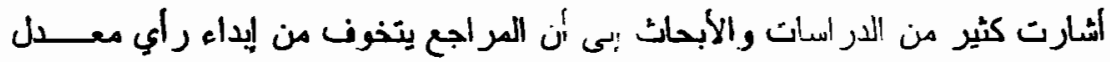

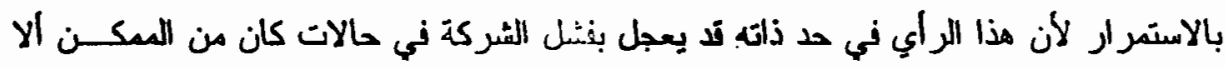

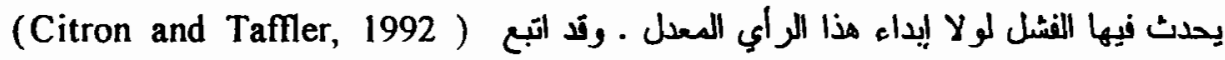

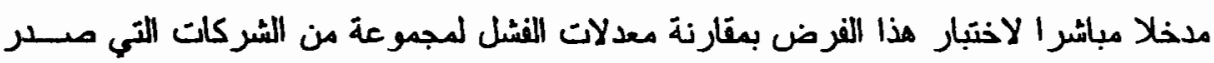

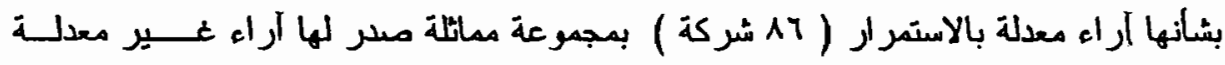

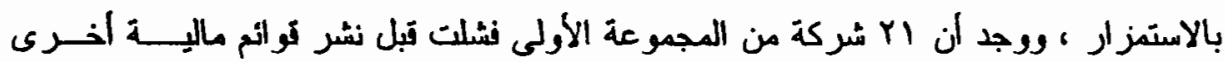

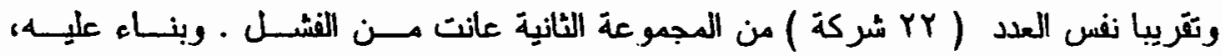

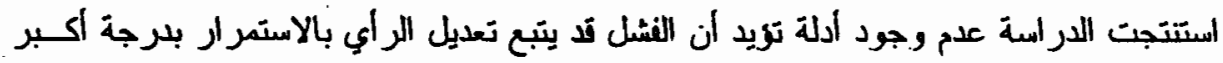

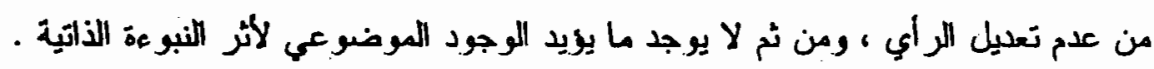
حادي عشر : متغيرات أخرى

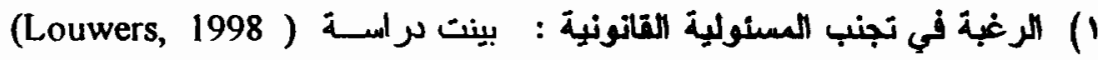

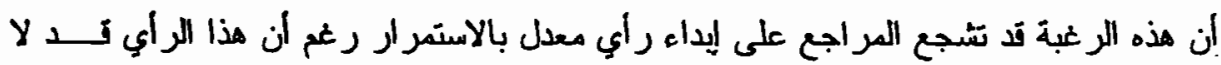

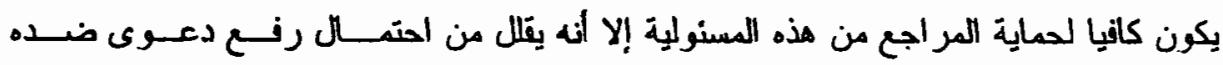

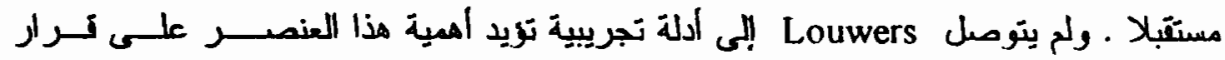

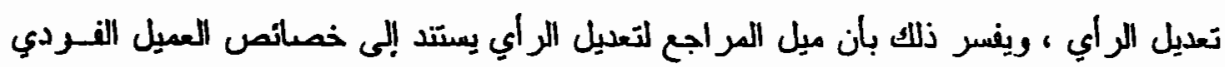
وليس إلى عوامل خاصة بمكتب المراجعة .

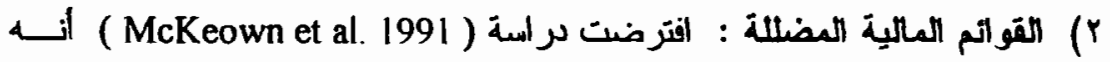

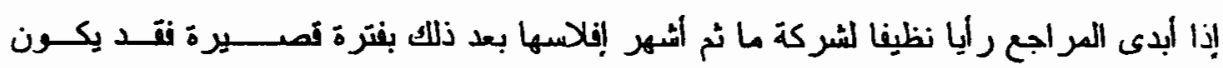

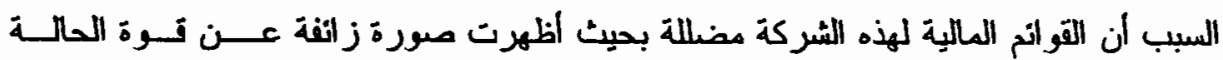

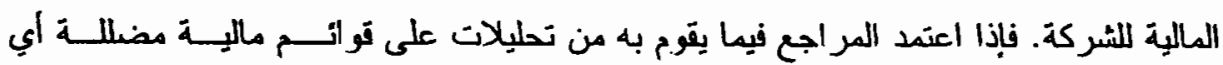

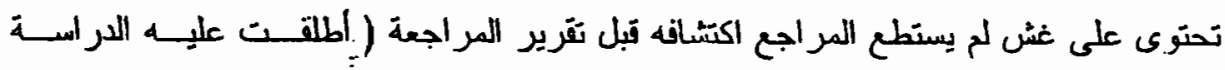

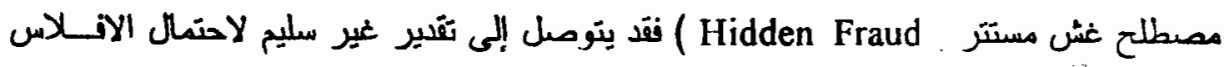

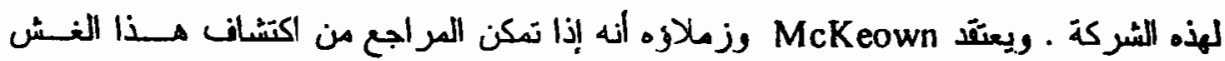

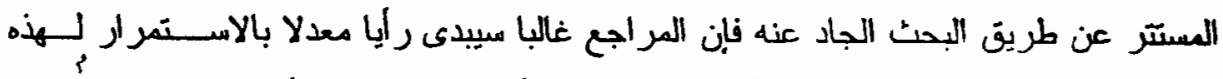

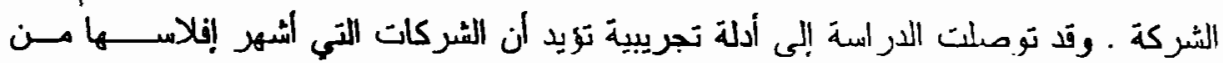




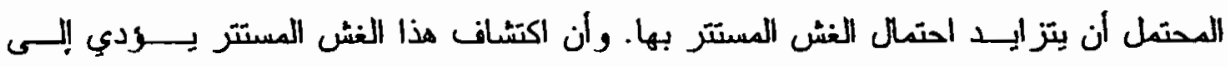

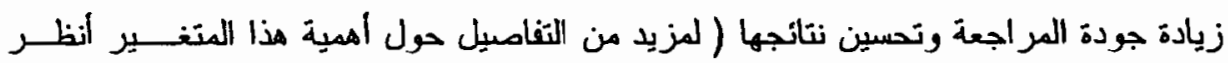
تعليق McKeown et al., ر على هذا التعليق ).

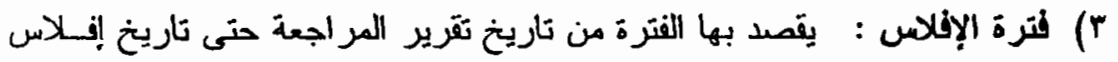

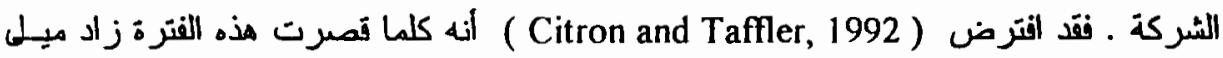

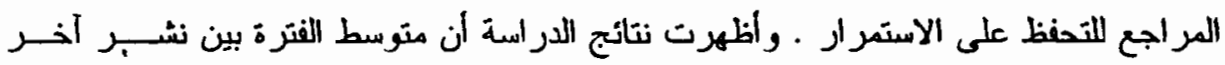

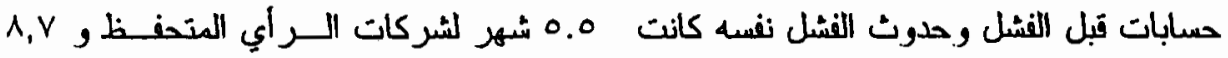

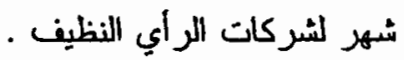

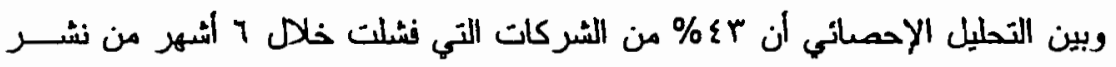

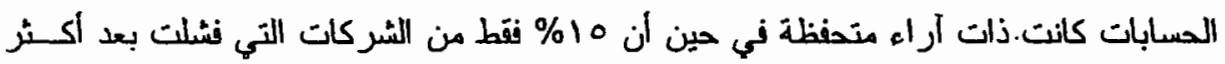

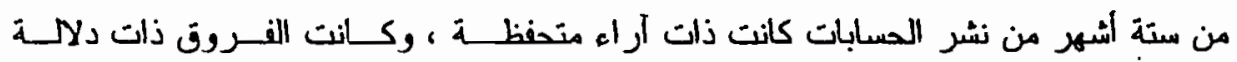

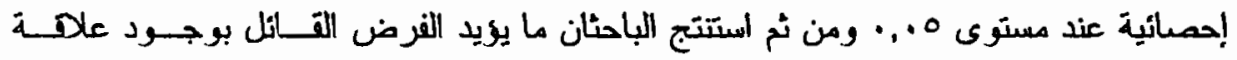

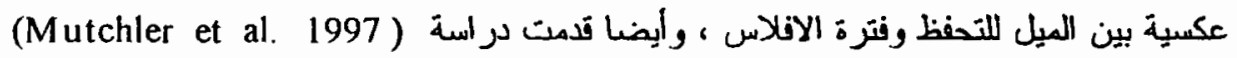

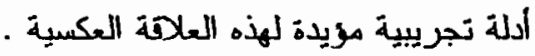

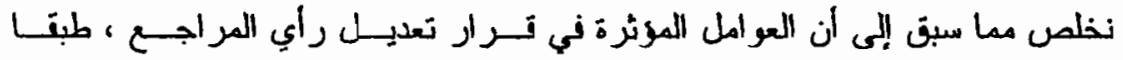
للار اسات السابقة يمكن تقسيمها إلى مجموعتين :

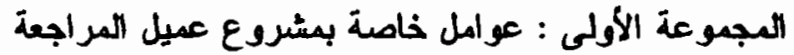

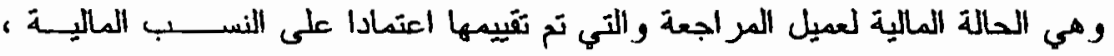

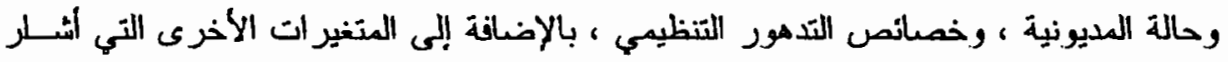

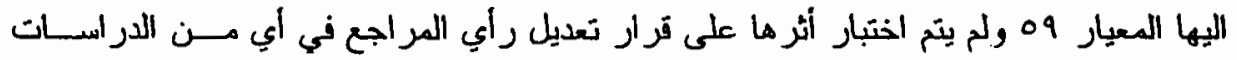
العابقة .

المجموعة الثانية : عوامل خاصة بمكتب المراجعة

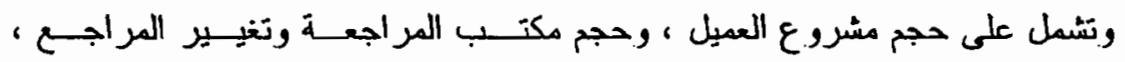

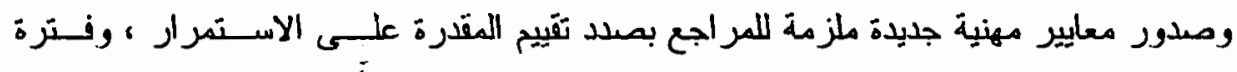

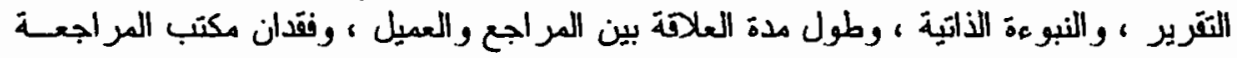

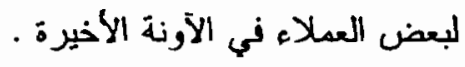

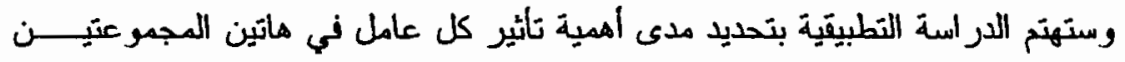

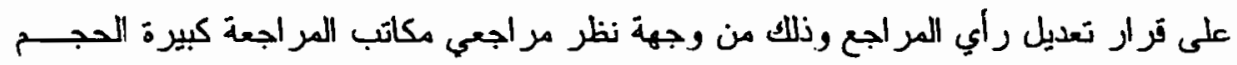


ومراجعي مكاتب المراجعة صغيرة الحجم ، العاملة ني المملكة العربية الســعودية ، لتحديـــ

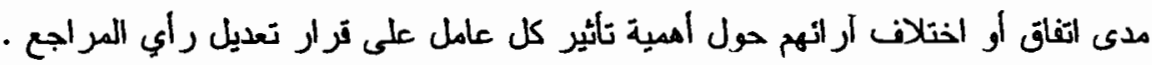

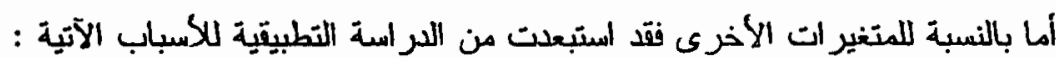

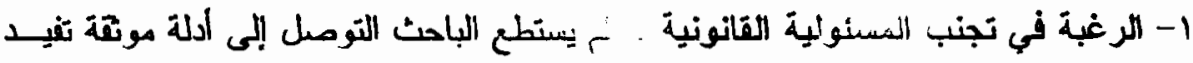

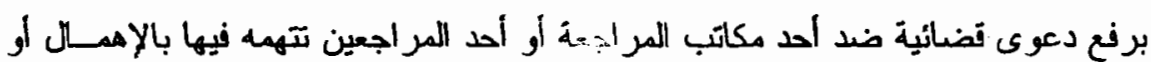

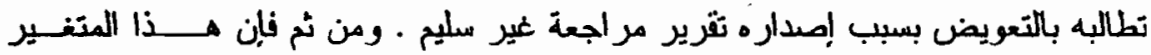

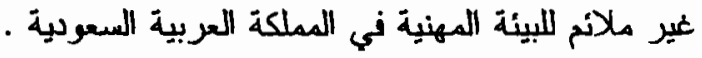

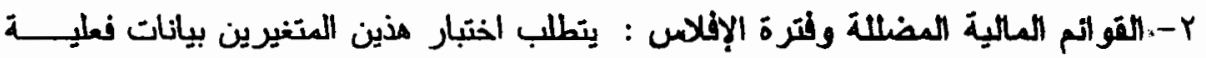

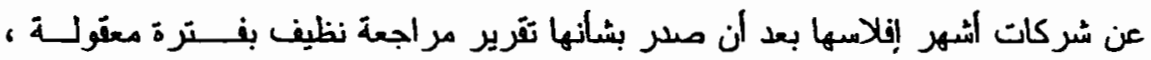

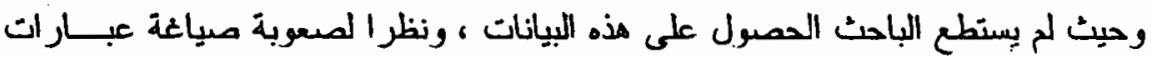

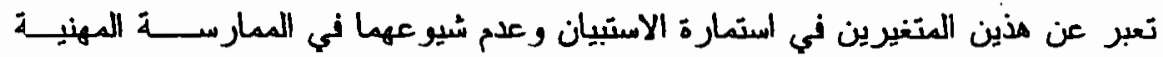

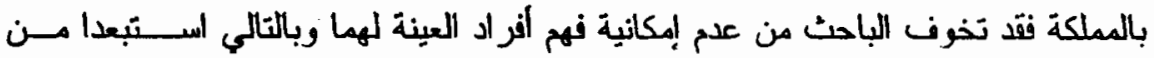
الدر اسة التطبيقية . 


\section{القسم الثاني : الار اسة التطبيقية}

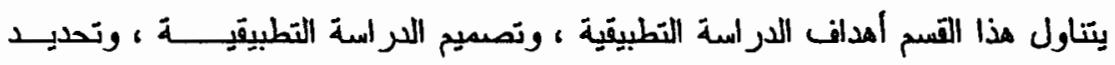

مجتمع الدراسة واختيار العينة ، والأساليب الاحماثية المستخدمة ونتائج العراسة التطبيقية.

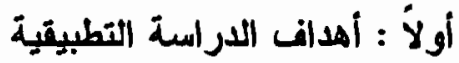

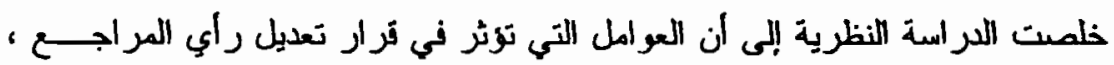

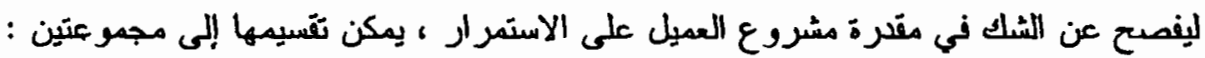

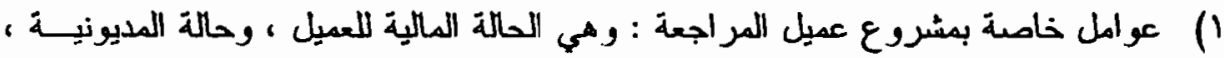

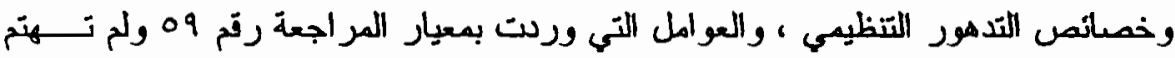

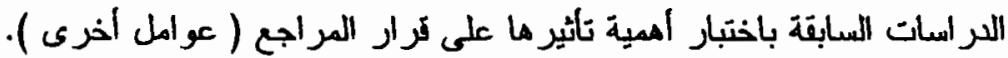

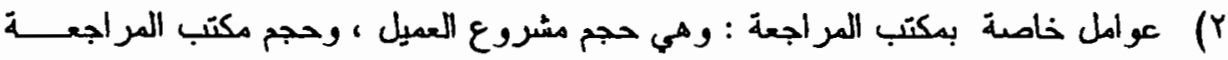

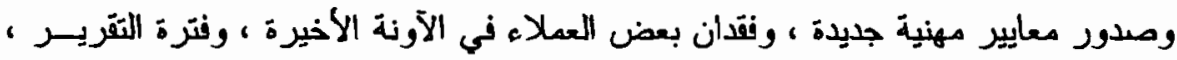

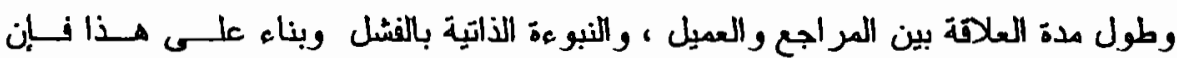
تهدن الدراسة التطبيقية إلى الاجابة على الاستفسارين الآتيين :

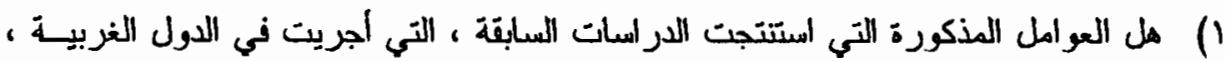

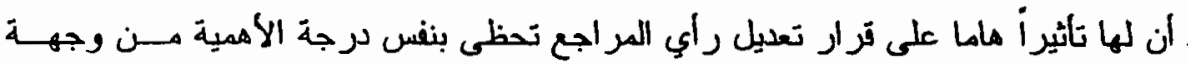

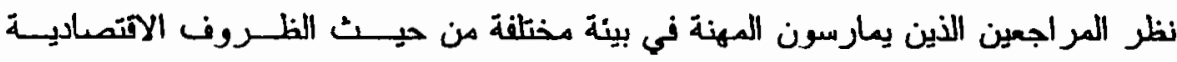

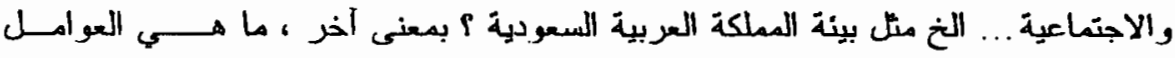

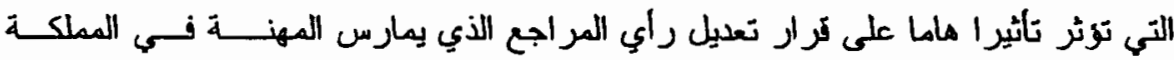

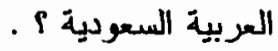

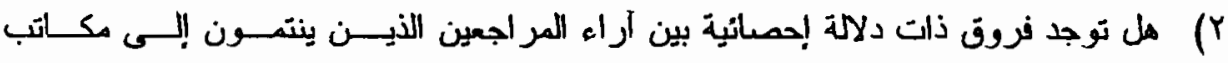

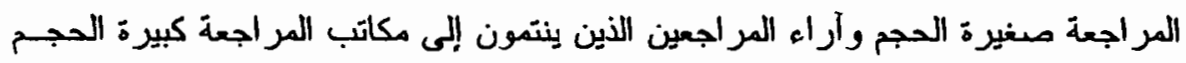

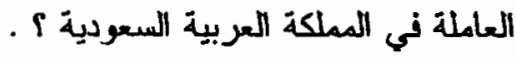
ثانياً : تصميم الاراسة التطبيقية

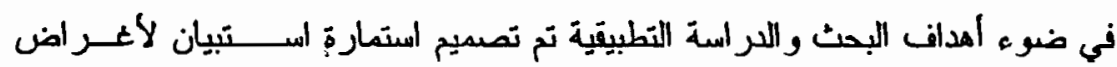

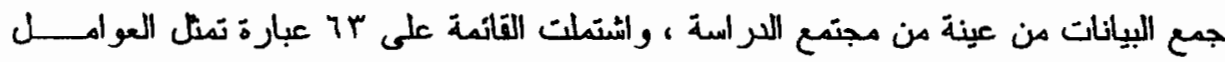

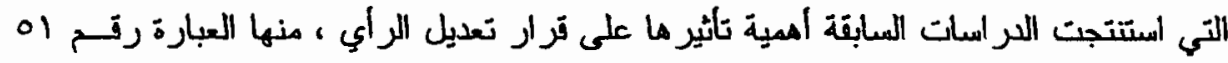

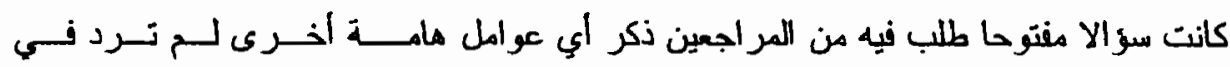


الاستبيان. وقد تم تقسيم هذه العوامل الفردية إلى إحدى عشر متغيرا ، نعرض فيما بلـــي كـل

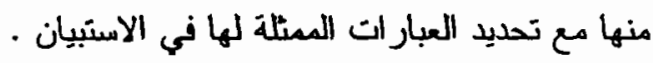

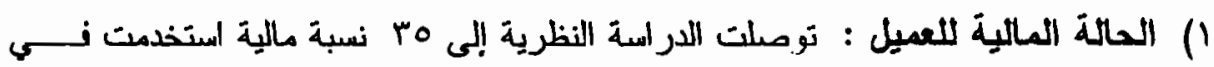

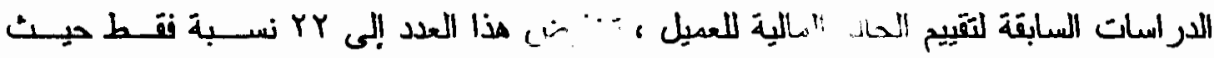

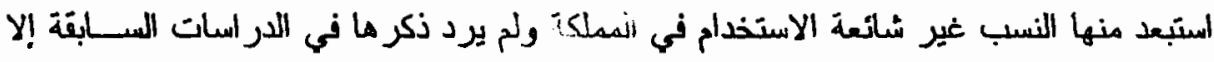

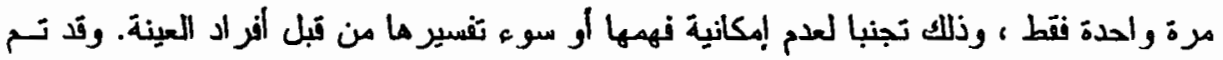

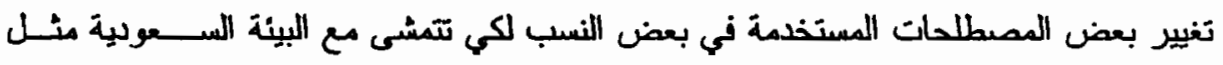

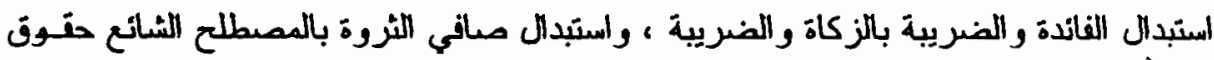

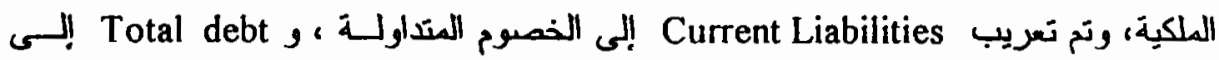

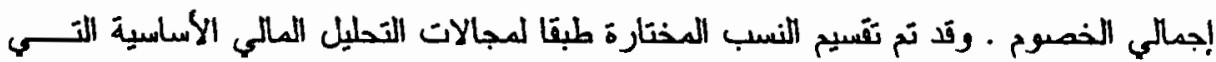

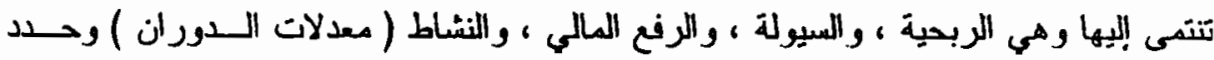

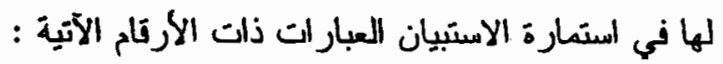
| النسب المالية

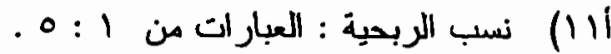

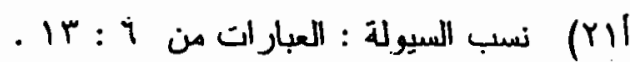

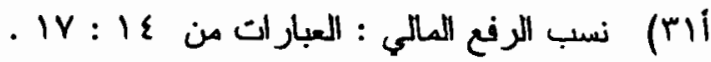

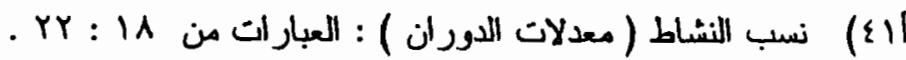

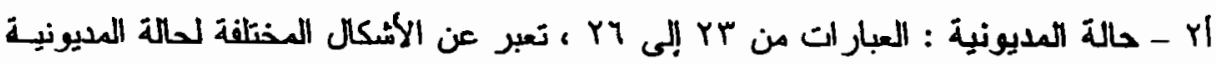
في ضوع ما ورد بالدر السات السابقةَ.

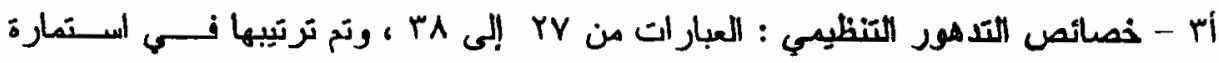

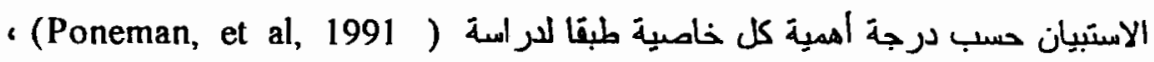
لتسهويل إجراء المقارنة.

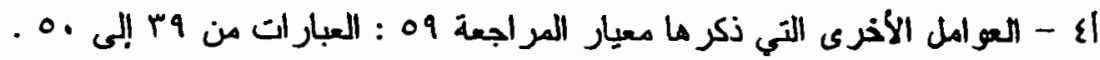

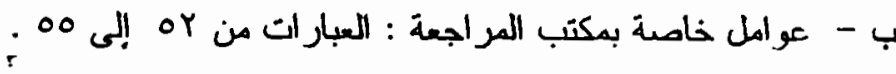
تم تقسيمها كما بليه :

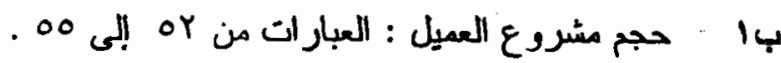

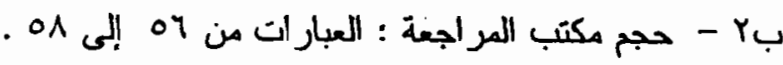

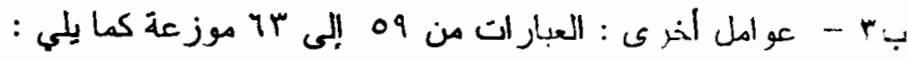




$$
\text { ه- إصدار معايير مراجعة جديدة. }
$$$$
\text { . }
$$

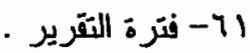

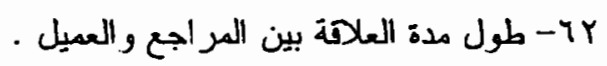

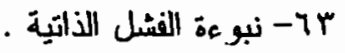
وتم تَسيم استمارة الاستبيان ككل إلى ثلاثة أقسام :

القسم الأول : مطومات عامة : تتعلق بالوظيفة ، وسنوات الخبرة ، ، وحجم مكتب المر اجعة.

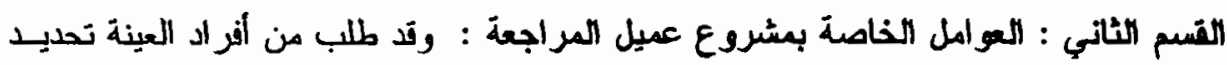

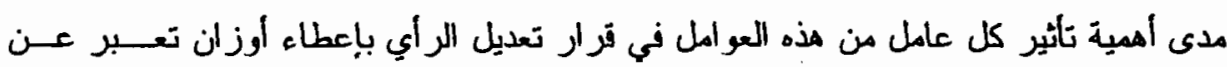

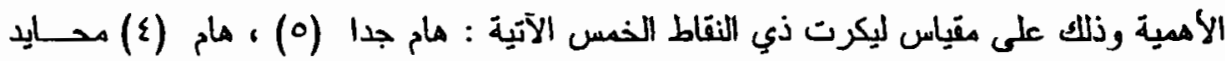

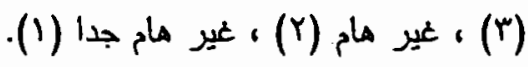

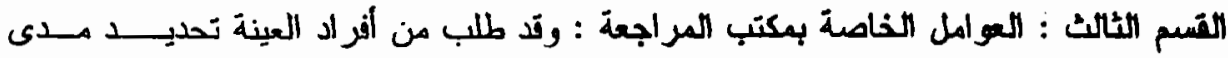

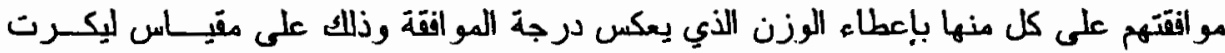

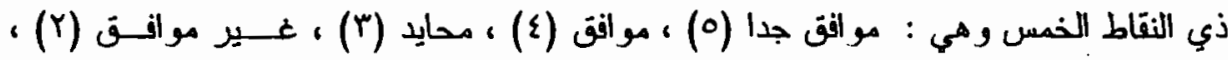
غير موافق إطلاها (1) وتد قام الباحث باججر اء الاختبار " القبلي " Pretesting لاستمارة الاســبيان عـن طريستق

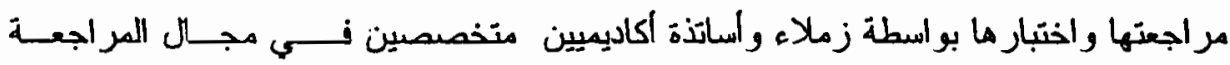

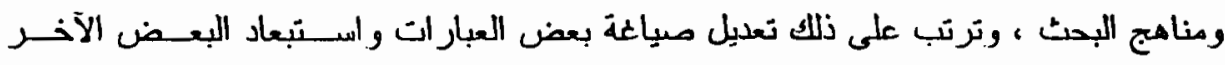

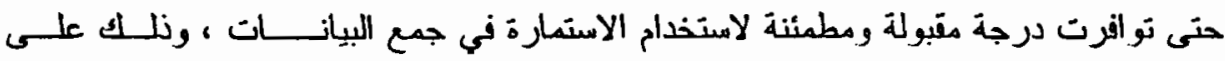

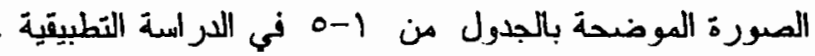

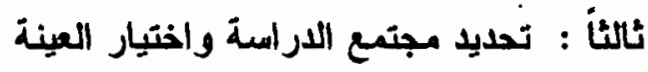

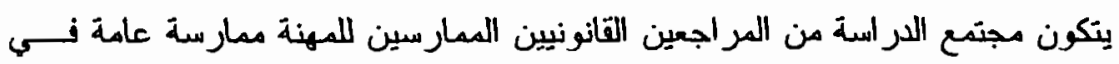
مكاتب المحاسبة والمر اجعة العاملة في المملكة العربية السعودية ، وتد تم اختيار المملكة لـــهـا

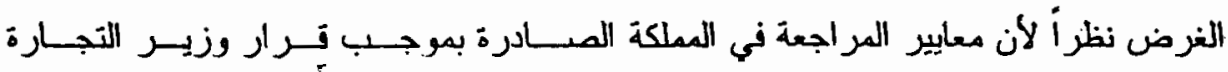

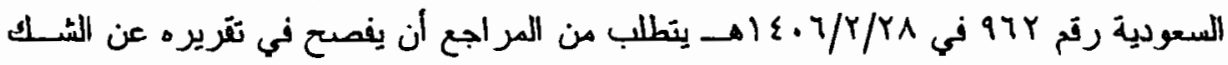

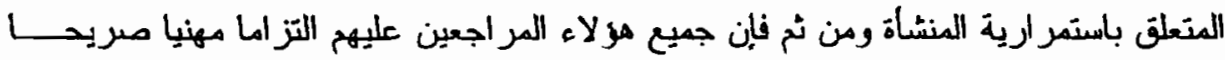

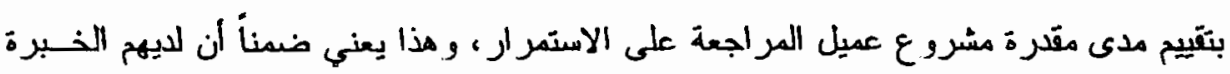




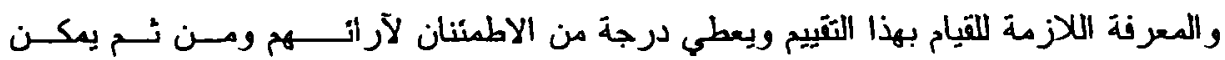

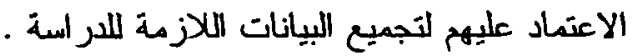

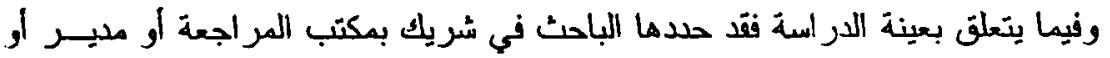

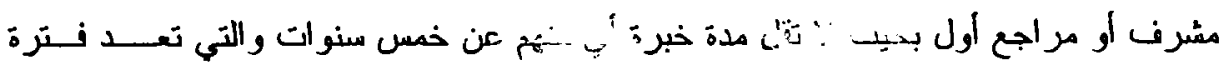

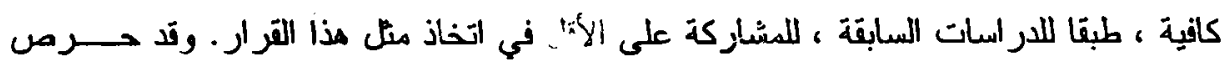

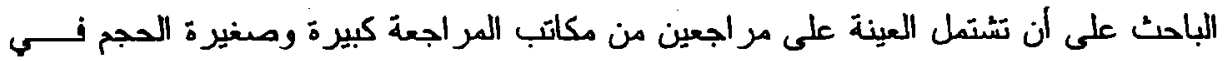

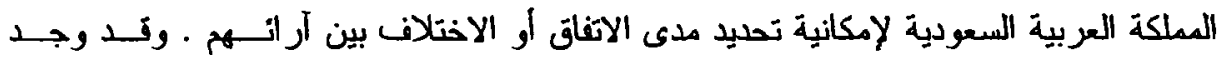

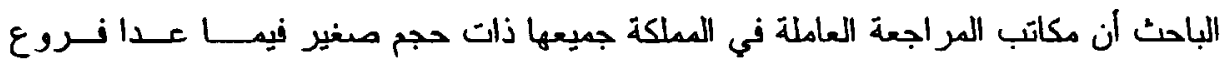
المكاتب المحاسبية العالمية ـ وحاول الباحث الحصول على أعلى نسبة ردود فقام بالاتصـــــال

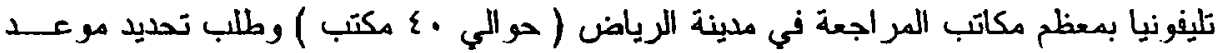

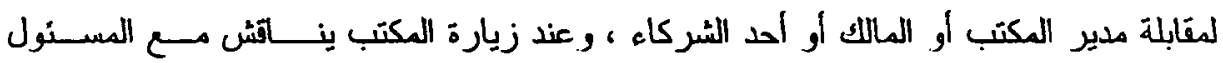

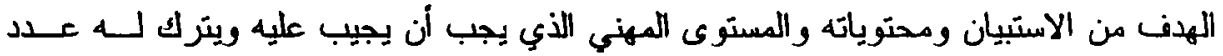

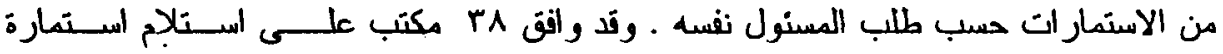

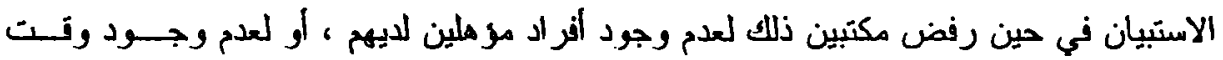

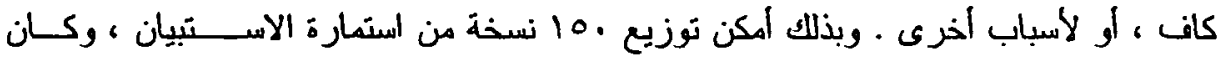

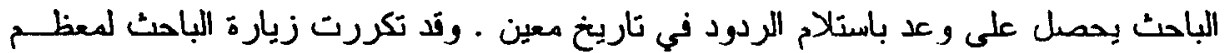

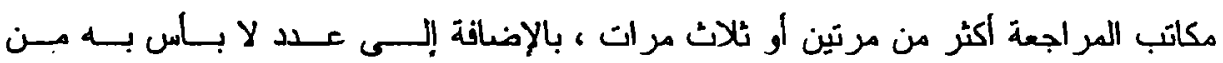

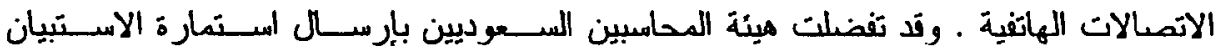

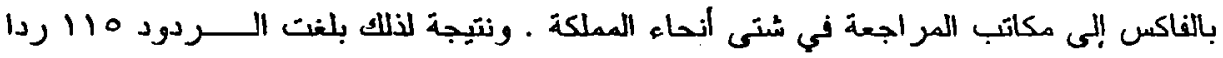

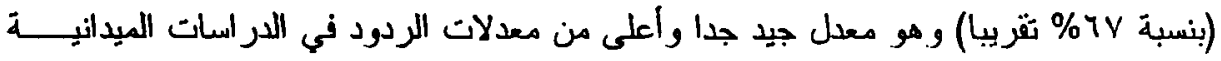

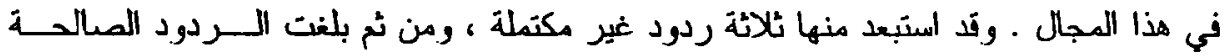

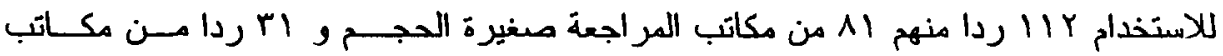

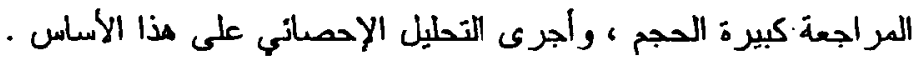

رابعا : الأساليب الإحصائية المستخدمة واجنة

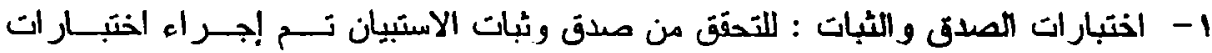

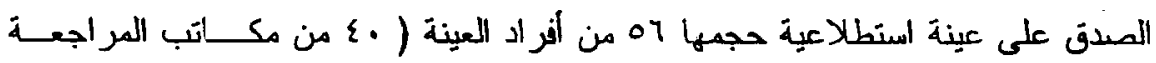
صغيرة الحجم و, 17 من مكاتب المر اجعة كبيرة الحجم ) . وذلك على النحو التالهي;: 


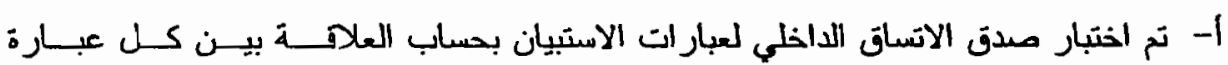

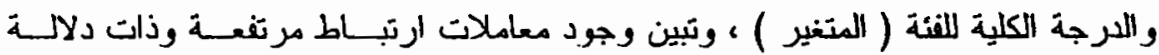

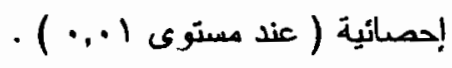

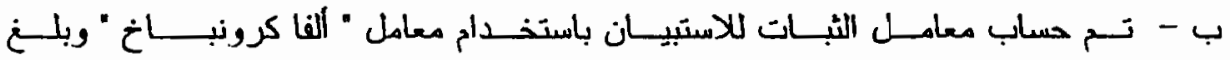

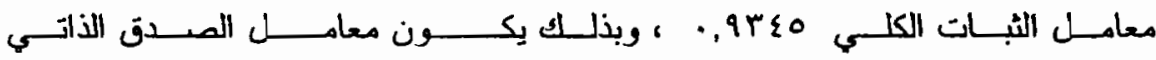

$$
\text { ل } 0.97=\sqrt{0.9345}=
$$

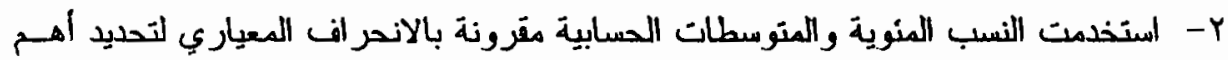
العوامل التي تؤر في قرار تعديل رأي المراجع من وجهة نظر جميع أفراد العينة .

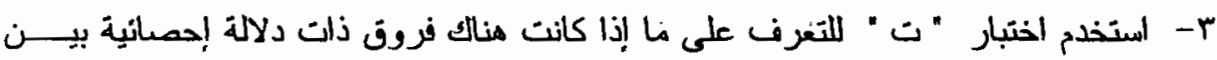

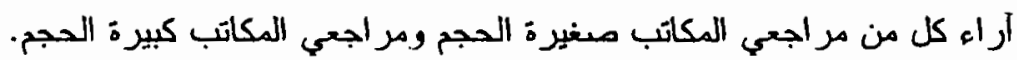
خامسا : مناقشة نتائج الاستبيان و التحليل الإحصائي .

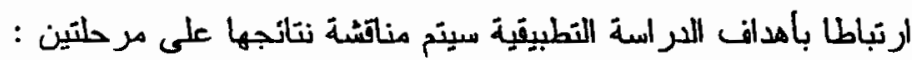

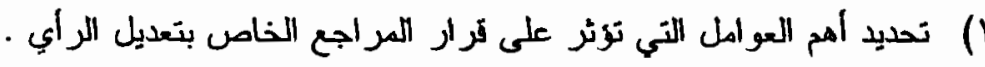

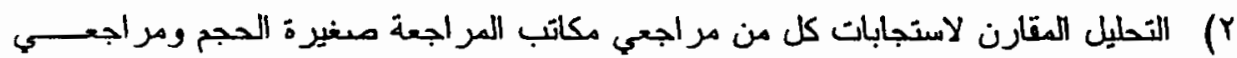

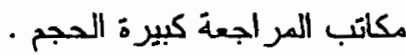

$$
\text { 1) الموامل التي تؤثر لوي قرار المراجع }
$$

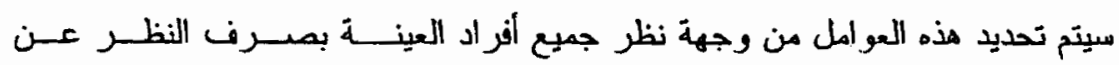

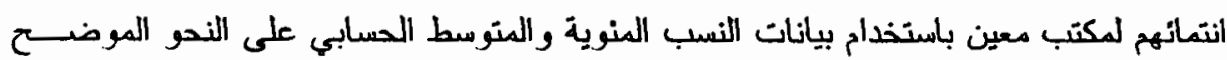

$$
\text { أ- الميما يلي : الموامل الخاصة بمشروع المعيل }
$$

أ - النسب المالية : ويشتمل جدول (1) على البيانات اللازمة لهذا التحليل.

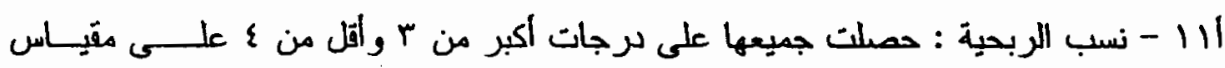

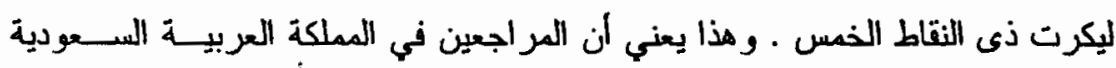

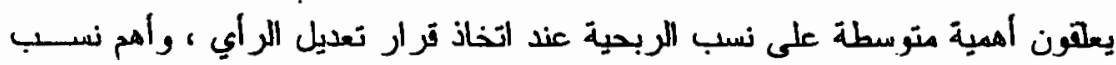

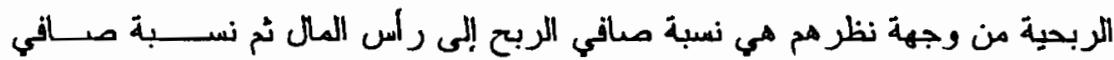

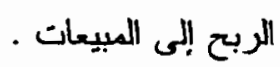


(1)

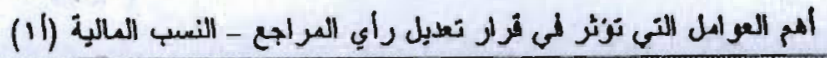

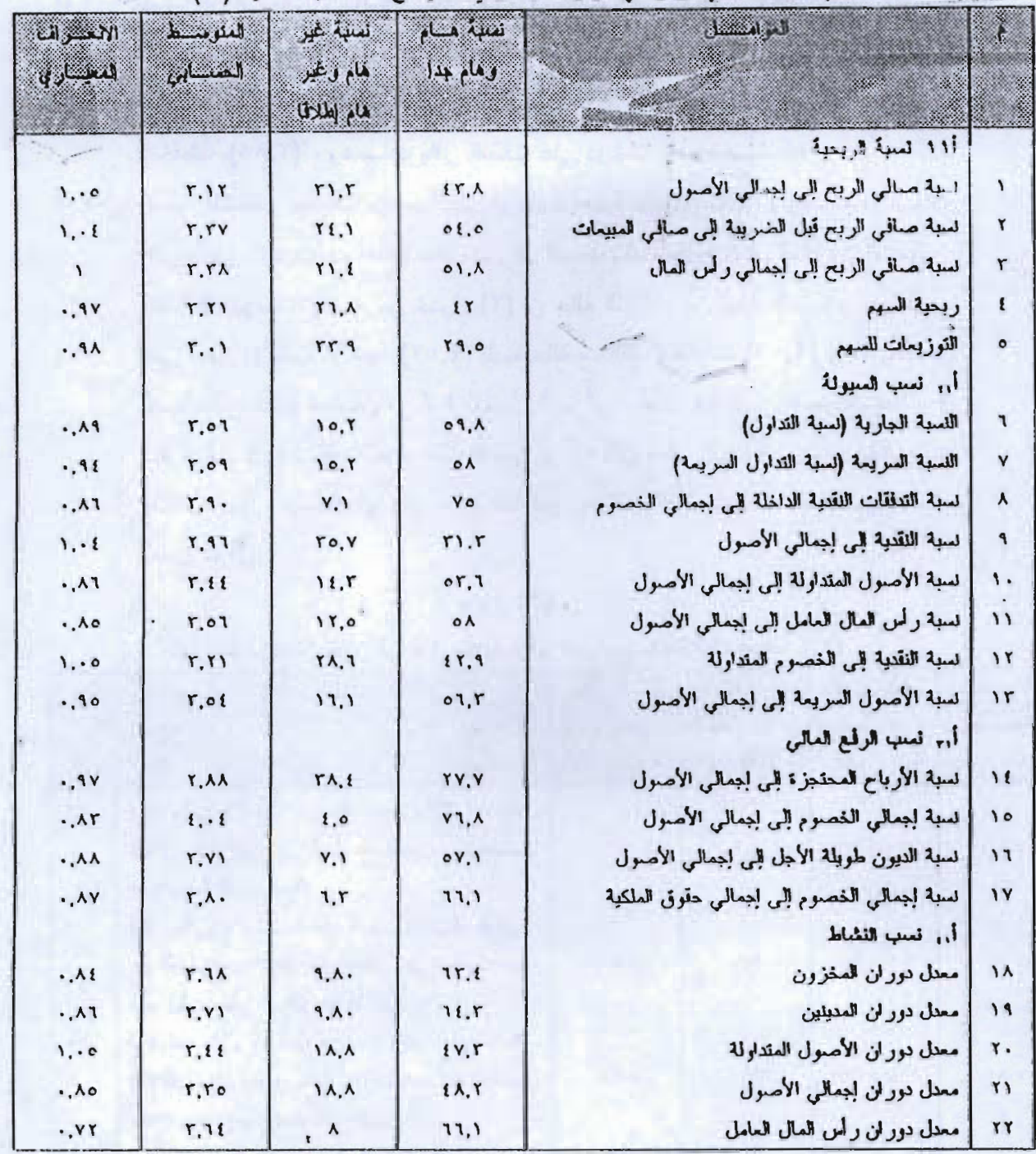

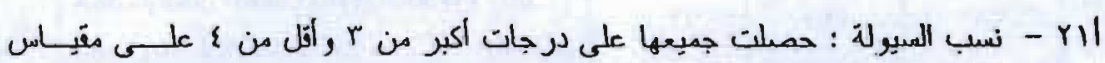

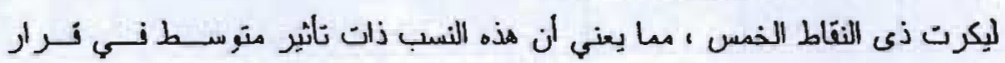


تعديل الر اي ، فيما عدا نسبة النقدية إلى إجمالي الأمبول نقد تحدد لها أهمية الكل مسـن

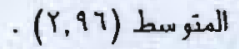

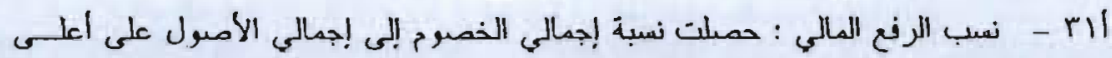

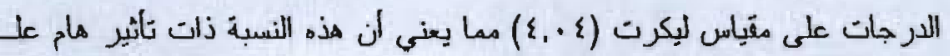

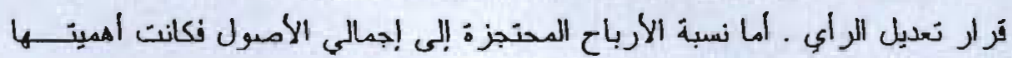

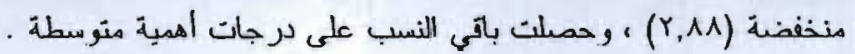

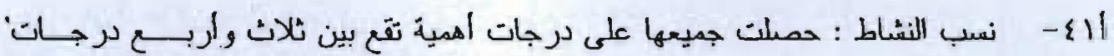

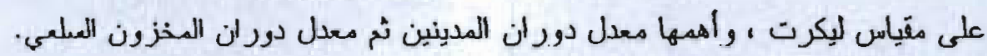

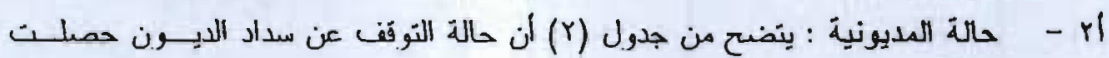

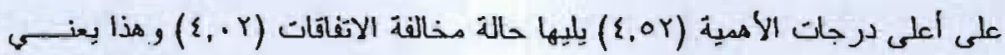

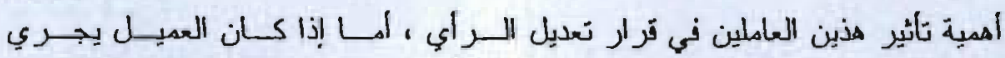

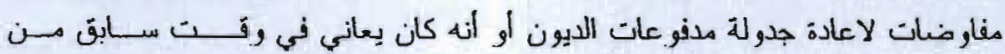

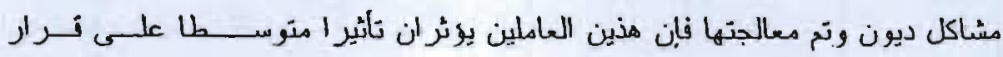

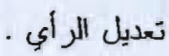

(r) لجد

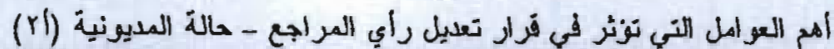

\begin{tabular}{|c|c|c|c|c|c|}
\hline 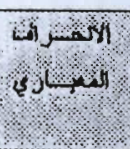 & 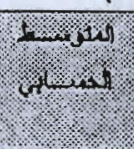 & 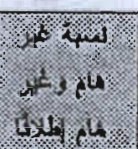 & 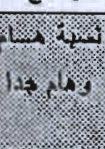 & $3.2,31$ & \\
\hline$\therefore, \lambda_{\varepsilon}$ & $1 . . r$ & $\begin{array}{c}11,1 \\
\vdots\end{array}$ & $\{r, 1$ & 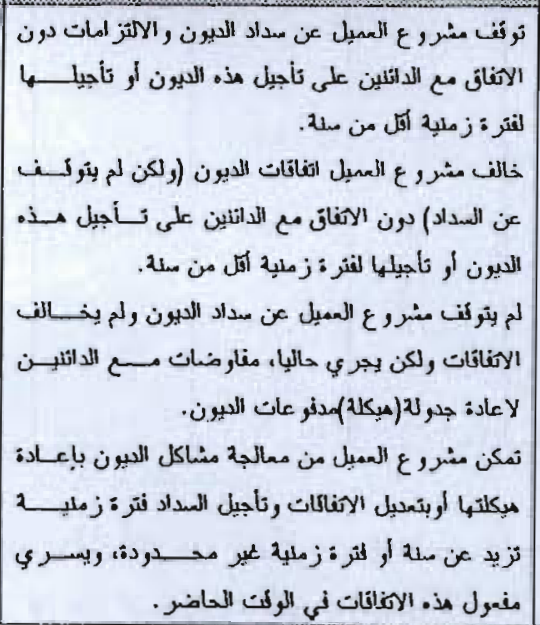 & $r r$ \\
\hline
\end{tabular}




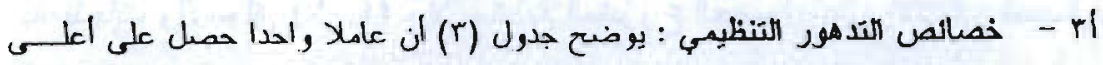

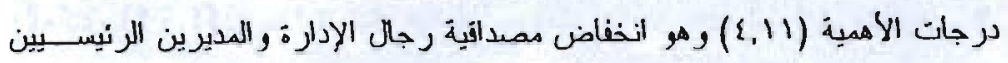

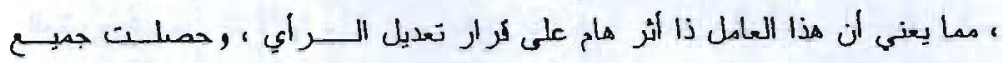

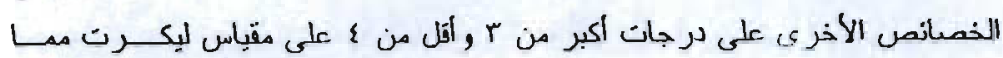

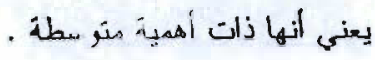

(ii) جد جد

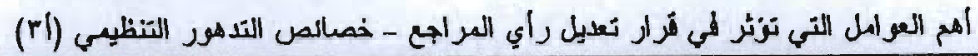

\begin{tabular}{|c|c|c|c|c|c|}
\hline 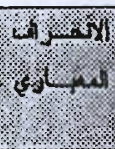 & $\operatorname{lin}(-3)$ & 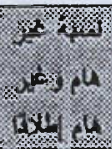 & 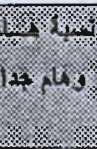 & (2) $-1 ; 0,1$ & 8 \\
\hline .97 & r.10 & $1 \mathrm{r}, \mathrm{i}$ & $1 ., \mathrm{V}$ & عم وجود تخطيط طويل الأجل لاى مثرو ع أعميل. & rv \\
\hline 1.1 & r.te & iv & o. & انذفاض معلويات العاملين بالمشرورع & rA \\
\hline $1 . .9$ & $r, A$ & ir.e & iv. 9 & نهرب الديرون من المسنوريه بالقانها على الأكرين. & 9 \\
\hline$r, 9$. & $r, v$ & $\because, 1$ & $14 . r$ & 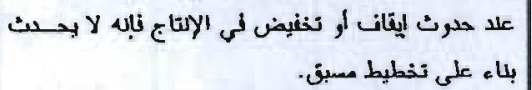 & $\theta$ \\
\hline $.9 \mathrm{r}$ & $r . i r$ & ir.i & 01.9 & 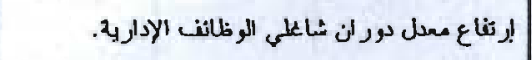 & r \\
\hline.$\wedge 1$ & r.vi & 1.9 & r.,o & 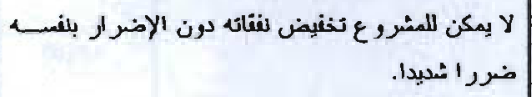 & $r$ \\
\hline .99 & r.Av & 1.9 & iv, & 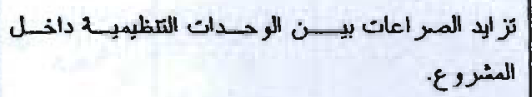 & rr \\
\hline$\cdot \wedge \mathrm{Av}$ & r.rv & $11, r$ & $2 r, 9$ & وجود كلر كبير من مقاومح التغيير. & $r$ \\
\hline$\cdot . \wedge r$ & r.ro & iv & ra.r & 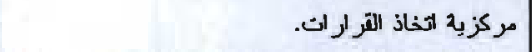 & $\circ$ \\
\hline$\cdot .19$ & r.vi & $\wedge$ & 11.1 & 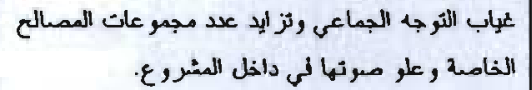 & \\
\hline .91 & 2,11 & 0,1 & จ१,० & الثغاضض ممدائية رجال الآدار : والمديرين الرنيسينين. & $\mathrm{v}$ \\
\hline$\cdot \mathrm{v9}$ & $r, 2 r$ & 1,9 & 11,1 & تخلم اللشاط الابتكار ب بالمثردع. & \\
\hline
\end{tabular}

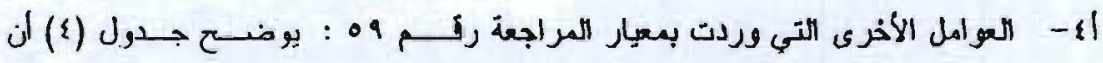

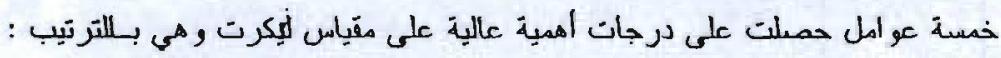

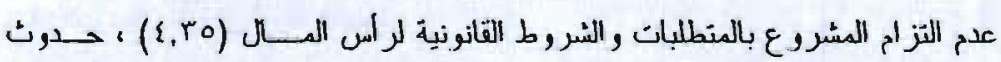

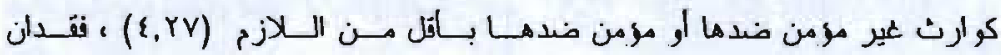

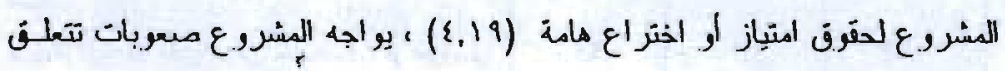




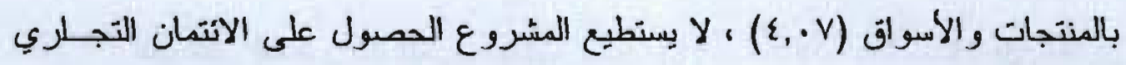

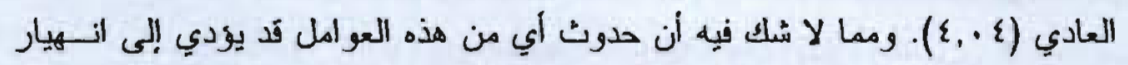

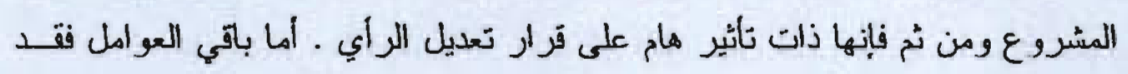

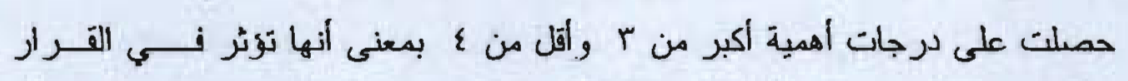

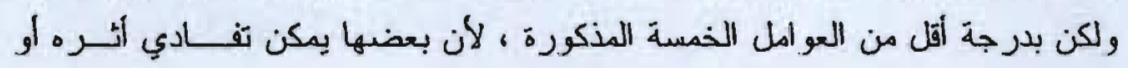
ايجاد بديل له وله

\section{(1) جدول}

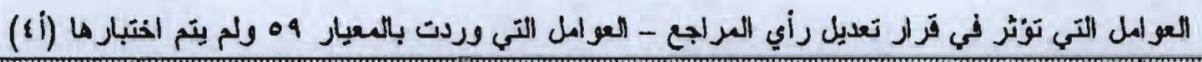

\begin{tabular}{|c|c|c|c|c|c|}
\hline 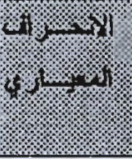 & 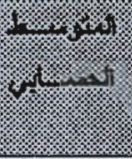 & 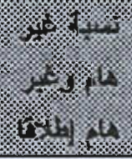 & 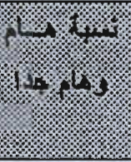 & 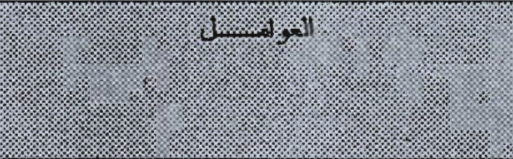 & 1. \\
\hline$\cdot 9$ & $r, 89$ & 17,1 & $07, r$ & تفونها. & rq \\
\hline$\because \wedge \varepsilon$ & $\varepsilon, \cdot 1$ & 0,1 & $A \cdot, l$ & 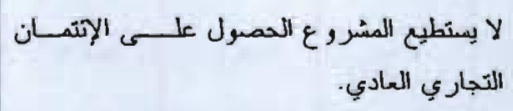 & $\varepsilon$. \\
\hline$\cdot, \wedge 1$ & E.To & 1.0 & $\wedge \vee, 0$ & 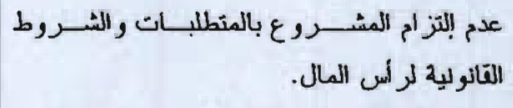 & \&) \\
\hline$\cdot, 10$ & $r, v q$ & $\left.v_{1}\right)$ & $\lambda \wedge, 1$ & لحسياج المشرو ع لمصادر وطرن تمويل جديدة. & \&Y \\
\hline$\cdot .17$ & $r .97$ & $7, r$ & vo, 9 & الأحيّاج المشروع للاتخلص من جز ه كبــبر مـن & $\varepsilon r$ \\
\hline$\cdot, \wedge_{0}$ & $r .90$ & $7, r$ & $V\{, 1$ & 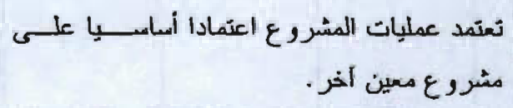 & $\{\varepsilon$ \\
\hline$\cdot, V_{7}$ & $r, \wedge T$ & 1.0 & $v r, r$ & 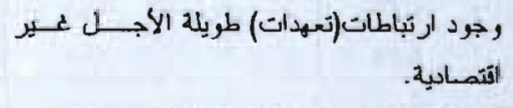 & 10 \\
\hline $.9 r$ & $r, 7 r$ & 11.7 & $T r, 0$ & العمليات الالنتاجياه. & 87 \\
\hline$\cdot \wedge \xi$ & $r, 91$ & $7, r$ & $v 1, \wedge$ & 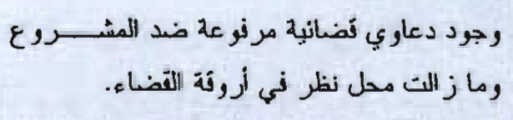 & iv \\
\hline$\cdot \wedge 0$ & $\{, 19$ & $7, r$ & $\wedge r, q$ & فقدان المثرد ع لحقون إمتياز أر حقون اذـــراع & $\{\wedge$ \\
\hline$\cdot .71$ & \&, rV & $r, V$ & 9T & 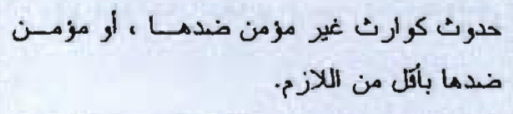 & 19 \\
\hline$\cdot \vee \vee \wedge$ & $\varepsilon, \cdot V$ & $\{, 0$ & $\wedge 1, \lambda$ & 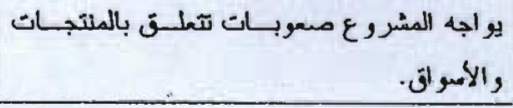 & 0 . \\
\hline
\end{tabular}


ب - العوامل الخاصة بمكتب المراجعة :

با - حجم مشروع العميل : توضح النتائج (جدول م) وجود اتفاق شبه تام بين المر اجعيـن

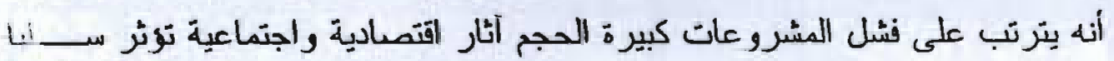

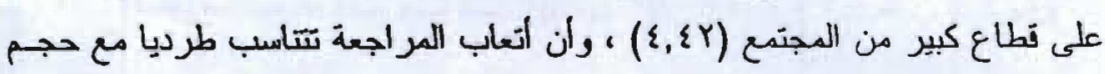

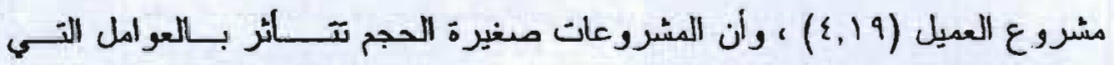

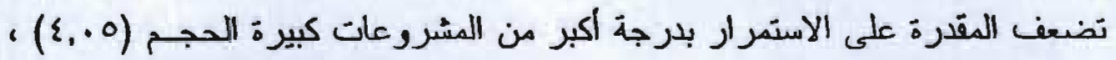

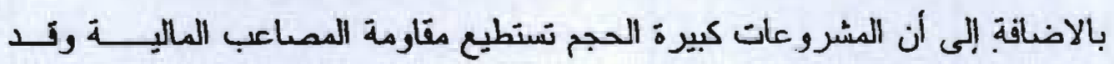

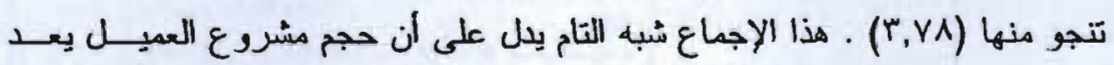

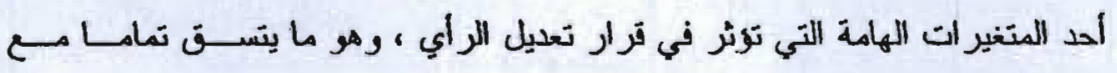

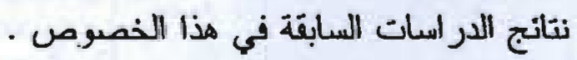

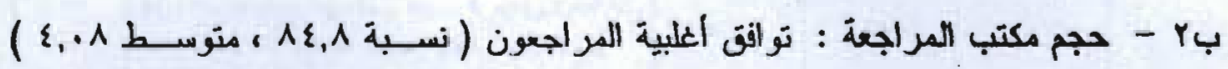

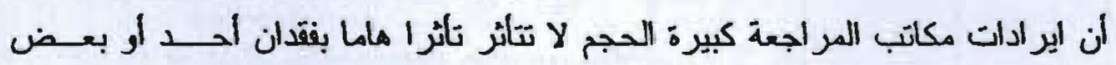

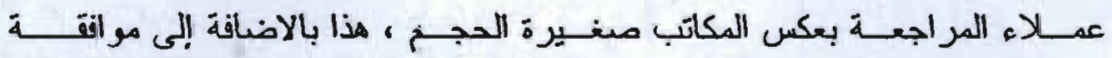

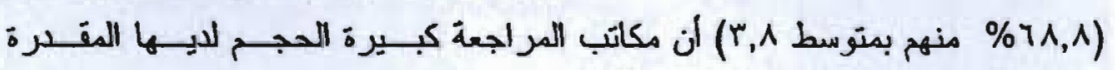

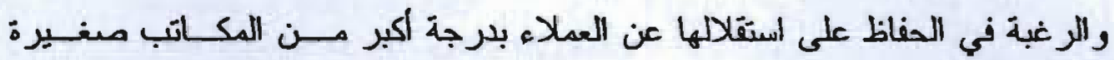

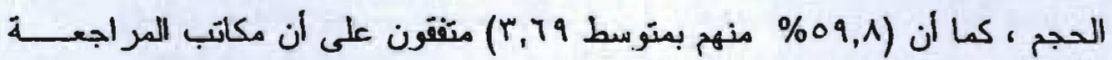

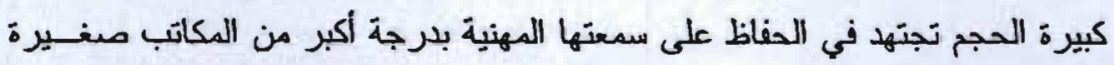

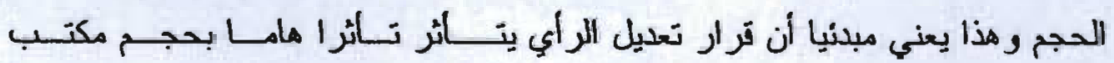

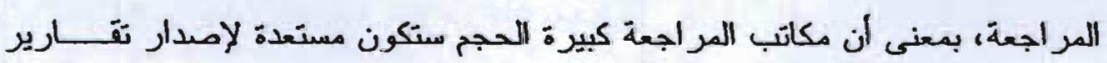

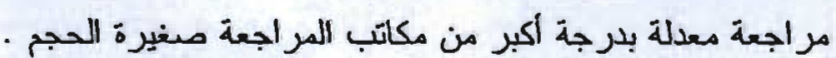

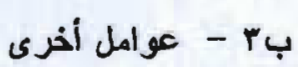

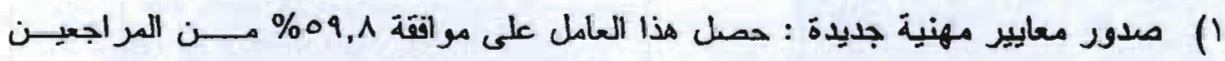

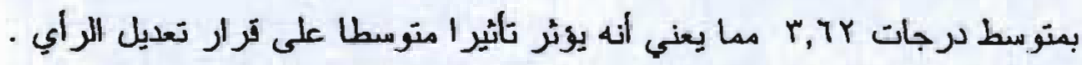

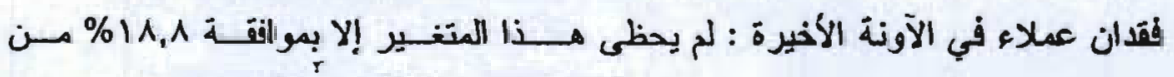

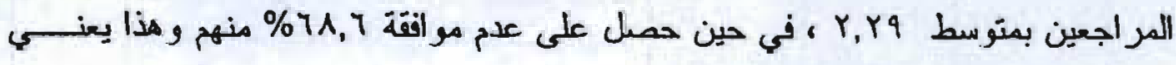

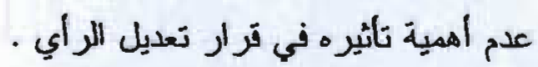

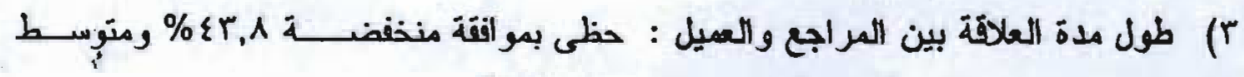
 
(•) جلمول

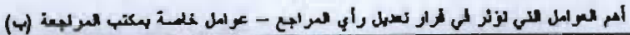

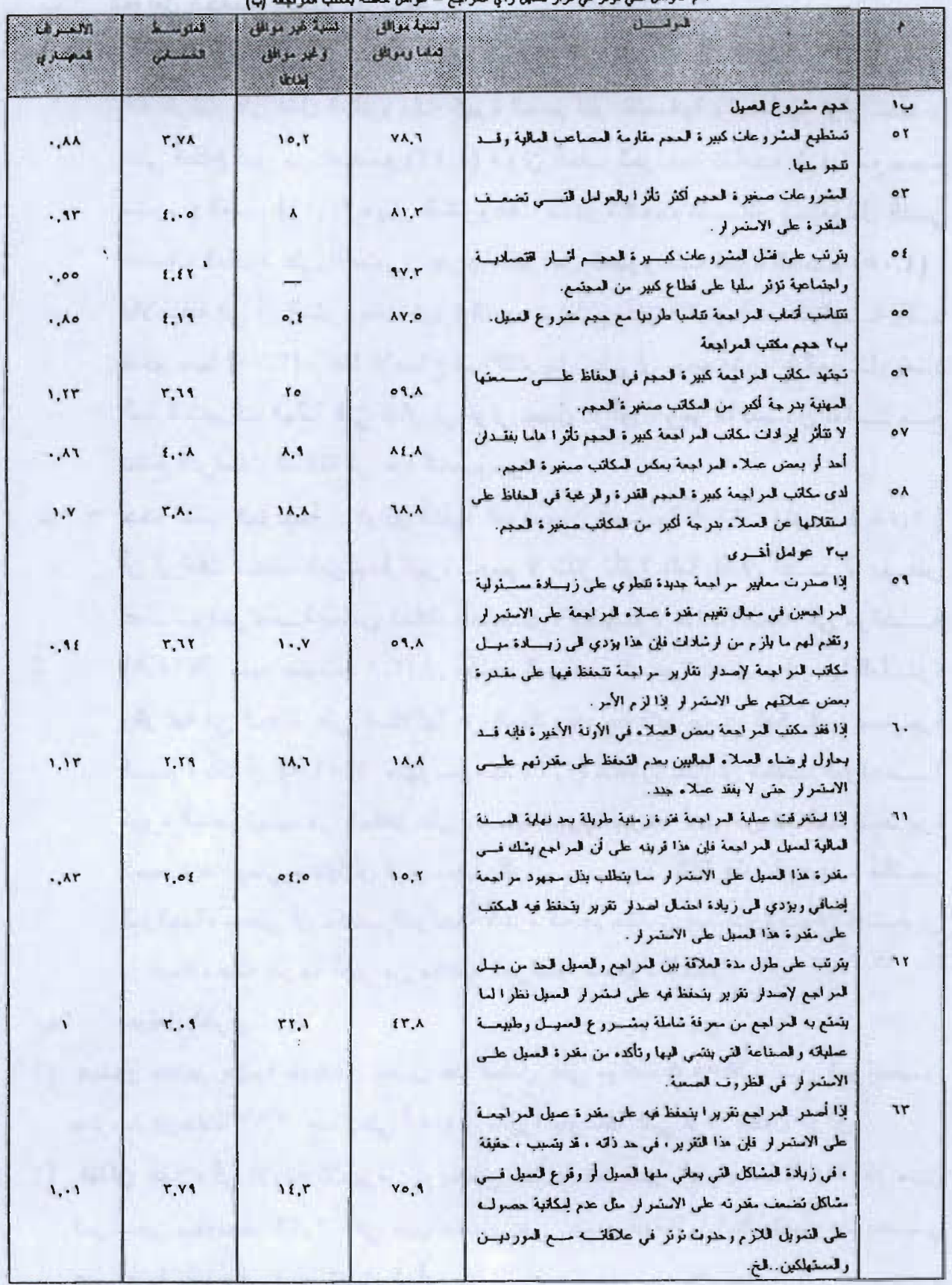




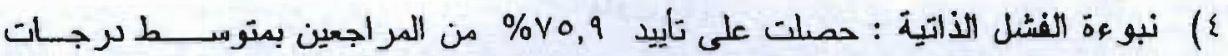

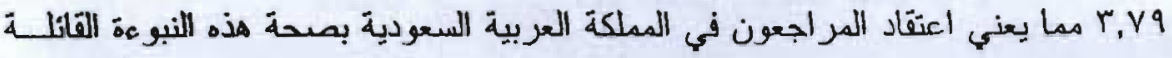

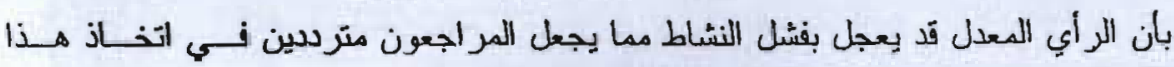

$$
\text { r- التحليل المقارن لآراء المر اجعين }
$$

تشنمل هذه الجزنية على تحليلا مقارنا لآر اء كل من مر اجعي المكاتب مغيرة الحبرم

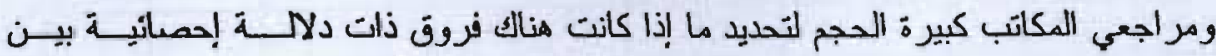

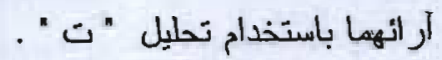

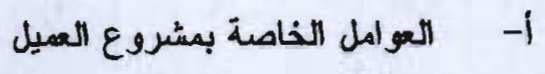

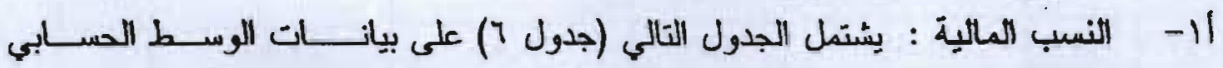

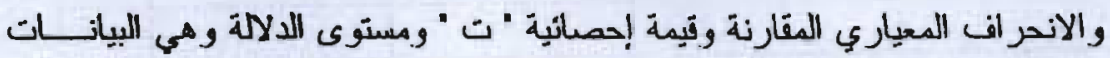
الازمة لهذا التحليل المقارن.

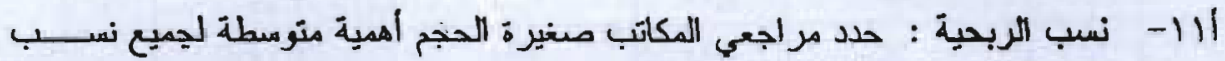

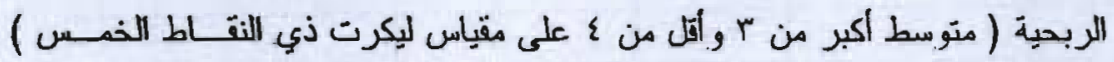

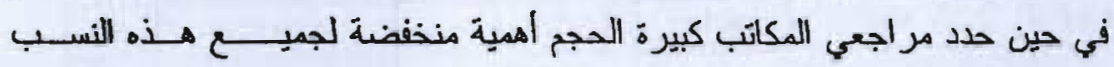

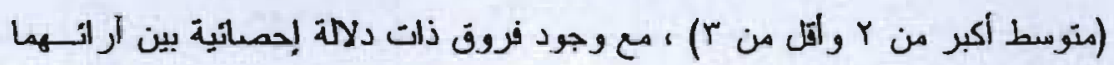

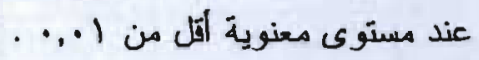

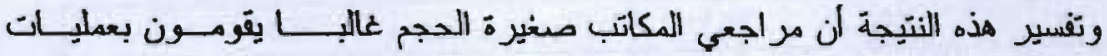

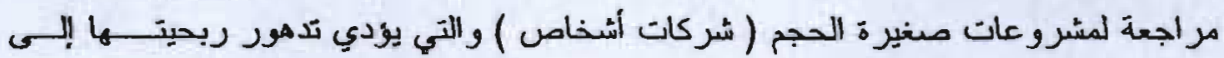

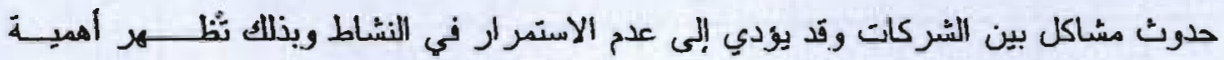

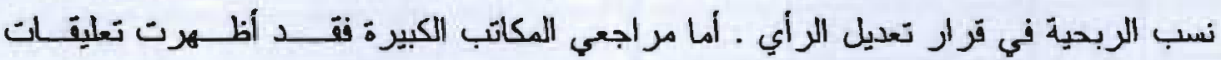

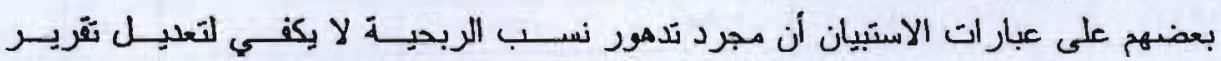

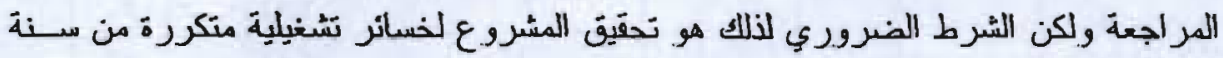

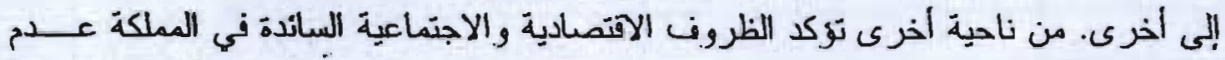

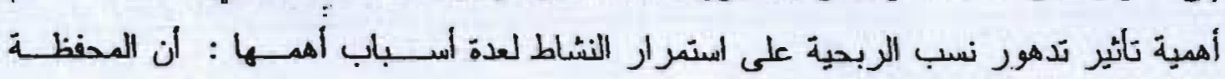

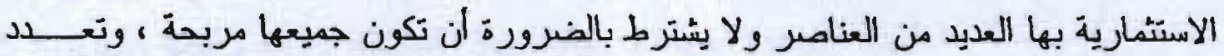

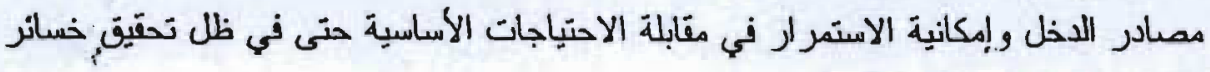


(7) جدول

المقارنة على أساس حجم المكتب - النسب المالية (11)

\begin{tabular}{|c|c|c|c|c|c|c|}
\hline 45 & 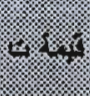 & 14 & & $y=x$ & & 8 \\
\hline & & 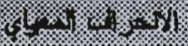 & 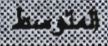 & 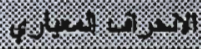 & (x, w & \\
\hline & & & & & & 111 \\
\hline$\because \cdots 7$ & $r, \wedge r$ & $1, \cdot 1$ & $r, 7 \Lambda$ & $\cdot .99$ & $r, r \wedge$ & 1 \\
\hline$\therefore$, & $r, v A$ & $\cdot 90$ & $r, \wedge)$ & 1 & $r, 09$ & r \\
\hline$\ldots \ldots$ & $r, r q$ & $1, \cdot 1$ & Y, १. & .91 & $r, o r$ & $r$ \\
\hline$\ldots$, & r.ov & י & $r, r)$ & $\cdot 90$ & $r, 8)$ & 1 \\
\hline$\because \cdots 1$ & $r, 11$ & .19 & $Y, O r$ & $\cdot 90$ & $r, Y$. & 。 \\
\hline & & & & & & ril \\
\hline$\because, \vee v V$ & 1,19 & $\cdot \wedge r$ & r.rr & $\cdot, 9$ & $r, 70$ & 7 \\
\hline$\cdot, 1.1$ & 1,70 & $\cdot, \wedge \mathfrak{l}$ & r.ro & $\cdot 97$ & $r, 71$ & $v$ \\
\hline$(, \ldots)$ & $r, r r$ & $\cdot, 9 r$ & $r .11$ & $\cdot \vee \vee A$ & $\{, \cdot\}$ & $\wedge$ \\
\hline$\cdot \ldots$ & $r, \wedge\rangle$ & $\cdot \wedge$. & $Y, r q$ & 1.18 & $r .19$ & 9 \\
\hline - or. & ri, & -99 & r.ro & $\cdot, \wedge i$ & $r, i v$ & 1. \\
\hline .0 oro & $\cdot, 71$ & $\cdot, \Lambda$. & 5.70 & $\cdot, \wedge \vee$ & r.or & 11 \\
\hline$\cdot, \ldots$ & $r, v \&$ & $\cdot, \wedge t$ & $Y, 70$ & $1, .0$ & $r, \varepsilon r$ & Ir \\
\hline$\cdot .1 Y\}$ & $\cdot, \wedge$. & $\cdot, 10$ & $r .\{r$ & $\cdot, 99$ & $r, 01$ & ir \\
\hline & & & & & & rii \\
\hline - rer & .90 & .97 & $Y, Y Z$ &., 99 & Y.9! & 18 \\
\hline$\because \cdots 9$ & 9,70 & $\cdot \wedge r$ & $r, v)$ & $\cdot, \wedge$. & 2,17 & 10 \\
\hline$\because 991$ & $1,7 \mathrm{~V}$ & $\cdot, \wedge 1$ & $r, 11$ & $\therefore \wedge 9$ & r.vq & $\therefore$ \\
\hline.$r \notin 1$ & $\cdot 90$ & $\cdot \wedge r$ & $r, 71$ & $\cdot, \wedge \wedge$ & $r, \wedge 0$ & iv \\
\hline & & & & & & 111 \\
\hline$\because, Y \cdot V$ & $1, r v$ & .71 & r.or & $\cdot, \wedge 9$ & $r, v \varepsilon$ & 11 \\
\hline$\because \times 1$ & $1, \times 7$ & $\cdot, 71$ & $r, \& A$ & $\cdot .91$ & $r, \wedge$. & 19 \\
\hline$\cdots \cdots$ & $r, 01$ & $\cdot .91$ & $r, q$. & 1 & $r, 7 \varepsilon$ & $r$. \\
\hline$\because \cdot Y V$ & $Y, Y \xi$ & $\cdot, \wedge 1$ & $r, \cdot 1$ & $\cdot, \wedge\}$ & $r, 87$ & ri \\
\hline$\cdots \cdots$ & $r, r i$ & r.A. & $r, Y q$ & זר. & $r, v \wedge$ & Yr \\
\hline
\end{tabular}

لبعض المشروعات ، بالاضافة إلى المظهر والقيود الاجنماعة وخامة الضنغــط الاجتمـاعي للفشل. 


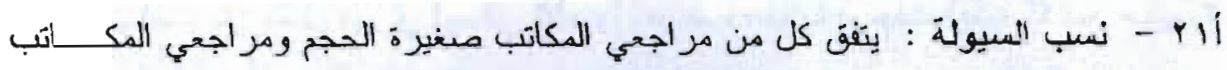

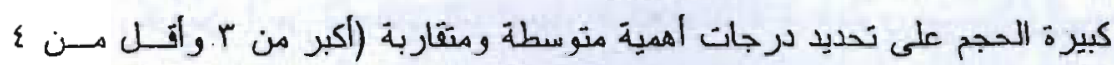

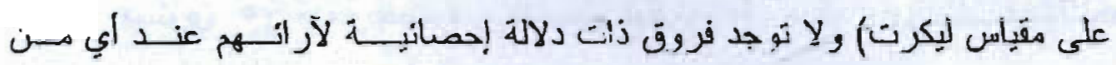

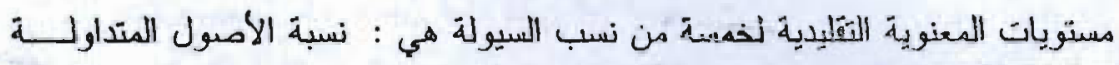

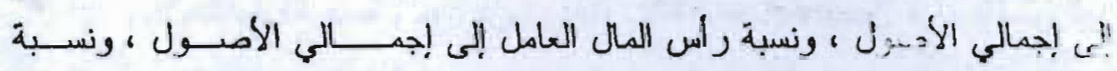

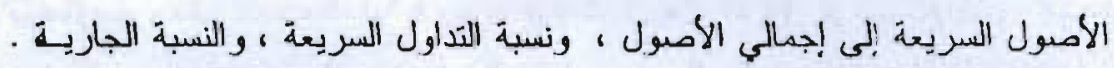

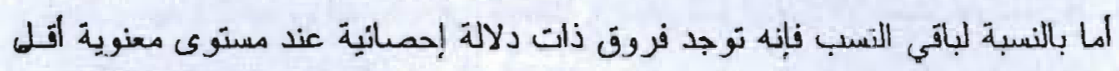

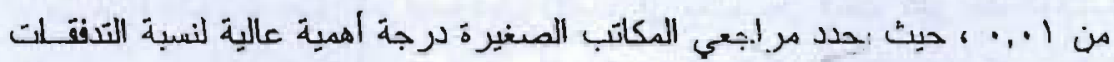

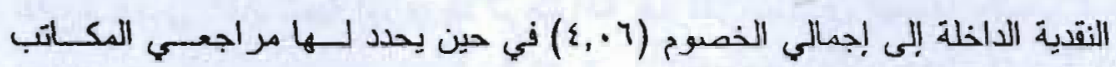

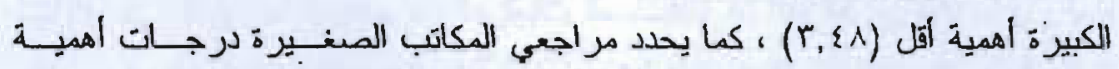

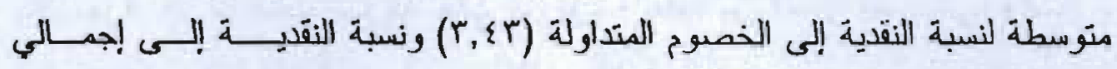

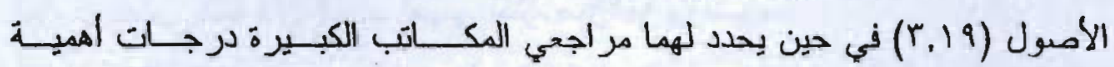

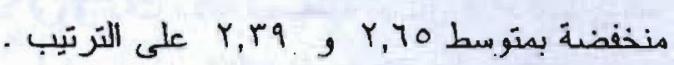

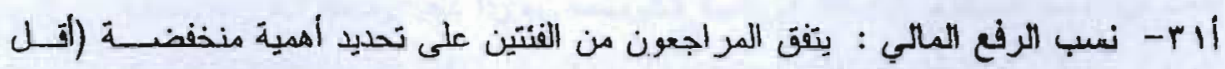

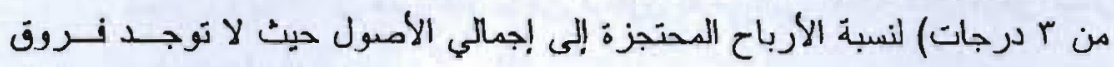

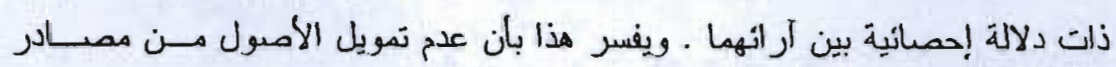

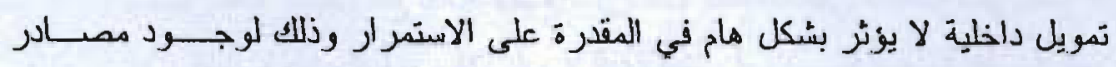

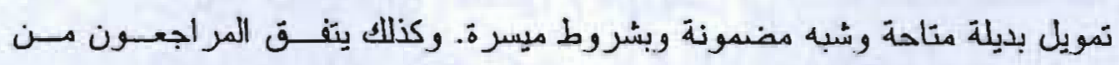

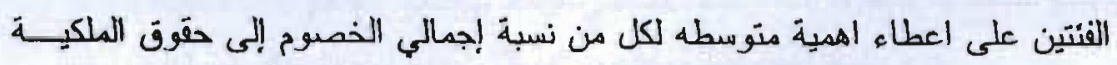

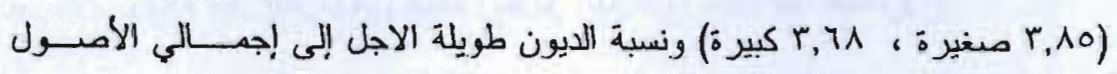
( r,Vo)

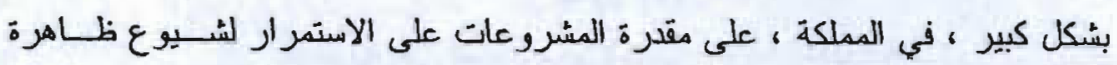

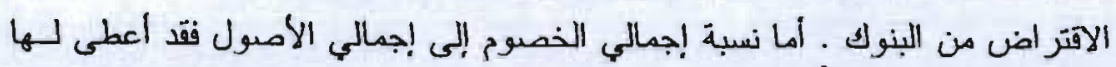

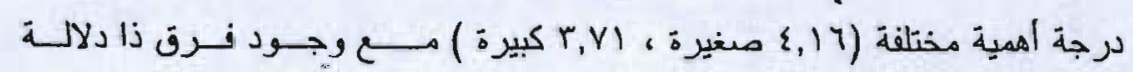

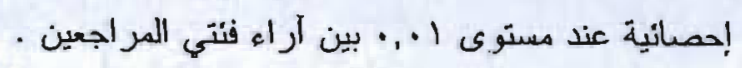

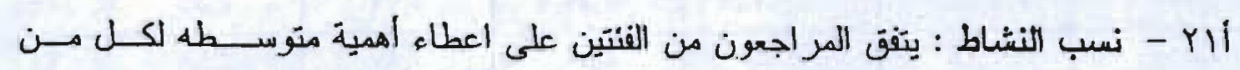

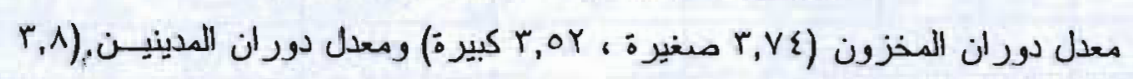

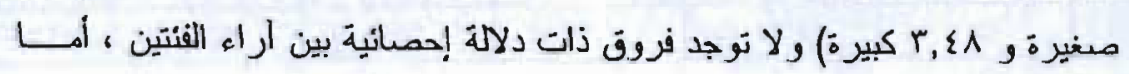




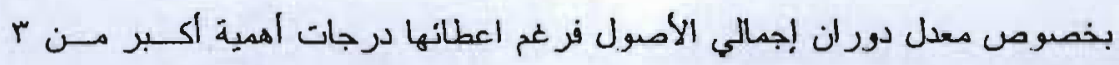

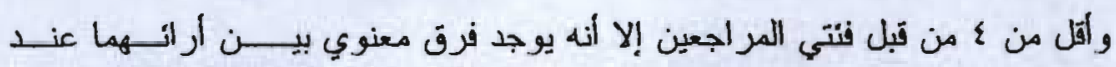

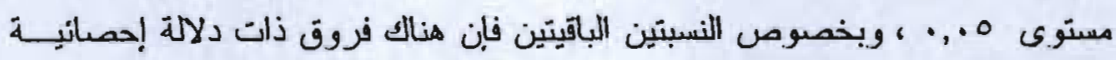

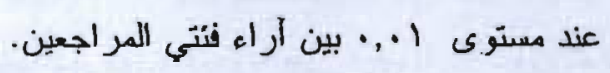

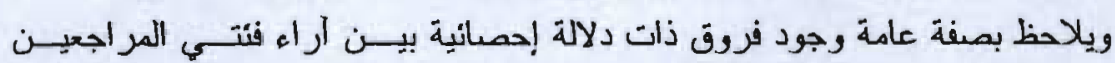

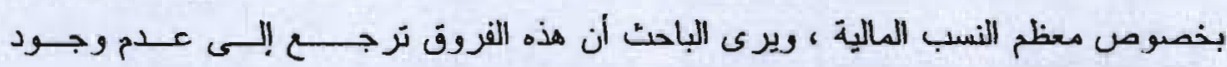

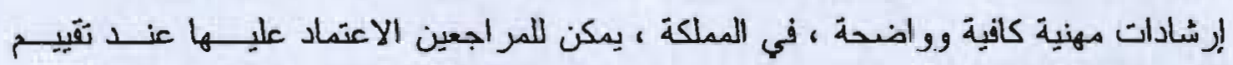

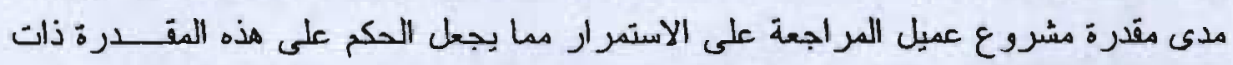

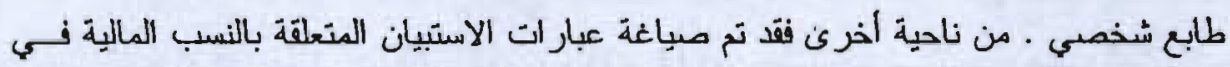

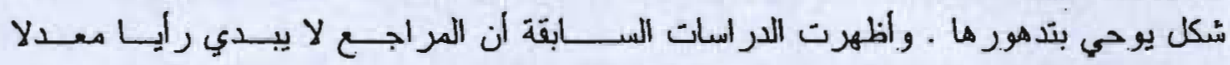

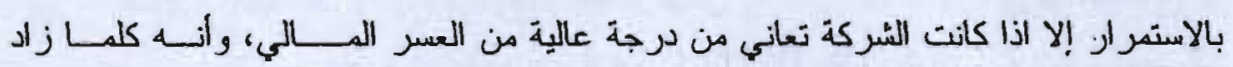

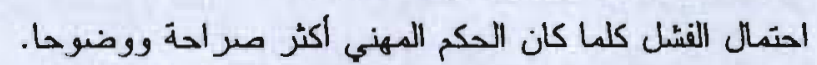

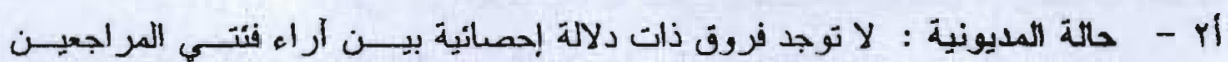

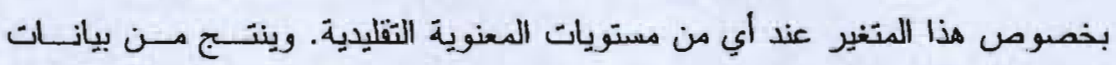

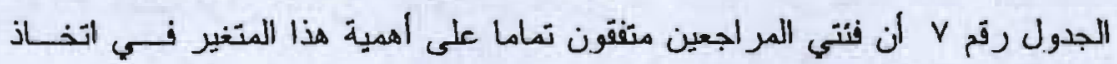

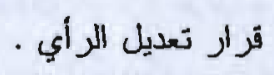

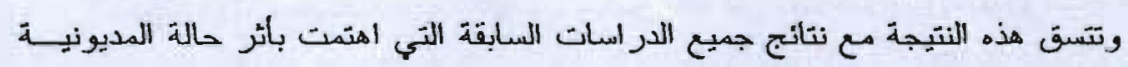

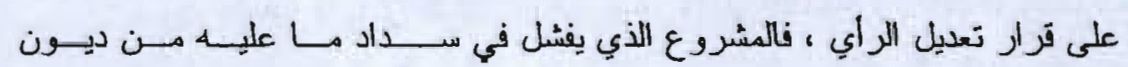

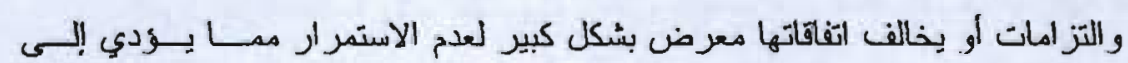

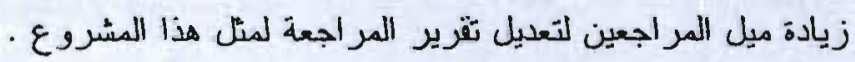

(V) جدول

\begin{tabular}{|c|c|c|c|c|c|c|}
\hline \multirow[b]{2}{*}{ Hin } & \multirow[b]{2}{*}{. } & \multicolumn{2}{|c|}{ 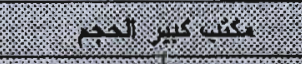 } & \multicolumn{2}{|c|}{ 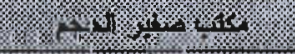 } & \multirow[b]{2}{*}{. } \\
\hline & & . & W & 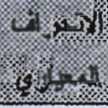 & , & \\
\hline$\cdot$, vAr & $\cdot, \mathrm{YA}$ & r & $\{, 00$ & $\cdot, \mathrm{V}$ & $\{, 0$. & $r r$ \\
\hline .071 & $\cdot, 0 \wedge$ & $\cdot 9\{$ & $\{, 1$. & $\cdot \wedge \vee$ & $r, 99$ & YI \\
\hline$\cdot$ YYA & $1, r_{1}$ & $\because V V$ & $r .00$ & $\cdot, \wedge Y$ & $r, r r$ & ro \\
\hline., 700 & $\cdot, 80$ & .94 & $r, r r$ & $1 . .2$ & r,rY & YT \\
\hline
\end{tabular}

المقارنة على أساس حجم المكتب - حالة المديونية (V) 


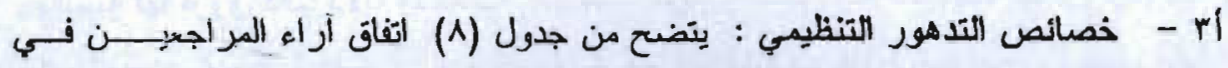

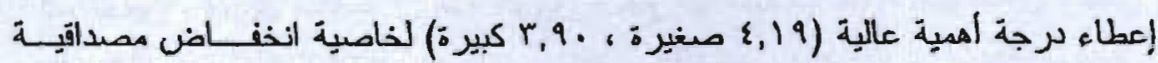

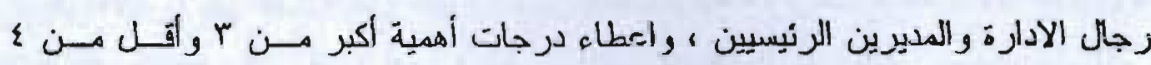

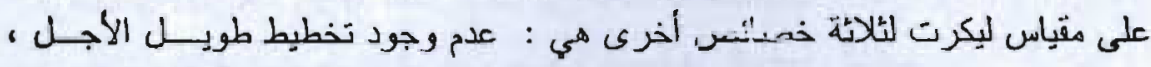

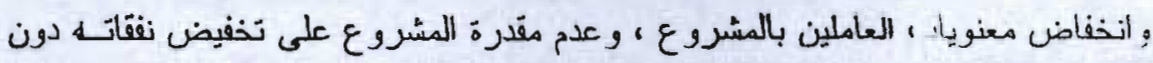

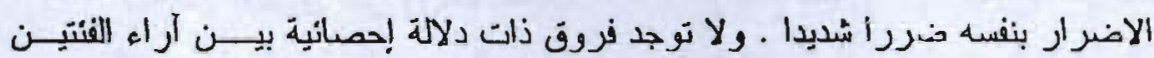

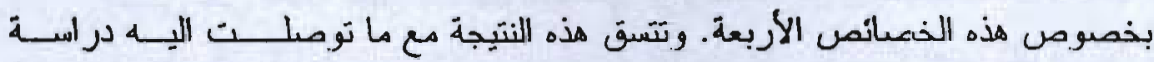
(Ponernan el al.,1991)

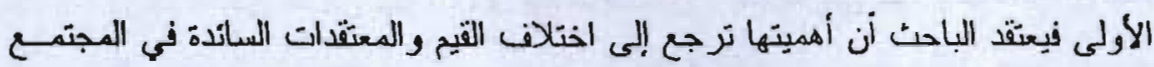

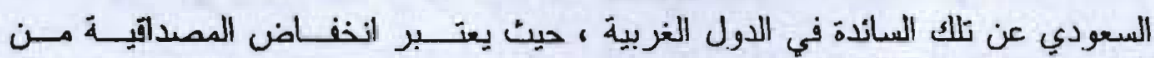

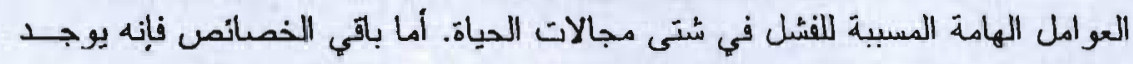

(1) جلول

المقارنة على أساس حجم المكتب - خصائص التذهرر التنظيمي (ri)

\begin{tabular}{|c|c|c|c|c|c|c|}
\hline \multirow[b]{2}{*}{ 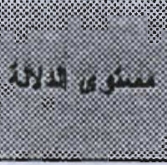 } & \multirow[b]{2}{*}{40} & \multicolumn{2}{|c|}{ (1) } & \multicolumn{2}{|c|}{ 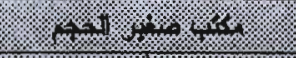 } & \multirow[t]{2}{*}{. } \\
\hline & & 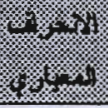 & 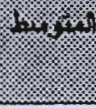 & (3) & (1) & \\
\hline r roo & .99 &., 95 & r,or & $\cdot 978$ & $r, r .$. & rV \\
\hline$\cdot$ IVr & $1 . r A$ & $\cdot, \wedge \Lambda$ & $r, r r$ & $1,1$. & $r, o r$ & $\mathrm{YA}$ \\
\hline$\cdot, \cdot$ YA & $r, Y Y$ & $1, \cdot r$ & $r, 10$ & $1 . \cdot 1$ & $r .91$ & Yq \\
\hline$\because \cdot r \lambda$ & $r, 1$. &., 19 & $r,\{Y$ & .97 & $r, \Delta r$ & $r$. \\
\hline$\because, \ldots r$ & $r, r r$ & 9,90 & 5.19 & $\cdot \wedge V$ & $r, \Lambda$. & H \\
\hline$\cdot, 1 K i$ & 1,01 & $\cdot, 11$ & r.or & $\cdot \wedge \Lambda$ & r.va & $r r$ \\
\hline$\because \cdots$ & $r, 7 r$ & $\cdot 90$ & $r, r_{0}$ & - $9 r$ & $\varepsilon, \cdot v$ & rr \\
\hline$\because \cdots 9$ & Y. $7 \ell$ & $\cdot, 91$ & $r . \cdot r$ & $\cdot, \lambda Y$ & $r .01$ & $r \xi$ \\
\hline$\because \cdot Y Y$ & $r, Y T$ & $\cdot \wedge I$ & ห.१V & $\cdot, \wedge 1$ & $r, r 7$ & ro \\
\hline$\because \cdots l$ & $\mathrm{r,90} r$ & $1, \cdot r$ & r.ro & $\cdot, \vee \vee$ & $r, 19$ & r7 \\
\hline$-1 \leqslant 0$ & $1,2 \mathrm{~V}$ & $1, \cdot 1$ & r.q. & $\cdot 10$ & 1.19 & rv \\
\hline$\cdot \ldots r$ & $r, 1 r$ & $\cdot 71$ & $r, \cdot 7$ & $\cdot, \vee 9$ & $r, o v$ & $r A$ \\
\hline
\end{tabular}




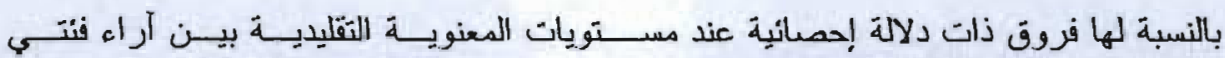

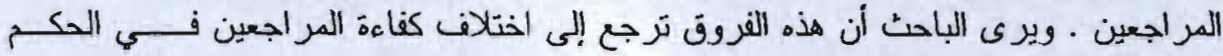

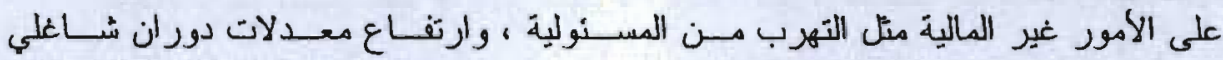

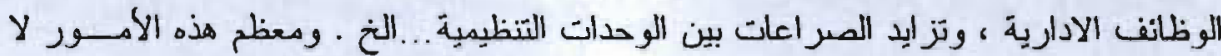
تخرج من نطاق اختصاص المراجع بصفته خبير ا في النواحي المالية.

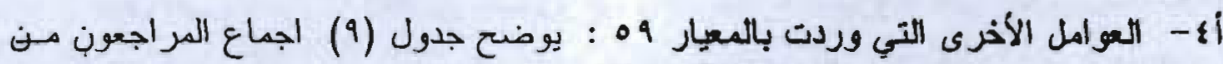

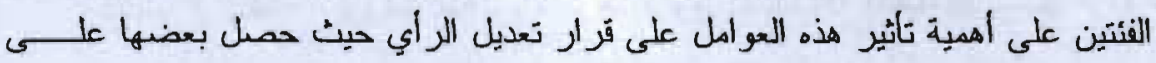

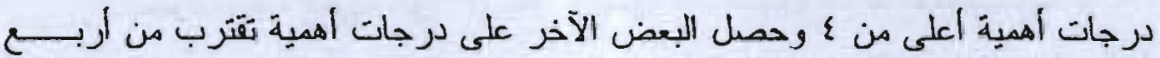
درجات على مقياس ليكرت ذى النقاط الخمس ، إضافة إلى عدم وجود فروت بيــن آراء

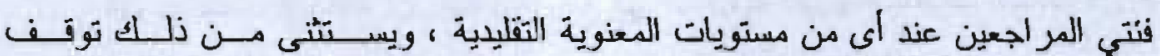

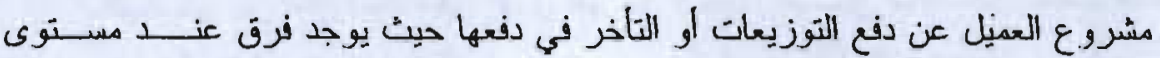

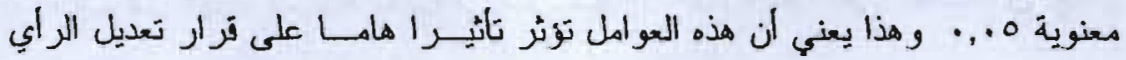

\section{(9) جدول}

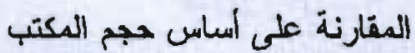

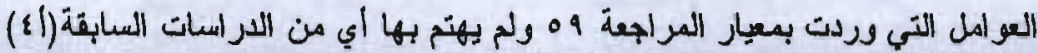

\begin{tabular}{|c|c|c|c|c|c|c|}
\hline \multirow[b]{2}{*}{ 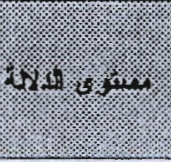 } & \multirow[b]{2}{*}{4.18 .9}$. & \multicolumn{2}{|c|}{ 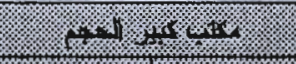 } & \multicolumn{2}{|c|}{ 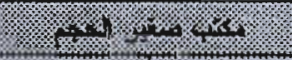 } & \% \\
\hline & & 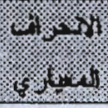 & 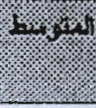 & 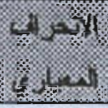 & (4) & \\
\hline$\because \cdot r$ & $r, r$. & .90 & $r, 19$ & $\cdot, \wedge \gamma$ & $r, r$. & $r q$ \\
\hline$\cdot, 1 \vee \wedge$ & $1, r 0$ & $\because, V_{7}$ & $r, \wedge V$ & $\because \wedge \mathrm{V}$ & $\{, 1\}$ & $\varepsilon$. \\
\hline$\because \vee 01$ & $\cdot, r I$ & $\cdot, \wedge\{$ & $\{, r q$ & $\cdot, 11$ & $\varepsilon, r r$ & \& \\
\hline$\cdot \mathrm{rr}_{7}$ & $\cdot, r !$ & $\cdot, \mathrm{VA}$ & $r, \wedge \varepsilon$ & $\cdot, \wedge \wedge$ & r.YA & $\{r$ \\
\hline$\cdot, \mathrm{vrv}$ & $\cdot r I$ & $\cdot, 71$ & $\varepsilon, \cdots$ & $.9 r$ & $r .9 q$ & $\{r$ \\
\hline. .07 & 1,95 & $\cdot .70$ & 8.19 & $\because 9$. & $r, \wedge 0$ & \{\} \\
\hline$\cdot, Y \cdot r$ & $\cdot, O r$ & $., 0\}$ & $r, \wedge 1$ & $\cdot, \wedge r$ & $r, \wedge \Lambda$ & 10 \\
\hline., 770 & $\cdot,\{r$ & $\because$ Vo & $r, 11$ & $\cdot 99$ & $r, 09$ & $\{7$ \\
\hline,$- \vee \vee 1$ & $\cdot, r V s$ & .91 & $r, q$. & $\cdot \wedge r$ & $r, 90$ & \&V \\
\hline 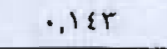 & $1,\{1$ &., 77 & \&,Yo & $\because 91$ & $2,1 Y$ & 21 \\
\hline$\cdot, 7 \wedge 9$ & $\because \varepsilon$. & $\cdot, 07$ & ¿.YY & $\cdot, v r$ & $1, Y A$ & 19 \\
\hline$\cdot 901$ & $\because \cdot 7$ & $\cdot, 11$ & $2 . \cdot 1$ & $\cdot \nabla V$ & $1, \cdot Y$ & 0. \\
\hline
\end{tabular}




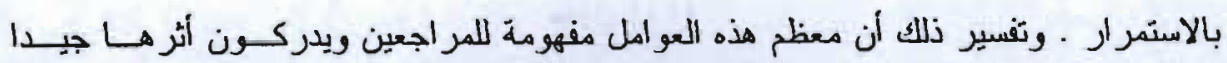

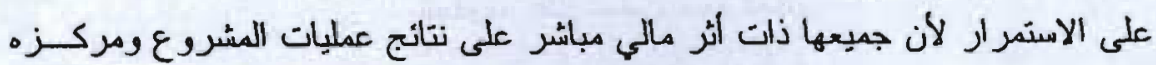
- المالى

$$
\text { ب - العوامل الخاصة بمكنب، المراجعة }
$$

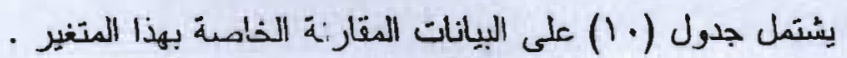

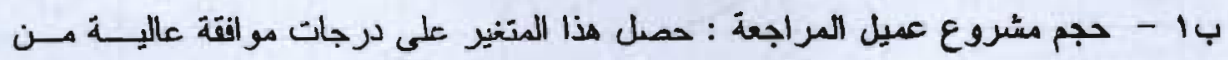

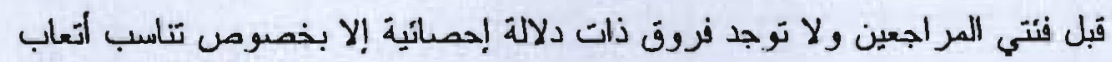

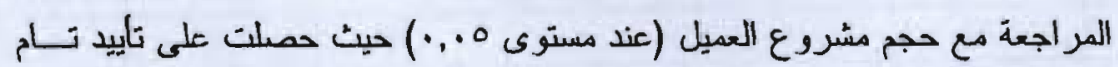

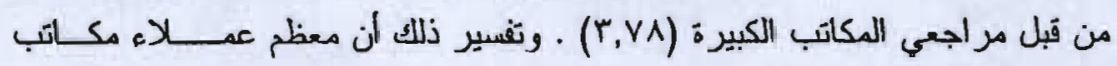

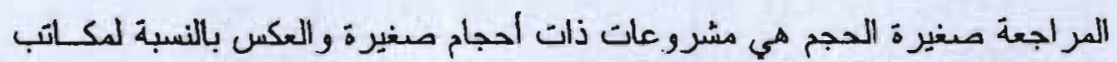

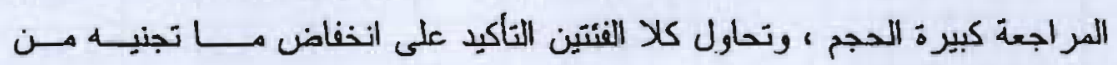

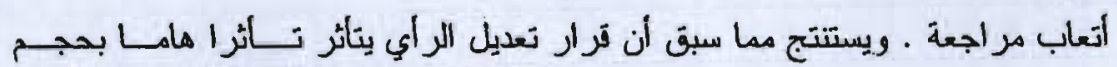

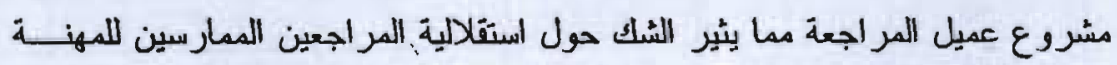

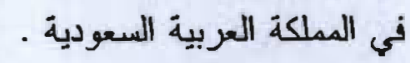

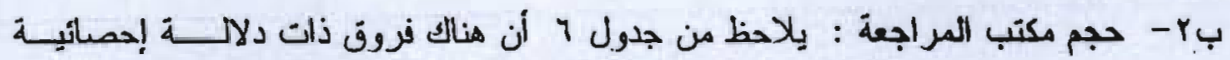

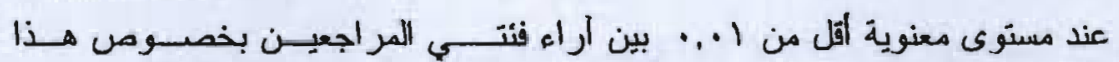

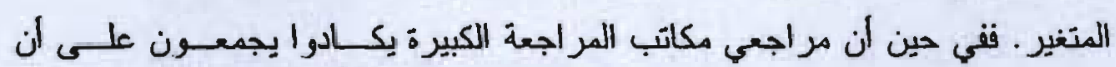

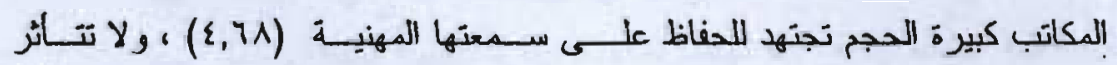

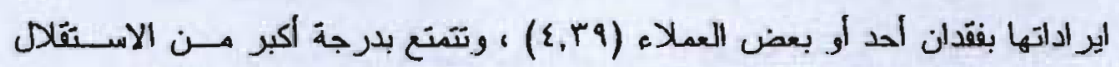

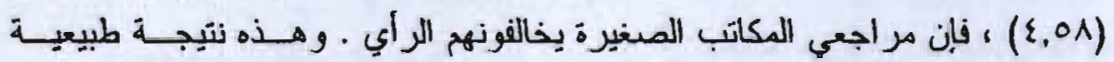

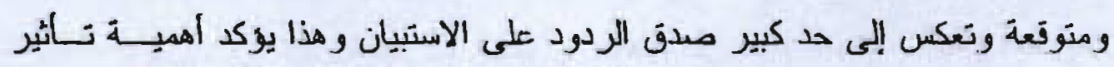

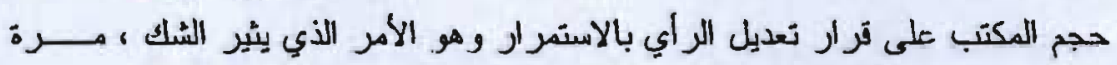

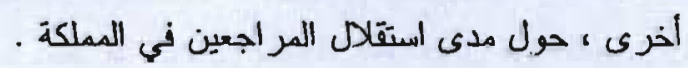

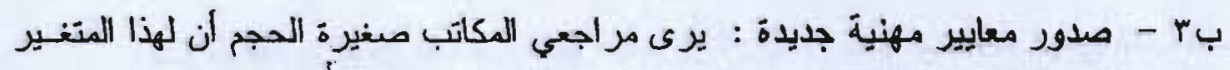

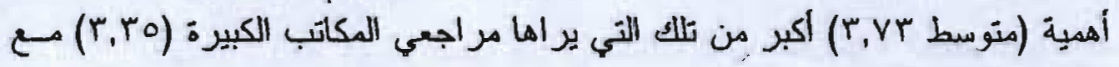

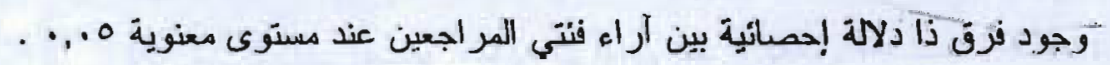


جدول (1.)

المقارنة على اساس حجم المكتب

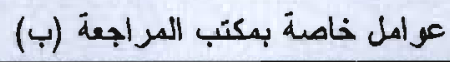

\begin{tabular}{|c|c|c|c|c|c|c|}
\hline \multirow[b]{2}{*}{$4 y^{4}$} & \multirow[b]{2}{*}{$\sqrt[4 i]{4}$} & \multicolumn{2}{|c|}{ 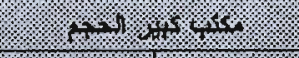 } & \multicolumn{2}{|c|}{ (1) } & \multirow[t]{2}{*}{ t. } \\
\hline & & $4.1 \%$. & 4 & (2) & (4) & \\
\hline$\cdot$ rYA & $\cdot, 91$ & $\cdot \wedge\{$ & $r .70$ & $\cdot, \wedge 9$ & $r . \wedge r$ & or \\
\hline$\cdot$ VIr & $\cdot, r$ & $\because$ Vo & $\{, 1$. & $\cdot 99$ & $\{, \cdot 1$ & or \\
\hline $.99 \mathrm{~V}$ & - & .0. & Q, \& &. $.0 \mathrm{~V}$ & $1,\{Y$ & of \\
\hline$\because, 10$ & $r,\{\Lambda$ & $\cdot .10$ & $r, \wedge v$ & $\cdot, \wedge r$ & $\{, r)$ & 00 \\
\hline,$\ldots$ & $v, 99$ & $\cdot 7$ & $\{, 71$ & $1, r$. & $r, r i$ & 07 \\
\hline$\because \cdots 7$ & $r, \wedge r$ & $.7 \mathrm{r}$ & $2, r^{9}$ & $\cdot 91$ & $r .97$ & ov \\
\hline$\cdots \cdots$ & $1, \wedge 1$ & .07 & 1.01 & $1, \cdot v$ & $r, 01$ & $0 \wedge$ \\
\hline$\cdot, \cdot 7$. & $1,9$. & $1 . .1$ & r.ro & $\cdot, 9$ & $r, v r$ & 09 \\
\hline$\cdot, \cdots$ & $r, v q$ & $\because \wedge \vee$ & 1,71 & $1,1 r$ & r,or & 7. \\
\hline$\therefore \vee \vee \wedge$ & $1, \mathrm{VA}$ & $\therefore v$. & $r, r r$ & $\cdot, \wedge 1$ & $r, 7 r$ & 11 \\
\hline .189 & $\therefore \vee \vee 9$ & 1.00 & $r, 9 V$ & $\cdot 911$ & r.li & ז \\
\hline.,$\infty$ & 1,99 & $1 . \cdot 7$ & $r,\{1$ & $\cdot 9 \mathrm{~V}$ & r.q. & ir \\
\hline
\end{tabular}

ويرى الباحث أن الحد التفسير ات المحتملة لهذا الاختلاف هو أن مكـــاتب المر اجعــة

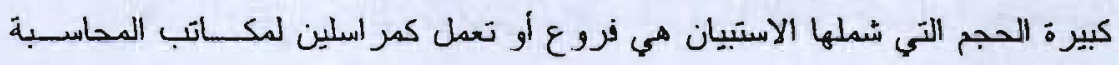

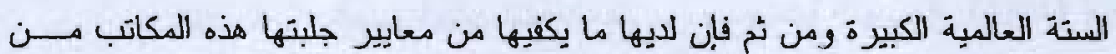

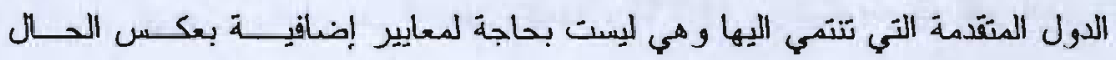

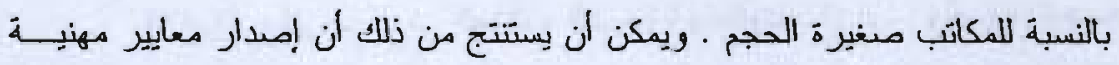

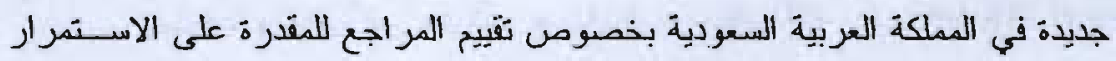

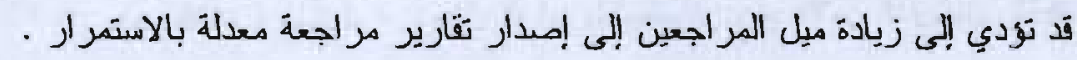

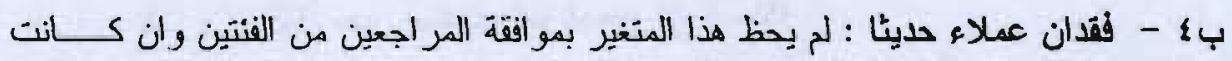

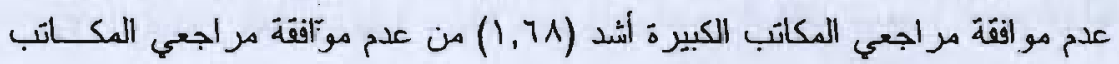

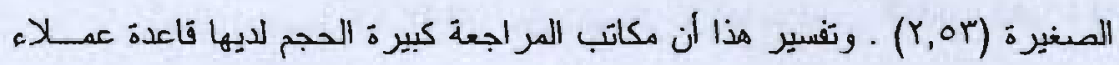

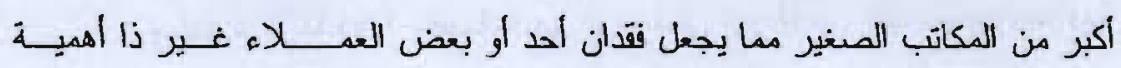


بالنسبة لها بعكس الحال بالنسبة للمكاتب الصغيرة ـ ـوبصفة عامة ليس لهذا المتغـــير

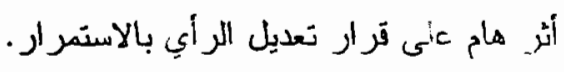

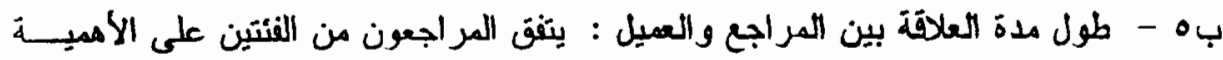

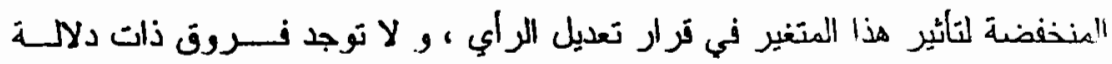

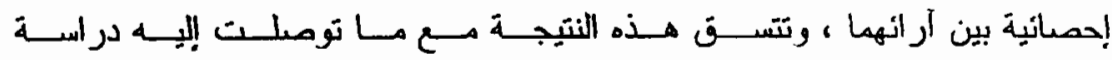
(Louwers, 1998)

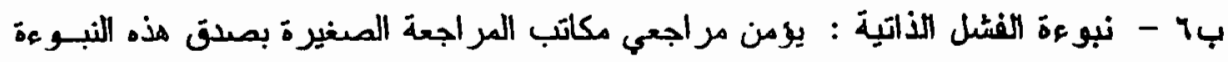

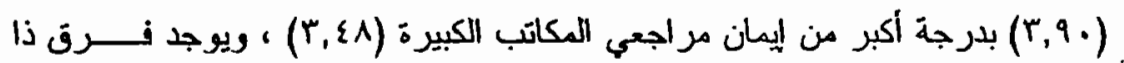

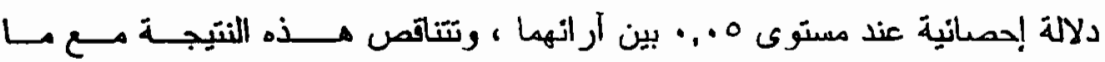

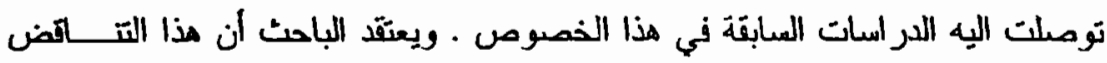
يرجع لاختلاف المعتقدات والظروف البينية .

\section{خلاصة ونتائج وتوصبات البحث}

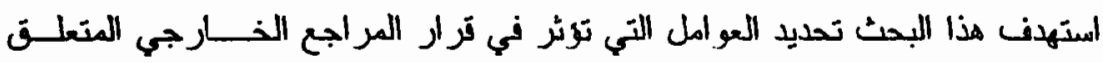

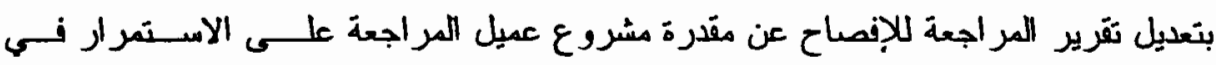

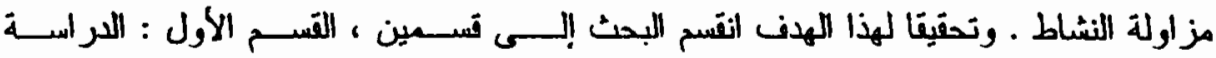

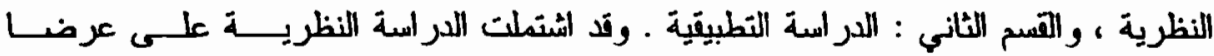

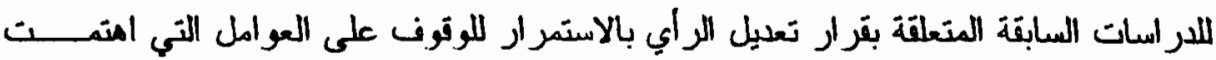

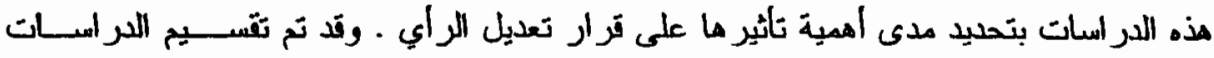

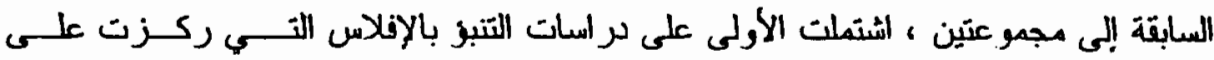

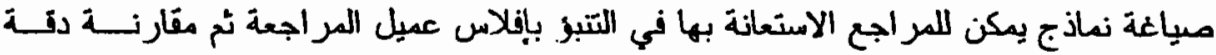

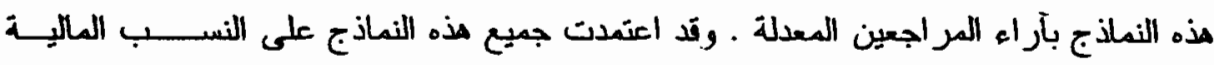

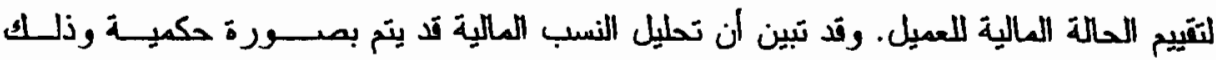

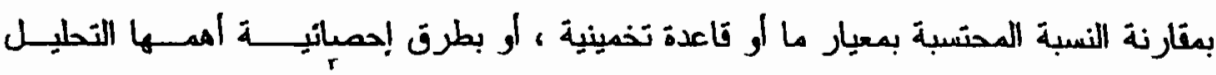

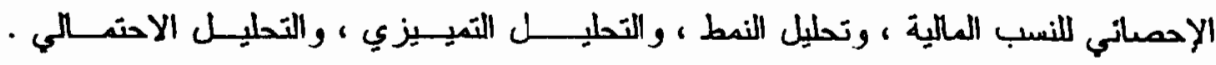

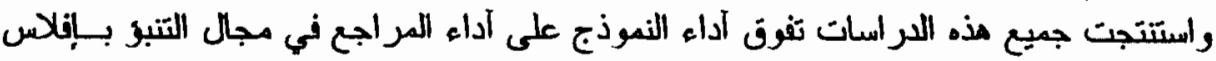
عميل المراجعة. 
والنتيجة العامة التي توصل اليها البحث من تقييم هذه الدراســـات أن نمـاذج التتبـو

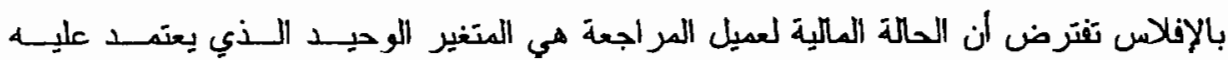

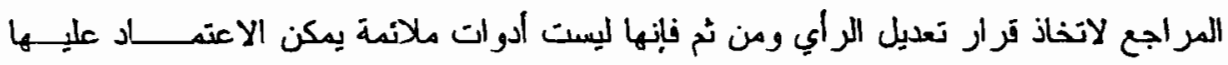

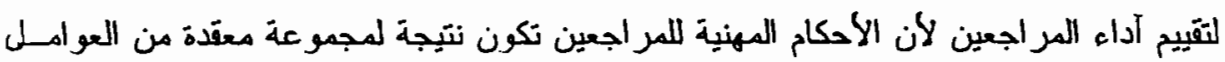

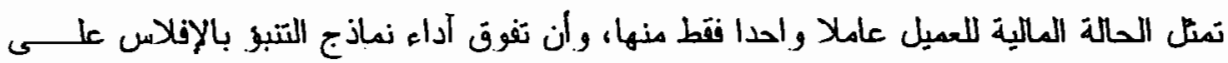

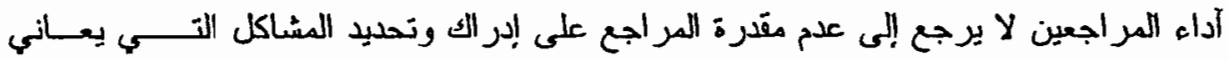

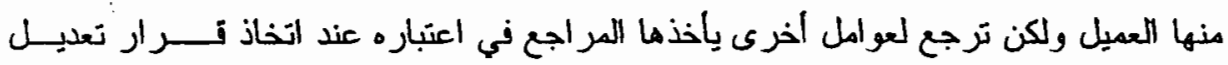

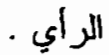

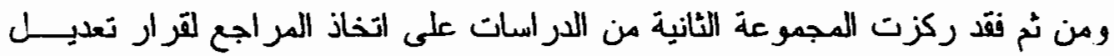

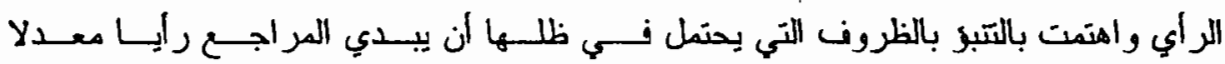

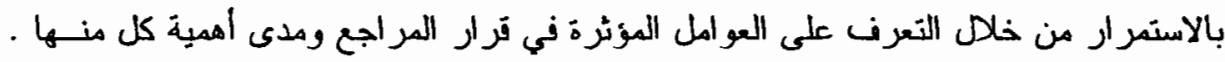

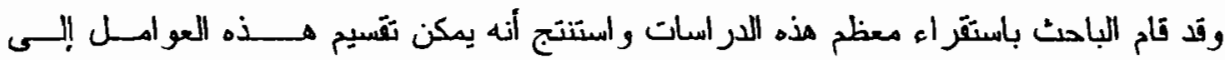

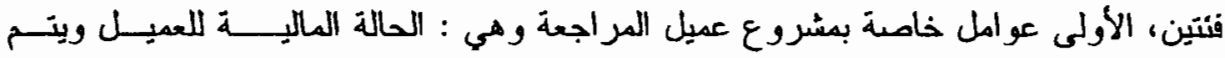

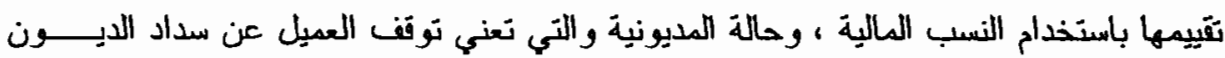

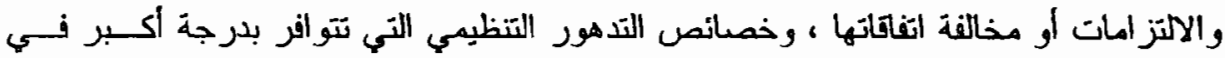

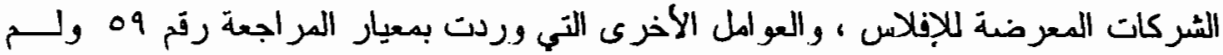

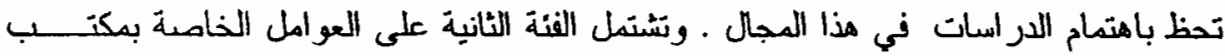

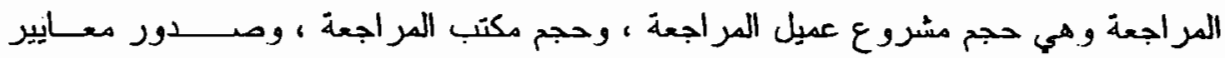

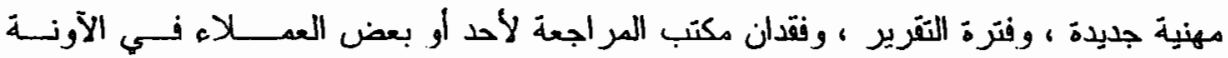

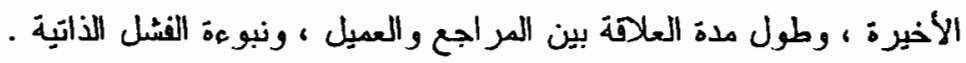

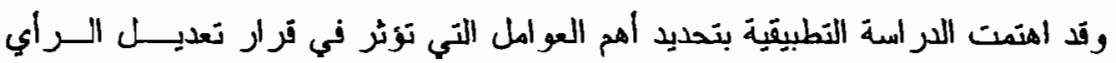

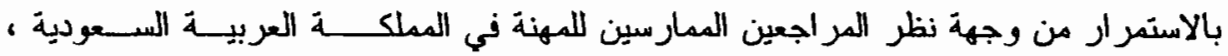

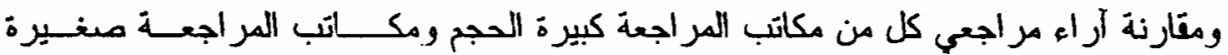

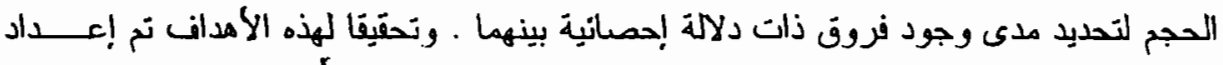

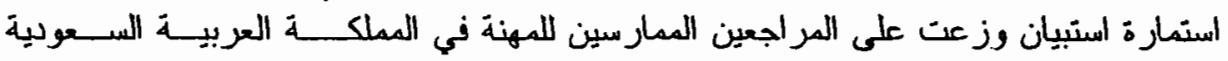

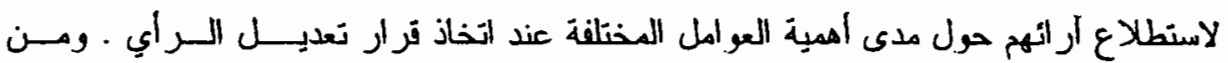
خلال التحليل الاحصاني للردود تم التوصل إلى العديد من النتائج أهمها : 


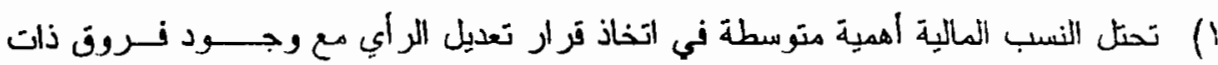

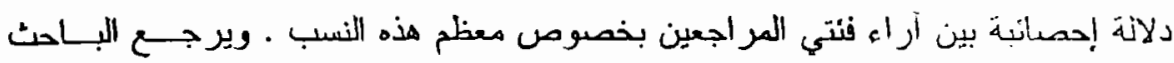

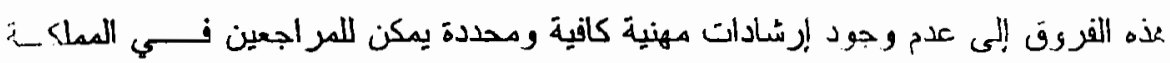

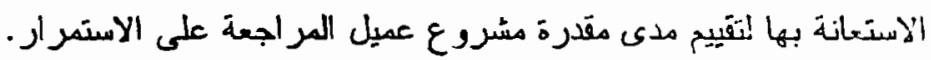

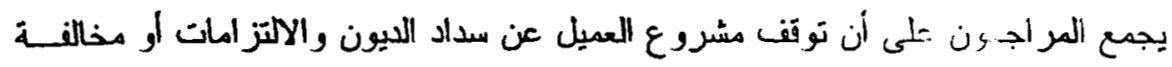
(r

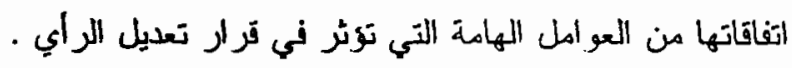

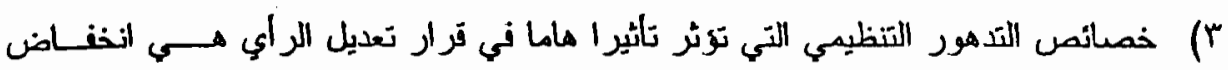

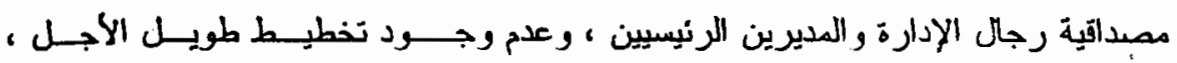

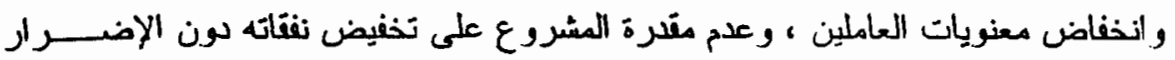
بنفسه ضررا شديدا .

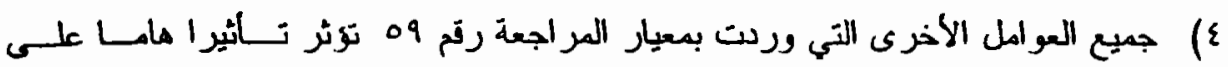

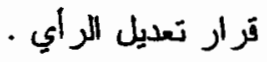

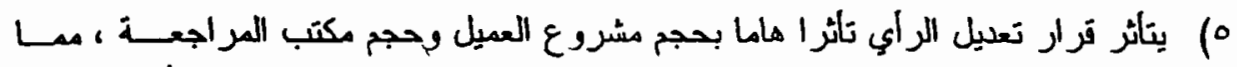

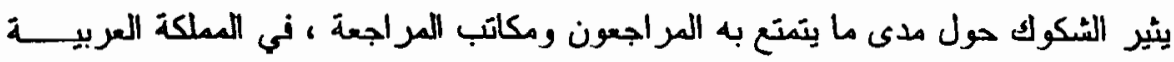

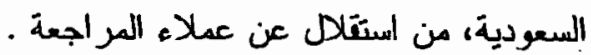

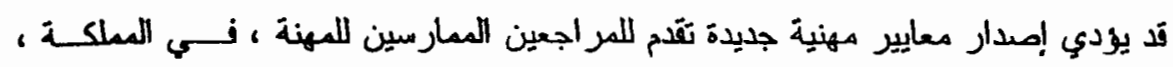

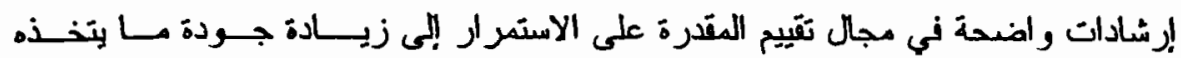

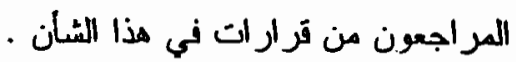

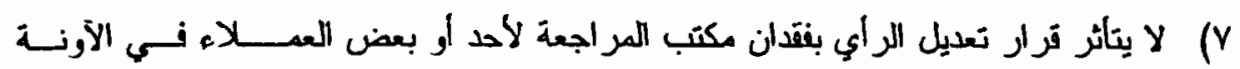

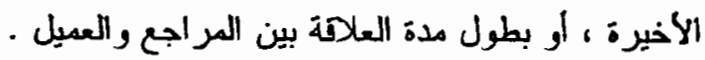

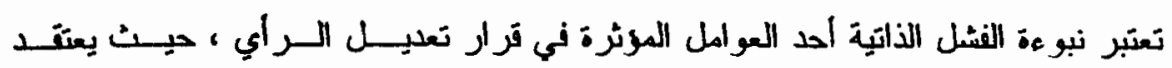
$(\Lambda$

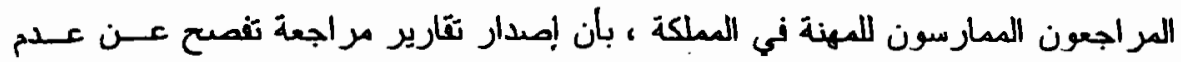

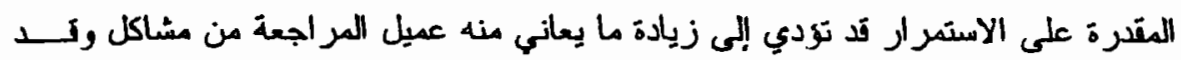
تعجل بفشل العميل. وفي ضوء هذه النتائج يوصي الباحث بالآتي :

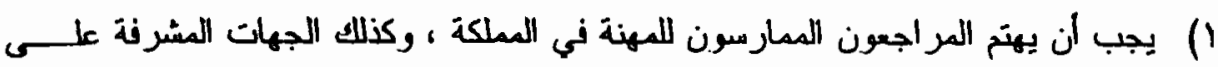

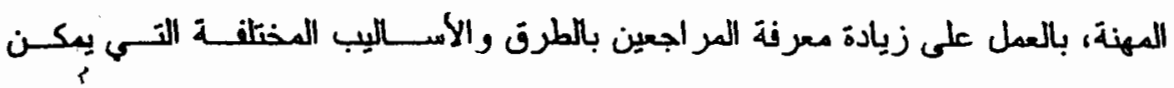




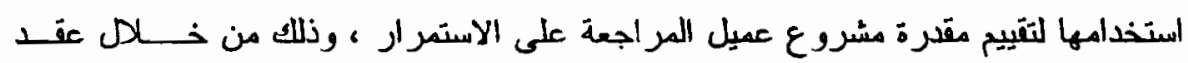

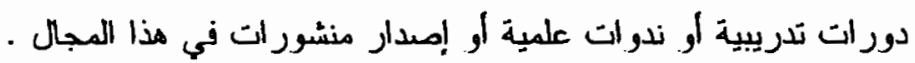

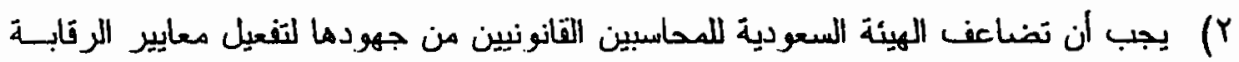

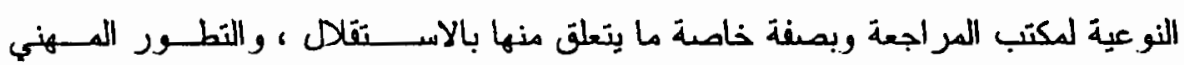
و التدريب لموظفي المكتب ، وقبول العملاء و استصر ارية العلاقة معهم .

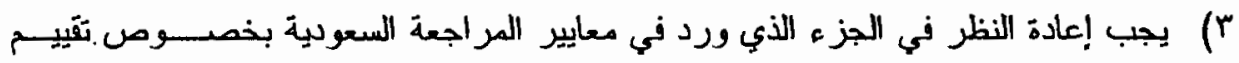

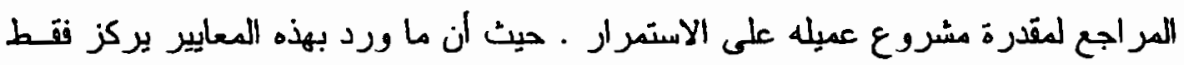

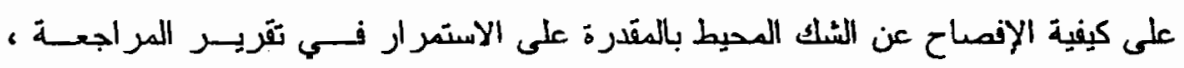

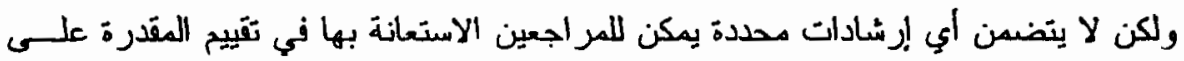

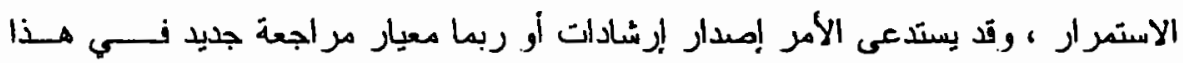
الشان .

حدود البحث

افترض البحث مبدئيا أن المراجعين الممارسين المهنة في المملكة العربية الســـعودية

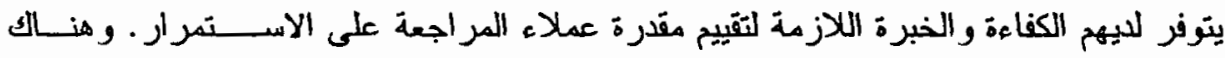

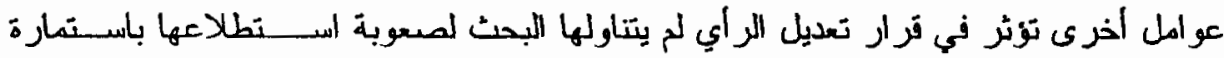

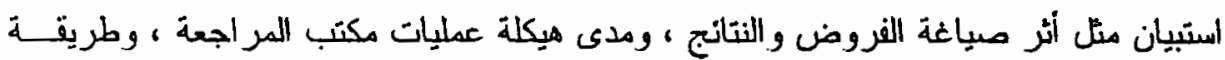

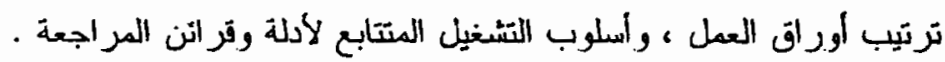

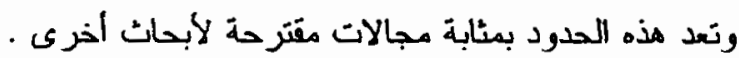




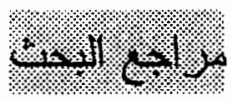

- Altman , E. I. , "Financial Ratios, Discriminant Analysis and the Prediction of Corporate Bankruptcy " , The Journal of Finance. (September 1968), PP. 589609.

- Altman , E.I. , and T.P. McGough, "Evaluation of a Company as a Going Concern, "Journal of Accountancy, (December 1974), IP. 50-57.

- Altman, E.I., R.G. Haldeman, and P. Narayaman, “Zeta Analysis: A New Model to Identify Bankruptcy Risk of Corporations, " Journal of Banking and Finance, (June, 1977), PP. 29-54.

- Altman, E.I. , and M.y. Levallee, “Business Failure Classification in Canada ", Journal of Business Administration, (Fall, 1980) , PP. 147-164.

- American Institute of Certified Public Accountants, (AICPA), "The Auditor's Considerations when a Question Arises About an Enitity's Continued Existence, “ Statement on auditing Standards No. 34 (March 1981).

"The.Auditor's Consideration of an Entity's Ability to Continue as a Going Corcen ", Statement on Auditing Standards No. 59 (April 1988) .

- Asare, Stephen K., “The Auditors Going - Concern Decision: A Review and Implications For Facture Research ", Journal of Accounting Literature, (1990), Vol. 9, PP.39-64.

- Barnes, P. and H.D.Huan, “The Auditor's Going Concern Decision : Some UK Evidence Concerning Independence and Competence ", Journal of Business Finance \& Accounting , ( January, 1993), PP. 213-228.

- Beaver, W. H. , "Financial Ratios as Predictors of Failure " , Journal of Accounting Research (Supplement 1966), PP. 71-111.

- Bell , T.B. , "Discussion of Towards an Explantation of Auditor Failure to Modify The Audit Opinions of Bankrupt Companies ", Auditing : A Journal of Practice \& Theory, Vol. 10, suppl. 1991, PP. 14-20. 1991, PP. 14-20.

“ Reply ", Auditing : A Journal of Practice \& Theory, Vol. 10, suppl.

- Bell, T.B., and A.M. Wright, "Auditing practice, Research, and Education" , AICPA , ( 1995).

- Boritz, J.E., "The Going Cocern Assupption: Accounting and Auditing Implications ", The Canadian Institute of Chartered Accountants, (1991). 
- Carcello, J., D. Hermanson, and F. Huss, "Temporal Changes in Bankruptcy Related Reporting ", Auditing : A Journal of Parctice and Theory, ( Fall, 1995), PP. 133-143.

- Casey, G.J., “ The Usefulness of Accounting Ratios For Subjects' Predictions of Corporate Failure: Replication and Extentions ", Journal of Accounting Research, (Autumn 1980), PP. 603-613.

- Chen, K.C.W., and B.K. Church, "Default on Debt Obligations and the Issuance of Going- Concern Opinions ", Auditing : A Journal of Practice \& Theory, (Fall, 1992), Vol. 11, No. 2, PP.30-49.

- Chen, K.H., and T.A. Shimerda, "An Empirical Analysis of Useful Financial Ratios “, Financial Management, (Spring 1981), PP.51-60.

- Citron D.B., and R. J. Taffler, "The Audit Report under Going Concern Uncertainties : an Empirical Analysis ", Accounting and Business Research, (1992), Vol. 22, No. 88, PP. 337-345.

- Ellingsen, J.E., K. Pany, and P. Fagan, "SAS No. 39: How to Evaluate Going Concern " , Journal of Accountancy ( January 1989), PP. 24-31.

- Hamer , M. , "Failure Prediction: Sensitivity of Classification Accuracy to Alternative Statistical Methods and variable Sets ", Journal of Accounting and Public Policy, (1983), Vol. 2, PP. 289-307.

- Kida, T., “An Investigations into Auditor's Continuity and Related Qualification Judgements “, Journal of Accounting Research, (Autumn, 1980), PP. 506-523.

- Kinney, W.R., "Attention - Directing analytical Review Using Accounting Ratios: A Case Study "; Auditing : A Journal of Practice \& Theory, (Spring 1987), PP. 59-73.

- Koh, H.C. and L.N. Killough, "The Use of Multiple Discriminant Analysis in The Assessment of The Going - Concern Status of an Audit Client", Journal of Business Finance \& Accounting, (Spring, 1990), PP. 179-185.

- $\quad$ and R.m. Brown, "Probit Prediction of Going and Non-Going Concerns “, Managerial Auditing Journal, (1991), Vol. 6, No. 3, PP.18-23.

Model Prdictions and Auditor Assessments of Going Concern Status ", Accounting and Business Research, (1991) Vol. 21, No. 84, PP. 331338. 
- Levitan, A.S., and J.A. Knoblett, "Indicators of Expectations to the Goug Concern Assumption ", Auditing: A Joumal of Theory' \& Practice, (Tr11, 1985), PP. 26-39.

- Lev, B., and S. Sunder, "Methoddgical Issues in the Use of Financial Raitus". Journal of Accounting and Economics, (December, 1979), PP. 187-210.

- Louwers, T.J., “The relation Between Going - Concern Opinions and The Auditor's Loss Function “, Journal of Accounting Research, (Spring 1998), PP. 143-156.

- Mackeown J.C, J. F. Mutchler, and W.S. Hopwood "Towards an Explanation of Auditor Failure to Modify the Audit Opinions of Bankrupt Companies ", Auditing : A Journal of Practice Theory, (Suppl. 1991), PP. 1-13.

- Menon, K., and K.B. Schwartz, “ An Empirical Investigation of Audit Qualification Decisions in the Presense of Going Concern Uncertainties", Contemporary Accounting Research, (Spring 1987), PP. 302-315.

- Mutchler, J.F., “ A Multivariate Analysis of The auditor's Going Concern Opinion Decisionn “, Journal of Accounting Research, (Autumn 1985), PP.668-682.

- __., “ Empirical Evidence Reganding the Auditor's Going Concern Opinion Decision ", Auditing: A Journal of Practice \& Theory, (Fall 1986), PP.148-163.

- Mutchler, J.F., W. Hopwood and J. M. McKeown, "The Influence of Cantrary Information and Mitigating Factors on Audit Opinion Decisions on Bankrupt Companies “, Journal of Accounting Research. (Autumn 1997), PP. 295-310.

- O'clock, P., and K. Devine, "An Investigation of Framing and Firm Size on the Auditor's Going Concern Decision ", Accounting and Business Research, (1995), Vol. 25, No. 99 PP. 197-207.

- Ohlson, J., "Financial Ratios and the Probabilistic Prediction of Bankruptcy “, Jounal of Accounting Research, (Spring, 1980), PP. 109-131.

- Ponemon, L.A. , and A. G. Schick, "Financially Distressed Companies and Auditor Perceptions of the Twelve Characteristics of Decline ", Auditing:A Journal of Practice \& Theory, (Fall, 1991), Vol. 10, No. 2, PP. 70-83.

- Raghunandan, K., and D.V. Rama, "Audit Reports For Companies in Financial Distress: Before and After SAS No. 59, "Auditing : A Journal of Practice \& Theory, (Spring 1995), Vol. 14, No. 1, PP. 50-63.

- Zavgren, C.V., " The Prediction of Corporate Faillure: The State of the Art ", Journal of Accounting Literature, (1983), Vol. 2, PP. 1-38.

- Zmijewski, M.E., “ Methodological Issues Related to the Estimation of Financial Distress Prediction Models", Journal of Accounting Research. (supplement 1984), PP. 59-82. 